TFXAS TECH UNIVERSITY

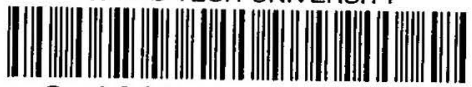

31295013466130 






DEPARTMENT OF THE INTERIOR

UNITED STATES GEOLOGICAL SURVEY

GEORGE OTIS SMITH, DIRECTOR

BULletin 388

\section{THE COLLOID MATTER OF CLAY AND ITS MEASUREMENT}

BY

HARRISON EVERETT ASHLEY

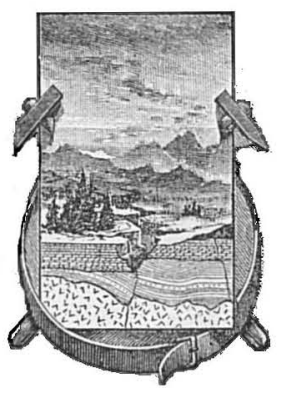

WASHINGTON

GOVERNMENT PRINTING OFFIOE $19 \cap 9$ 



\section{CONTENTS.}

Preface, by A. V.

Introduction.................................................... 7

Colloids in clays . . . . . . . . . . . .

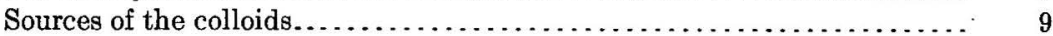

Hydrated silicates. . . . . . . . . . . . .

Gelatinous silica.................................... 9

Ferric and aluminum hydroxides. . . . . . . . . . . . . . . . . . 10

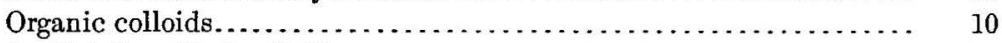

Artificially added colloids............................... 12

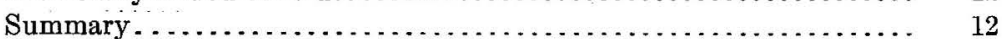

Aging and drying of clays $\ldots \ldots \ldots \ldots \ldots \ldots \ldots \ldots \ldots \ldots \ldots, 12$

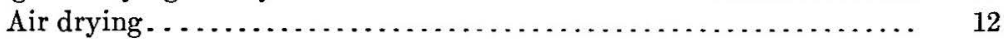

Drying under pressure................................... 13

Weathering of fire clays.................................. 13

Aging of feldspathic bodies . . . . . . . . . . . . . . . . . . . . .

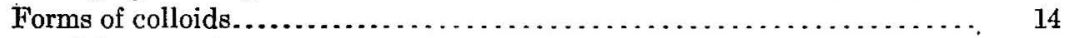

Sols and gels............................................. 14

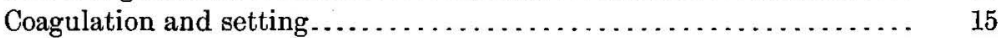

Examples of set gels.................................... 15

Formation of sols.................................... 17

Electrostatic charges in sols......................... 17

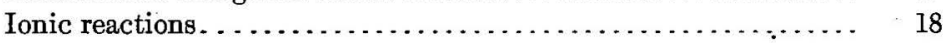

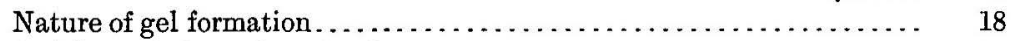

Stability of clay sols and gels . . . . . . . . . . . . . . . . . . . . $\quad 19$

Protection colloids...................................... 20

Properties of colloids......................................... 20

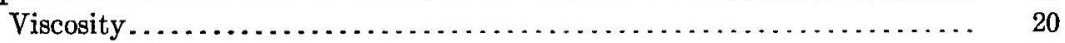

Viscosity of clay slips................................... 20

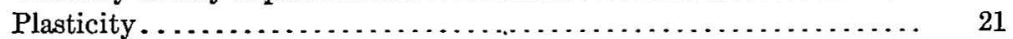

Action of electrolytes................................... 22

Exchange of bases. . . . . . . . . . . . . . . . . . . . . . . . 22

Organic colloids...................................... 24

Mellor, Green, and Baugh's experiments. . ............. 24

Laws of coagulation................................... 27

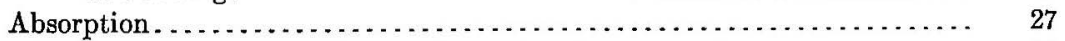

Lack of definite relation of absorption to temperature ........... 27

Relation of absorption to plasticity .......................... 28

Distribution of absorbed water among constituents............ 28

Volumes of clay gel in various salt solutions ................. 29

Distribution of salts in gels.............................. 30

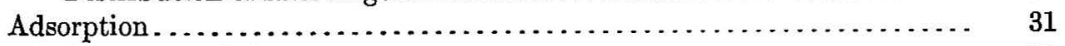

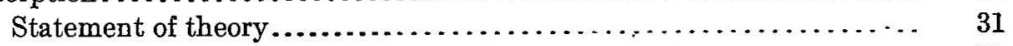

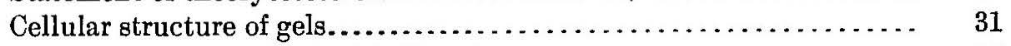

Partition between immiscible liquids....................... 32

Partition between a liquid and a gel...................... 32 
Properties of colloids-Continued.

Adsorption-Continued.

Partition between a liquid and a gel-Continued.

Silk and picric acid. ............................ 32

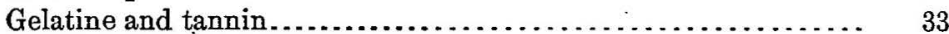

Hagerstown loam and gentian violet.................... 34

Quartz flour and gentian violet........................ 35

Klingenberg clay and barium chloride.................. 37

Silver iodide and silver nitrate........................ 38

Silver iodide and potassium iodide. . . . . . . . . . . . . . . . 39

Tennessee ball clay and malachite green.................. 41

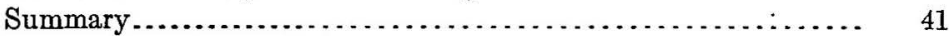

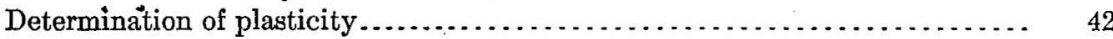

Dependence on colloids................................ 42

Adsorption tests of clays................................ 43

Adsorption tests with brilliant green....................... 43

Comparison of brilliant green with malachite green $\ldots \ldots \ldots \ldots \ldots \ldots .45$

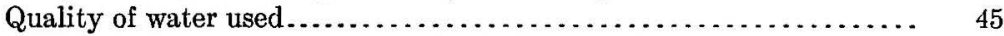

Malachite-green adsorption and physical properties of clays .......... 46

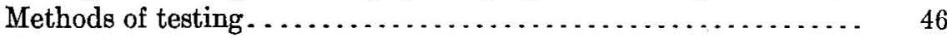

Results of tests. .................................. 47

Malachite-green adsorption..................... 50

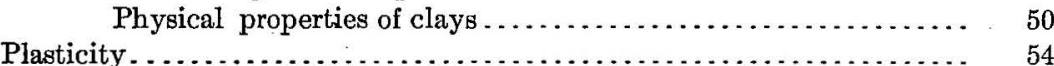

As determined by malachite-green adsorption tests. . . . . . . . . . 54

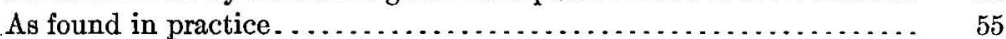

Miscellaneous applications of malachite-green test. . . . . . . . . . . . . 56

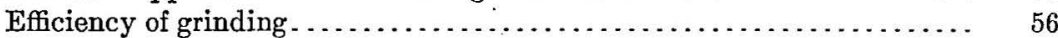

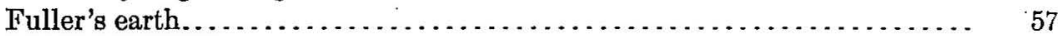

Paris whites. . . . . . . . . . . . .

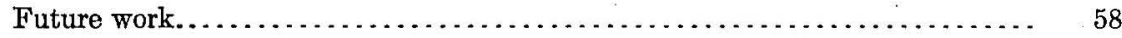

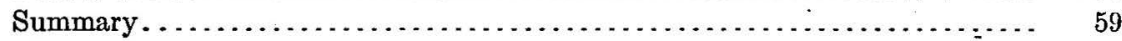

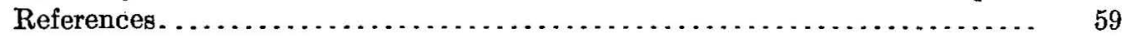

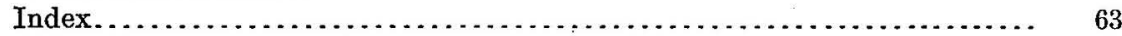

\section{ILLUSTRATIONS.}

Plate I. Apparatus for colorimetric test of adsorption . . . . . . . . . . . . 46

Fraure 1. Adsorption of tannin by gelatine........................ 34

2. Adsorption of gentian violet by Hagerstown loam . . . . . . . . . 35

3. Adsorption of gentian violet by quartz flour . . . . . . . . . . . . $\quad 37$

4. Adsorption of barium chloride by Klingenberg clay . . . . . . . . . $\quad 39$

5. Adsorption of potassium iodide by silver iodide.............. 41

6. Adsorption of malachite green by Tennessee Ball and Sagger Clay Company's Tennessee ball clay No. 3..................... 42

7. Structural formulæ of malachite green and brilliant green . . . . . 46

8. Adsorption of malachite green by Potters' Supply Company's Tennessee ball clay No. 3......................... 50

9. Surface concentration and specific air shrinkage of clay colloids as related to deformability............................ 52 


\section{PREFACE.}

By A. V. Bleininger.

The United States Geological Survey, in carrying out the provisions of the act of Congress approved May 27, 1908, which authorized "the continuation of the investigation of the structural materials belonging to and for the use of the United States, such as stone, clays, cement, and so.forth," has established at Pittsburg, Pa., as part of its testing station there, a plant for the investigation of various problems bearing on the selection, preparation, and testing of clays and clay products for use in the building and engineering construction work of the Government.

The work now being carried on at this plant falls into three groups:

(1) The testing of such clay products as common and pressed brick, paving brick, hollow tiles and conduits, enameled brick, fireproofing, terra cotta, fire brick, glazed tile, floor and roofing tile, porcelain electric insulators and other building ware submitted by the structural bureaus of the Government. This work includes the working out of technical specifications of the various materials for use in government construction.

(2) The development of specifications and methods of making tests of clays and clay products to determine the purposes for which they are best suited, and the application of these tests to the valuation of deposits of clay or glass-making and other structural material on public lands.

(3) The study incidentally of problems of manufacture, the solution of which would mean the elimination of much loss or would tend to the making of a more efficient product, better suited to the needs of the Government, such as the proper physical structure of fire brick, partition tile, floor tile, and terra cotta in different forms, of other heat-resisting materials, the drying of those difficultly drying clays that are found in many locailties where there are no workable beds of better clay, and the proper heat treatment for various clay products.

The topic discussed in the following bulletin comes within the second of these three groups.

The most characteristic property of clays is their plasticity, on which depends their use in the arts. Yet this peculiar function of clay has been the most difficult to explain and to measure. Heretofore no criterion has been found which would enable the clay worker 
to compare with any degree of accuracy the varying degrees of plasticity found in the clays employed in industry. In this bulletin Mr. Ashley has made an attempt to explain the character of the plastic constituents of clay in the light of recent researches in the field of colloids, and also to offer a method for the comparison of the different clays with respect to this property. He is dealing, therefore, with a subject which is of fundamental importance not only to the scientific investigator but also to the manufacturer, for the success of the practical operations of shaping and drying hinges largely on the character and amount of the plastic matter present in clays.

These studies by Mr. Ashley were for the most part incidental to his investigation of clay products, but the defects in clay products purchased for the use of the Government should be much improved by the placing of such information as this paper contains in the hands of the manufacturers. 


\title{
THE COLLOID MATTER OF CLAY AND ITS MEASUREMENT.
}

\author{
By Harrison Everett Ashley.
}

\section{INTRODUCTION.}

Scope of paper.-In this paper a definition of clay is given which is in accordance with the colloid theory and is sufficiently broad to include all substances worked as clays. The colloid theory is then applied to a description of the properties of clays. The result represents several months' searching of scientific literature, in the course of which the endeavor has been made to use so far as possible only studies on clays, avoiding studies on other colloids, such as gelatine, albumens, metallic sulphide suspensions, and metal suspensions.

Special attention is given to adsorption, that property, so well developed in colloids, of taking other substances out of solution or suspension. It is finally shown that the adsorption of certain dyes by clays furnishes a means of estimating the colloidal matter present, and that when classified according to colloidal content the clays are also classified approximately according to plasticity. Some of the results of this latter investigation, undertaken while the writer was in the employ of the Homer Laughlin China Company, Newell, W. Va., are included herein by permission of the company, with further studies along similar lines now being continued in the clayproducts laboratories of the United States Geological Survey. The present is a preliminary report.

Definitions.-Solids were formerly defined as crystalline and amorphous. The term "colloid" now comprises everything formerly known as amorphous. In this classification organic structures are considered as representing the highest type of crystallization. Clays usually present the amorphous or colloidal appearance, any crystalline matter present being largely masked by a coating of colloid matter.

Clays may be defined as mixtures of minerals of which the representative members are silicates of aluminum, iron, the alkalies, and the alkaline earths. The hydrated aluminum silicate, kaolin $\left(\mathrm{Al}_{2} \mathrm{O}_{3} \cdot 2 \mathrm{SiO}_{2}\right.$. $2 \mathrm{H}_{2} \mathrm{O}$ ), is the most characteristic of these. Some feldspar is usually present. The grains of these minerals may show crystal faces (especially in the case of kaolins), but more commonly they are of 
irregular shapes. Upon most of these grains is an enveloping colloid coating. This is mainly of silicate constitution, but may consist partly of organic colloids, of iron, manganese, and aluminum hydroxides, and of hydrated silicic acid. Quartz grains, which are generally present, and mica, which is frequently present, do not have the colloid coating or have it in much less degree. Almost any mineral may be present in clays and modify the properties somewhat. The combination of granular materials and colloids is in such proportion that, when reduced to sufficiently fine size (by crushing, sifting, washing, or other means) and properly moistened with an appropriate amount of water, plasticity is developed. If the colloid matter is in excess the clay is considered very plastic, fat, or sticky, but if the granular matter is in excess it is called sandy, weak, or nonplastic.

Isolation of colloid matter by Schloesing.-In 1874 Th. Schloesing $\left(1^{a}\right)$ made a careful examination of a number of clays, removing carbonates by weak hydrochloric acid, washing, and then examining the separated portions which settled with different velocities in slightly ammoniacal distilled water. Kaolin was allowed to stand 24 hours before decanting. The settled matters were fractioned, also the 24hour suspension (second levigation).

The following table shows the results with 40 grams of kaolin from M.'Demondesir (Manche):

Fractionation of kaolin.

\begin{tabular}{|c|c|c|c|c|c|c|c|}
\hline \multirow[b]{2}{*}{$\cdot$} & $\begin{array}{c}\text { First levi- } \\
\text { gation. }\end{array}$ & \multicolumn{5}{|c|}{ Second levigation. } & \multirow[b]{2}{*}{$\mathrm{Al}_{2} \mathrm{O}_{3} .2 \mathrm{SIO}_{2} .2 \mathrm{H}_{2} \mathrm{O}$} \\
\hline & $\begin{array}{l}\text { Sand-free } \\
\text { portions: A, } \\
\text { 31. grams. }\end{array}$ & $\begin{array}{c}(a) \\
1 \text { day } \\
4.35 \\
\text { grams. }\end{array}$ & $\begin{array}{c}(b) \\
1 \text { day } \\
2.49 \\
\text { grams. }\end{array}$ & $\begin{array}{c}(c) \\
5 \text { days } \\
0.72 \\
\text { grams. }\end{array}$ & $\begin{array}{c}(d) \\
27 \text { days } \\
0.30 \\
\text { grams. }\end{array}$ & $\begin{array}{c}(e) \\
\text { In sus- } \\
\text { pension } \\
0.59 \\
\text { grams. }\end{array}$ & \\
\hline $\begin{array}{l}\text { Water }\left(\mathrm{H}_{2} \mathrm{O}\right) \\
\left.\text { Sillica }(\mathrm{SiO})_{2}\right) \ldots \ldots \ldots \\
\text { Alumina }\left(\mathrm{Al}_{2} \mathrm{O}_{3}\right)\end{array}$ & $\begin{array}{l}13.73 \\
46.28 \\
39.92\end{array}$ & $\begin{array}{l}13.93 \\
46.55 \\
40.05\end{array}$ & $\begin{array}{l}13.92 \\
46.20 \\
39.85\end{array}$ & $\begin{array}{l}14.28 \\
\text { Lost. }\end{array}$ & $\begin{array}{r}12.70 \\
48.57 \\
36.46\end{array}$ & $\begin{array}{l}10.30 \\
49.57 \\
32.32\end{array}$ & $\begin{array}{l}13.91 \\
46.63 \\
39.46\end{array}$ \\
\hline $\begin{array}{l}\text { Ferric oxide }\left(\mathrm{Fe}_{2} \mathrm{O}_{3}\right) \\
\text { Magnesia }(\mathrm{MgO}) \ldots \\
\text { Potassa }\left(\mathrm{K}_{2} \mathrm{O}\right) \ldots \ldots\end{array}$ & $\begin{array}{l}.09 \\
.28\end{array}$ & $\begin{array}{l}.04 \\
.04\end{array}$ & .22 & & $\begin{array}{l}1.36 \\
1.03\end{array}$ & $\begin{array}{l}1.98 \\
1.29 \\
4.25\end{array}$ & $\begin{array}{ll}\cdots \\
\cdots \\
\cdots\end{array}$ \\
\hline
\end{tabular}

Most of the fraci ons thus approximated the composition now ascribed to kaolin, $\mathrm{Al}_{2} \mathrm{O}_{3} \cdot 2 \mathrm{SiO}_{2} \cdot 2 \mathrm{H}_{2} \mathrm{O}$. Owing to the unsatisfactory state of analytical chemistry 35 years ago, too implicit reliance can not be put on the figures of column $e$. On precipitating the 0.59 grams of material therein it occupied, after standing 24 hours, a volume of 146 cubic centimeters; this is five times as bulky as the precipitates of iron and alumina obtained in chemical analysis. This matter $(e)$ was filtered, washed, put into a porcelain dish, and dried over calcium chloride. It became a broken film, horny, slightly trans- 
lucent, adhering strongly to the porcelain. There was no cohesion in A, very little in $a, b, c$, or $d$; a great amount in $e$. There was no gradual change, but an abrupt difference in properties between $d$ and $e$. Schloesing concluded, "From these characteristics I consider that the clay $e$ is colloidal."

\section{COLLOIDS IN CLAYS.}

\section{SOURCES OF THE COLLOIDS.}

\section{HIYDRATED SILICATES.}

Many investigators, observing the adsorptive power of soils, have sought to find out to which of its constituents this quality is due. According to Wiley (12), Way-

passed a solution of ammonia through tubes containing pure sand, and found that it came through apparently unaltered from the first, while a soil treated in the same way removed the ammonia for a considerable time. He concluded from this that the adsorptive power does not exist in the sand. He next oxidized the organic matter in a soil with nitric acid and then treated it with ammonia in the same way. The first portions of the filtrate showed no ammonia in any form; hence he concluded that organic matter is not essential to the act of absorption [adsorption]. He further showed that clay alone is capable of causing absorption [adsorption] phenomena. * * * He next tried to trace out the particular compound which caused the absorption [adsorption]. Having tried various natural silicates, he at last succeeded in producing a hydrated silicate of aluminum and soda which exhibited displacement and absorptive [adsorptive] properties very similar to those shown by the soil $\left(46.1 \mathrm{SiO}_{2}, 26.1 \mathrm{Al}_{2} \mathrm{O}_{3}, 15.8 \mathrm{Na}_{2} \mathrm{O}, 12.0 \mathrm{H}_{2} \mathrm{O}\right)$. * * * Eichhorn [13] thought of trying natural hydrated silicates or zeolites, and found that they exhibited the same power as Way's artificial preparation.

Cushman (11) says in regard to Way (14):

The more clayey the soil, the more water it seemed capable of absorbing. But this was not all; besides water, this clay substance exhibited a greater facility for absorbing [adsorbing] the bases contained in certain salts which were dissolved in the water. Also this action was shown to be selective, certain bases and substances being held so that they could not be washed out again. Let us hear what Way himself had to say on the subject: "Coloring matters are actually precipitated unchanged or in the state of insoluble pigments [technically known as lakes] by mere mixture with white clay. Neither to the action of capillarity or to that of oxidation are we to attribute the property of soils to retain the mineral bases and animal and vegetable ingredients of manure." Way found, moreover, that exposure to a high heat destroyed this peculiar absorptive [adsorptive] power of the clay substance.

\section{GELATINOUS SILICA.}

Later investigators failed to confirm Way in thinking that silica, organic matter, etc., take no part in adsorbing salts, dyes, etc. $\mathrm{He}$ himself (15) found gelatinous silica in very considerable proportion (40 per cent) in a "chalk" used for agricultural purposes. Van Bemmelen (2) found that a silica gel of the formula $\mathrm{SiO}_{2} \cdot 4 \mathrm{H}_{2} \mathrm{O}$ retains aluminum chloride $\left(\mathrm{AlCl}_{3}\right)$ so tenaciously that repeated washings 
with water fail to show even traces in the wash water, yet that a solution of potassium chloride $(\mathrm{KCl})$ promptly displaces considerable amounts, being itself adsorbed. Van Bemmelen considered the adsorptive powers of silicates in soils as for the most part to be regarded as such substitutions. He says (16):

Soils contain colloids-colloidal silicates, ferric oxide, silicic acid, humus substances-all of which can show the above effects. The absorption [adsorption] effects obtained on treating soils with solutions are principally to be attributed to the colloidal silicates.

Cameron and Bell (19) say:

Evidence is wanting for the existence of $* * *$ silica coatings on the minerals of the soil. It is possible that such a coating of silica may take place to some extent. * * Microscopic examinations fail to disclose it, such coatings as exist being mainly of ferruginous materials, generally removable quite easily by mechanical means and permeable to water. *** The main argument against the formation of siliceous coatings on the minerals is, however, the fact that they are oontinuously soluble when treated with fresh amounts of water, or when the hydrolized products are removed from the solution.

From a study of the evidence collected in Clarke's data of geochemistry (44) it appears that gelatinous silica is most likely to appear in the products of recent rock decay, and least likely in old soils.

\section{FERRIC AND ALUMINUM HYDROXIDES.}

Colloidal ferric oxide is more likely to be found in the red-burning clays than in the lighter-burning ones. In 1868 Warington (17) found that hydrated ferric oxide, which is commonly present in soils and clays poor in color, and hydrated aluminum oxide, which is less frequently present ${ }^{a}$ are capable of absorbing (adsorbing) potash and ammonia, and that the absorptive (adsorptive) power of the ferric hydrate is two or three times that of aluminum hydrate. He further says that humus, and especially hydrated silicates, have also been shown to possess absorptive (adsorptive) powers.

\section{ORGANIC COLLOIDS.}

Peats are soils which consist almost entirely of organic matter, and thus exhibit separately the characteristics that are to be attributed to the organic matter in common clays and soils. Schreiner and Reed (6) state that "the amounts of organic matter in ordinary soils is * * * 2.06 per cent for the soil and 0.83 per cent for the subsoil." Such matters are called "humus" or "humic acid" when they may be extracted by 5 per cent ammonia after previous treatment with 1 per cent hydrochloric acid (7). Any humus in the kaolin examined by Schloesing would accordingly have been found in his colloidal residue $e$.

a Cameron and Bell(18) outof several thousand examinations have but once observed aluminum hydrate $\mathrm{Al}(\mathrm{OH})_{3}$ in a soil. The sample was from southern California. 
A. A. Julien (84) describes humic acid and many similar substances, in part, as follows: "Humic acid possesses a strictly colloid nature." It reddens litmus paper. It dissolves in 8,337 parts of water at $6^{\circ}$, though insoluble in water free of nitrogen or air. After drying at $120^{\circ}$ it dissolves in 13,784 parts of water at $15^{\circ}$. After perfect drying at high temperatures it becomes insoluble. "It has also the colloidal property of glueing together vegetable earths, such as the siliceous sands of the Landes near Bordeaux, into a layer impervious to water." Ammonium humate, $\mathrm{C}_{60} \mathrm{H}_{48}\left(\mathrm{NH}_{4}\right)_{6} \mathrm{O}_{27}$, dissolves in 22 parts of water. Calcium humate dissolves in 3,125 parts of water; magnesium humate, pretty easily; ferric humate, in 5,000 parts of water at $19^{\circ}$. Humic acids are unstable, and therefore tend to disappear from old deposits, though traces are found in some minerals. The humic acids are solvents for silica. The humic acids have decomposed the upper layers of the "Champlain" clays of New York and the New Jersey Cretaceous clays, white fire clays, and pipe clays of the "Coal Measures." The action consisted mainly in the removal of calcium and iron, which were redeposited to form a hardpan at the lower limit of the action. This hardpan may consist of a layer of limonite. Hardpan may often be found as a thin impervious layer in sands where clays are practically absent. Gibbsite, the aluminum hydrate, is occasionally associated as attached crusts with limonite, and is therefore of the same origin. Amorphous silica may occur as (a) animal skeletons, $(b)$ deposits from thermal waters, $(c)$ a gelatinous deposit formed directly by the decomposition of rocks by organic acids, $(d)$ a deposit from solution in organic acids.

Flint, hornstone, and amorphous chert, therefore, seem to me to present the colloid form of silica necessarily deposited from a solvent of a colloid nature, such as humic acid and probably the azohumic acids have been found to possess. Granular chert, jasper, etc., * * * appear to be the crystalline forms of silica, probably in part deposited from solution in thermal waters.

H. Bornträger (85) finds in peat:

Analyses of peat.

\begin{tabular}{|c|c|c|}
\hline & 1. & 2. \\
\hline \multirow[t]{2}{*}{ 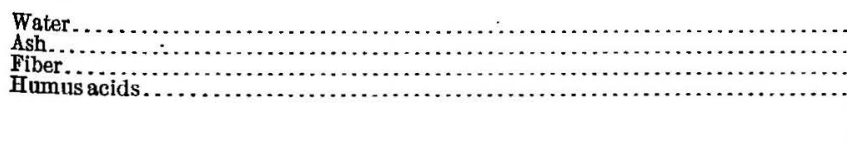 } & $\begin{array}{r}29.50 \\
3.05 \\
54.95 \\
12.50 \\
\end{array}$ & $\begin{array}{r}20.0 \\
3.0 \\
47.0 \\
30.0 \\
\end{array}$ \\
\hline & 100.0 & 100.0 \\
\hline
\end{tabular}

Charles A. Davis (5) states that:

Some types of peat, notably the brown ones, are said to become nearly impervious to water after they are once thoroughly dried out, because the organic acids which they contain are colloidal or gluelike in form, and when they dry they become insoluble. * * * With fineness of texture goes greater plasticity. * * * The plastic black peats are higher in ash, are more difficult to burn, and are harder when dry, reaching nearly the consistency of soft coal. 


\section{ARTIFICIALLY ADDED COLLOIDS.}

Considering alluvial clays, E. G. Acheson (8) made a few experiments with those substances he thought likely to be found in the washings of vegetation. Addition of gallotannic acid or catechu was found by him to give kaolin many of the properties of the best highly colloidal ball clays. An excessive amount of water was not required to temper it; plasticity, tensile strength, and hardness were increased. In the discussion of his paper it was brotght out that W. D. Gates had obtained similar results by the use of silicate of soda, and (according to Charles Weelans) that gums, glues, and gelatine have long been used in the pottery industry for obtaining such results. All of these materials are typical colloids.

\section{SUMMARY.}

The colloid matters in clay are therefore noncrystalline, hydrated, gelatinous, aluminum silicates, organic colloids, gelatinous silicic acid, and hydrated ferric oxide. Rarely there may also be present aluminum hydrate.

\section{AGING AND DRYING OF CLAYS.}

\section{AIR DRYING.}

Grout (9) found 0.08 per cent agar-agar (a colloid obtained from seaweed and resembling gelatine closely) to increase plasticity from 36 to 57 per cent with two different clays; that 0.2 per cent agar-agar causes a further but not proportionate increase; that gelatine has only one-tenth the effect of agar-agar; that 3 per cent of freshly precipitated alumina is required to give the same effect as 0.08 per cent agar-agar. But on air drying and then reworking in each case the plasticity was found to have dropped to its original figure. $\mathrm{He}$ found that air-dried silicic acid cuts down plasticity as much as angular quartz sand. He prepared an artificial hydrated silicate of alumina by mixing sodium silicate and alum solutions, and found that after drying it failed to soften in water. Therefore, to him, it seemed that none of these or other colloids could be responsible for the behavior of natural clays; for he apparently thought that clay can be dried and wetted repeatedly without affecting its plasticity injuriously, without affecting the activity of the colloids.

In this supposition he was not in accord with practical experience. The clay used by potters has in most cases never been deprived of its natural moisture. After once being dried out at as low a temperature as $60^{\circ}$, it is found to have lost noticeably in plasticity. In consequence many potteries make a practice of using their dry scrap for the preparation of casting slip, which requires a less plastic mixture than their other processes.

In soaking or blunging their clays potters know that the tougher the clay the more difficult it is to blunge it-to make it take 
up water and become uniformly suspended in the water. Paul Rohland (40) compared caoutchouc to the completely impervious, undried, highly plastic clays, which do not take up or allow to diffuse the slightest amounts of water, which are "completely impenetrable to water." One of these, the black Striegau clay, when moderately dried, would allow solutions of crystalloids, such as potassium dichromate, copper sulphate, sodium chlorides, barium chlorides, etc., to diffuse through it. It thus acted when it had been dried as a semipermeable colloid membrane.

Another reason for Mr. Grout's failure to duplicate the action of natural colloids is probably to be found in the fact that colloid and ultimate fine-granular matters are much more intimately mixed in natural clays than they could be in the mere superficial coating of large lumpy flocules in Mr. Grout's experiments. With experiments of longer duration Mr. Grout would probably have observed the return of plasticity to his treated clay, unless other circumstances intervened. He would have accelerated that return had he ground his material in water in a ball mill for a sufficient period.

\section{DRYING UNDER PRESSURE.}

According to W. B. Hardy (10) the gel, or solid form, of either agar-agar or gelatine, when subjected to pressure, loses water and becomes more concentrated. The resulting solid still retains the old structure, which is not destroyed by drying, and the system tends to reform itself on the old lines by refilling the original capillary spaces. In this resumption it shows considerable hysteresis, or lag. The structure of colloids has been shown by the microscopic work of Butschli and of Nagelli to be cellular or spongelike. Hardy's experiment is much like squeezing water out of a sponge. After the sponge has been dried, it will not immediately take up the water again, but requires time to soak it up through its capillary passages, like oil in a wick. Cushman (38) has recorded that:

Silicic acid which has been air-dried can have water pressed out of it by subjecting it to very high pressures; the same phenomenon is known in the case of clays in the manufacture of hydraulic pressed brick.

\section{WEATHERING OF FIRE CLAYS.}

Fire clays in their natural beds have been consolidated under great pressure and their water content reduced to but little over that chemically combined. Most emphatically the colloids of fire clay do not take up water promptly. On standing months or years with water they will soak it up. On grinding in a wet pan, an operation that may be compared with kneading and squeezing a dry sponge, they will take up water into their coarser pores. In its natural bed, fire clay exists at a very uniform temperature, but when it comes to the surface, either in a natural outcrop or in the clayworker's "pile" 
of weathering clay, it is subjected to alternations of heat and cold, consequently its minute pores expand and contract. If the pile is kept moistened the water will penetrate as the pores expand, and as the pores contract a portion will be forced farther in. In some plants it is considered necessary to steam the clay, as diffusion of water is more rapid at high temperatures. In glass-pot factories it is considered necessary to age or store the damp body for a year, in order to let the water have time to penetrate the clay uniformly. The finished pots are then allowed months or years to get thoroughly dry. Evidently plasticity is not the creature of a few hours' laboratory work.

\section{AGING OF FELDSPATHIC BODIES.}

Cushman (37) considers Grout's reasoning invalid, "as both plasticity and binding power can be shown to be due to a softening or decomposing action of water on the surface of the fine particles, which is invariably increased by the action of wet grinding, pugging, and puddling." He points out that "colloids are formed much more slowly in nature under temperature and pressure conditions we can not imitate."

The "decomposing action of water on the surface of fine particles," mentioned by Cushman, is not of importance in the case of highly compressed clays low in feldspathic materials, such as fire clays. But with a body containing ground feldspar the aging must continue until, first, the decomposition of feldspar by water into colloidal silicates, colloidal silicic acid (?), and free alkali (37) has ceased or become greatly retarded; and until, second, this free alkali has been neutralized either by acids originally present in the clay or more likely by the products of bacterial activity (41) in the aging clay. Rollland (43) has advanced what is practically this idea, but he applies it to a too wide range of clays. He refers the matter wholly to the quantity of $\mathrm{OH}$ ions present, plasticity varying somewhat inversely with the quantity of these, and says that as rise of temperature increases the quantity of $\mathrm{OH}$ ions it decreases plasticity. In opposition to this view it may be noted that the old pottery slip kiln gave much more plastic bodies than does the modern cold-working filter press, and that the steaming of fire clays decidedly increases their plasticity.

\section{FORMS OF COLLOIDS.}

\section{SOLS AND GELS.}

Colloids exist in two characteristic forms: (1) as a homogeneous suspension in a liquid, oalled a "sol;" and (2) as a continuous jelly with pore walls (and pores) filled with a liquid, called a "gel." Solids are included under (2) as a limiting case. The sol or gel is named by a prefix according to the liquid with which it is associated, as hydrosol, 
alcosol, hydrogel, etc. This nomenclature was proposed by Graham (86) in 1861, and, as it has been adopted by practically all writers on colloids, should be used in preference to Cushman's terms "pectoid" (for gel) and "colloid" (for sol).

\section{COAGULATION AND SETTING.}

Colloids are commonly spoken of as reversible and irreversible, according to whether they will pass from sol to gel and back to sol, or whether, having passed into the gel form, they can not be reconverted to the sol.

The process of passing from sol to gel is best called "coagulation," though sometimes "pectinization" is used; that of passing from gel to sol is called peptinization. When granular matter also is present, the terms flocculation and deflocculation are preferable.

Weber (20) speaks of "pectisation" as an irreversible process that may perpetuate "any physical state (sol or gel) of a colloid." As this word so closely resembles "pectinize," he has not been followed in its use. A more serviceable phrase for the same idea is "setting," proposed by Hardy (10). Some colloidal solutions (sols) set spontaneously on standing, some by boiling, a large number of the inorganic colloids by freezing, the majority of inorganic colloids on adding to their solutions minute quantities of electrolytes. If resoluble, sols do not "set" but merely "coagulate" without setting.

Sols when set form amorphous precipitates which are exactly alike, whatever the concentration of the sol acted upon. In setting, a chemical change is usually produced in the molecule. Therefore, more than a physical change of conditions is required to reverse it.

EXAMPLES OF SET GELS.

As examples of set gels, may be mentioned fired clay wares; gelatine treated with alum or formaldehyde, as in the Leuchter process of reducing or enlarging models (22).

India rubber.-According to Weber, india rubber (polyprene, of empirical formula $\mathrm{C}_{10} \mathrm{H}_{10}$ ) is a gel practically freed of solvent (therefore a solid); while ebonite (polyprene disulphide, $\mathrm{C}_{10} \mathrm{H}_{16} \mathrm{~S}_{2}$ ) is the set modification of the same gel produced by the action of sulphur in vulcanization. In ebonite, polyprene disulphide and the excess of sulphur (15 to 70 per cent) form a new system, probably a solid solution. (This discussion does not include the case of solid solutions.) As a chemical process, time, temperature, and mass alone affect the composition of the vulcanization product (set gel); but the physical properties largely depend on the physical state of the india-rubber colloid (gel) employed. Ordinary rubber goods consist of a mixture of ebonite and india rubber. Therefore they are entirely coagulated and partly set. 
Charcoal.-Charcoal is another example of set gels. It results from a very complete decomposition of organic gels by heat, and its structure depends on theirs. Liquids are probably not absorbed into the substance of its pore walls, but dissolved substances (solutes) or suspended substances (sols) are readily attached to the surfaces of its pore walls (adsorption). All of the external and internal surfaces are wetted by the liquid.

Silica.-Van Bemmelen (21) showed that the silica hydrogel when concentrated by evaporation undergoes an irreversible inversion when the water content is from 3 to 1.5 molecules $\mathrm{H}_{2} \mathrm{O}$ to 1 molecule $\mathrm{SiO}_{2}$ and the vapor pressure between 10 and 4.5 millimeters. The position of this point depends on the mode of preparation, the age of the gel, the velocity of the dehydration, etc. The gel at this point becomes dull, opalescent, and fluorescent, then white like porcelain, and finally opaque white, like chalk without any gloss. After the inversion, dehydration takes place more rapidly than before, and the dimness disappears just as it has appeared, remaining bright until the final dehydration. As this modified gel can not resume the condition of the original gel, it might seem to be set. But as it fails to perpetuate the physical state of the original gel, and has all the ordinary properties of a gel, we must consider it a gel. Therefore, the original silica gel might be called the $a$ gel, and the modified or intermediate gel, the $\beta$ gel.

In chemical analysis silica is separated from solution by forming the set gel by dehydration at $100^{\circ}+$. The failure of the $\beta$ gel to go over completely to the set gel is a frequent cause of inaccuracy. Hillebrand (23) has shown that while the bulk of the silica is removed from solution by evaporating the hydrochloric acid solution to approximate dryness, taking up in hydrochloric acid, and filtering, yet about 1 per cent more is recovered on repeating the operation. "Blasting for 20 to 30 minutes is necessary to expel all moisture from the silica, and it is then not hygroscopic."

A few analysts, in rapid processes, separate silica from solution in a form which is probably the $\beta$ gel. The process is as follows: One gram of blast-furnace slag is put into a Royal Meissen dish, 25 cubic centimeters of $1: 1$ hydrochloric acid is added, and the whole is covered with a watch glass and boiled violently till all the free liquid appears to be gone, but nothing is dry. Next 10 cubic centimeters of $1: 1$ acid is added, the mixture boiled for 1 minute, and 25 cubic centimeters of hot water added. It is again boiled and can then be filtered very rapidly. The process is far from accurate, and it is questionable if its employment is ever justifiable. A peculiarity of the process is that Royal Berlin ware can not be used, as the silica sticks badly to it, a difficulty not found with Royal Meissen ware. 
The practicability of this process is related possibly to the fact noted by Hillebrand, that "The presence of much calcium chloride seems to facilitate dehydration of the silica."

\section{FORMATION OF SOLS.}

According to Whitney (27), "Whenever any substance which is by nature insoluble in a liquid is produced in a fine state of division in that liquid; it will remain in colloidal state (sol) until coagulated or precipitated by external means." Thus "Bredig [28] has shown that a great many metals may be produced in the hydrosol state by simply forming an electric arc under water between terminals of the metal desired. The heat of the arc volatilizes the metal, and the vapors condense in the water, yielding deeply colored suspensions or colloidal solutions." Many aniline dyes do not truly dissolve in water, but enter into colloidal suspension. In the cases of some dyes it is difficult to determine whether the properties are those of a large molecule of a crystalloid or of a small colloid particle. It is sometimes one or the other according to the concentration of the liquid. There is probably no dividing line $(32,34)$. Sols may also be produced by chemical reaction within the liquid; for example, by the action of hydrogen sulphide on arsenious oxide.

\section{ELECTROSTA'TIC CHARGES IN SOLS.}

From a review by Whitney and Ober (24), the following paragraphs are taken:

A clearer idea of the value of what follows will be gained if one recognizes at this point the probable necessity of attributing electrostatic charges to particles of any kind when suspended in a liquid, and of assuming that these charges, while they may be positive or negative for different kinds of suspended matter, must still be of the same sign for all particles of the same substance. It is known that two different substances in contact assume equal and opposite electrostatic charges at their contact surfaces, and the work of Quincke, Coehn, and others have brought to light the regularities of this phenomenon.

Suspended particles of finely divided sulphur, silica [probably also nongelatinous clay], etc., in water exhibit negative charges exactly as larger masses of the same substance in contact with water do, and when the suspension is placed between two electrodes connected with a source of electromotive force, the particles all migrate in the direction of the negative current. Conversely, too, water in capillary tubes made of such materials as charge themselves negatively in contact with it moves with the positive electricity through the capillary under the influence of the electric current. Similarly, particles suspended in turpentine assume in most cases the opposite charge as compared with the water, and under influence of the electric current move in the opposite direction.

Coehn [25] was led to conclude that a substance having a higher dielectric constant than the liquid in which it is suspended assumes the positive charge, while if of lower dielectric constant its charge is negative. It is probable that this does notalonedetermine the nature of the charge, which, at least in many cases, must depend also on 83865-Bull. 388-09-2 
electrolytic solution pressure and the partition coefficient for the ions of dissolved electrolyte between the suspended material and the liquid [26].

We seemed forced then to recognize electrostatic charges on suspended particles, ind it seems just as necessary to accept the conclusion that, as a result of these charges, : vuspended particles whose masses are small enough are equally distributed throughout the liquid and prevented from ever coalescing or settling because of the mutual repulsion of these charges. This mutual repulsion might also cause measurable osmose :nd corresponding osmotic pressure, properties which colloids have to a small degree.

IONIC REACTIONS.

According to Mayer, Schaeffer, and Terroine (29), in all of a series of tests the addition of traces of alkali to an ultramicroscopic suspension had the effect of increasing the size of the colloidal granules if the suspension was positive and of diminishing them if the suspension was negative; and the addition of acids produced the inverse effect.

According to Whitney and Ober, "Spring [30] believes the statical charge, which it is assumed the ions of electrolytes carry, neutralizes the statical charges of opposite sign on colloidal particles. *** For example, he states that certain colloids are negative and therefore require for their immediate precipitation or coagulation a certain concentration of a positive ion." Picton and Linder (42) see in such precipitations "a remarkable mimicry of ionic dissociation." Others consider it true ionic dissociation.

A. Lottermoser (31) considers that-

The hydrosol condition is only possible if one of the reacting ions $\left(\mathrm{I}^{\prime}+\Lambda \mathrm{g}^{\prime}, \mathrm{Fe}^{\prime \prime \prime}+\right.$ $3 \mathrm{OH}^{\prime}, \mathrm{SiO}_{3}^{\prime \prime}+2 \mathrm{II}^{\prime}$ ) remains up to a certain minimum amount in excess; that on exceeding this limit the gel formation begins; and that with the completed reaction, therefore (if equivalent amounts of the reacting ions are brought together), the gel formation becomes complete. *** The hydrosol condition is bound up with the presence of certain ions in the colloid, which are added naturally to the colloid as electrolyte or remain in the same.

Dialysis decreases stability and leads to precipitation. Increasc of the same electrolyte increases stability up to a maximum, then lets it fall to zero.

\section{NATURE OF GEL FORMATION.}

Some of the simpler colloids, such as those of the nobler met:als, probably do not form gels at all; their decomposition is always the irreversible one to set gels. Substances that form gels have a tendency to form crystals, and especially complex forms, under favorable (')nditions. With the reaction of gel formation, sufficient freedom or directive force is apparently not given the particles to orient themselves into crystal ranks. The precipitation seems to take place when the particles get within a certain maximum range of each other. This probably gives a certain regularity of structure which microscopic workers describe as cellular and an immense area of surface. 
The precipitating ion, when the cause is the action of an electrolyte, also tends by its presence to break up the symmetry of arrangement required for crystals. In the precipitate, positive and negative valencies satisfy each other where near enough, but possibly many unsatisfied valencies are present. Some who are not ready to accept the conception of wholly unsatisfied valencies are yet ready to accept the idea of residual valencies. The more complex the chemical ions and the more viscous the medium the more unlikely it is that when concentrated by itself or precipitated with a substance of opposite electrical sign the ions of a substance will ever be able to arrange themselves on crystal lines. Heat, giving greater mobility, tends to assist these complex sols to arrange themselves in such manner as to precipitate or coagulate; while the simpler ones, having at all times sufficient mobility, require merely the oppositely charged electrolyte. Heat may also assist by decompositions to simpler molecules and by the increase of static charges. This leads to the conception of permanent colloids, which, in short, are substances that never find conditions favorable for coagulation. Such probably have only small electrostatic charges in proportion to their mass; so that but little effect upon their properties results from the neutralization of that charge by an oppositely charged ion. The formation of gels is not noticeable in such cases.

\section{STABILITY OF CLAY SOLS AND GELS.}

J. M. Van Bemmelen (2) went into the question of the settling of a clay suspension. As soon as the loosely bound salts are washed out of a clay it becomes difficult to cause it to settle, and it can not be filtered, but runs through the filter paper. On adding a small amount of acid or a salt or an alkali (in short, any electrolyte), the milk-white liquid coagulates and settles in a short time. It also can now be filtered. Washing again with water, another point is reached when the particles become infinitely fine and pass through the filter.

Adolph Mayer (3) has determined the limiting amounts of electrolytes which will permit a fine clay (free from soluble salts by treatment with hydrochloric acid) still to be kept in suspension in water (100 grams clay, 500 cubic centimeters water). The limits are: Ammonia; 2.5 per cent; sulphuric, hydrochloric, and nitric acids and the alkali salts of these acids, 0.025 per cent.

Van Bemmelen assumes that the finely divided substance forms larger molecular aggregates in which the added substance takes part. The solution to do this must have a definite concentration, otherwise too many molecular aggregates are decomposed by the water and roturn to the finer molecular condition.

Although 2.5 per cent of ammonia caused precipitation in Mayer's experiments, a less amount favors the deflocculation, or breaking 
up of the lumps. Thus it is the practice in the laboratory of the Bureau of Soils of the Agricultural Department (4) to add 10 drops of strong ammonia to a 5-gram sample of clay in 75 cubic centimeters of distilled water in order to assist in separating the clay into itsfinest particles preliminary to mechanical analysis. With alkaline soils ammonia hinders the deflocculation, and should therefore be omitted in dealing with such.

Inorganic sols (34) are frequently coagulated by freezing or evaporating; this is often really due to the traces of electrolytes always present in the liquid, which become concentrated until they reach the minimum necessary for flocculation.

\section{PROTECTION COLLOIDS.}

When a very stable sol in the presence of a less stable sol of the same sign is acted upon by an electrolyte that will not precipitate the former, but would precipitate the latter if alone, the influence of the more stable sol is often sufficient to "protect" the less stable sol from coagulation. Noncolloidal substances can exercise protection; for example, ether protects noble metal hydrosols. Gelatine is a common "protection colloid" for many substances of small-sized ions. The colloids of clay may carry into suspension solid particles that are wholly noncolloidal by ordinary ideas.

\section{PROPERTIES OF COLLOIDS.}

VIScosITY.

\section{VISCOSITY OF CLAY SLIPS.}

Bleininger (49) has made an investigation of the viscosity of clay slip with different percentages of clay and water. The first additions of clay (up to about 3 per cent) decreased the viscosity of the water. This is to be attributed, as just shown, to complete deflocculation of the clay by dilution, and also to the solution of the electrolytes found with the clay; since, as expressed by. Charles Henry (50), the kinetic theory of gases apprises us that the viscosity decreases when the diameter of the particles inceases, and the inverse. Bleininger therefore introduced particles larger than the water molecules into solution, and thereby decreased the viscosity. When, however, the additions had become so great that no further matter went into solution and the effect of the clay gel showed itself, then the viscosity increased with each addition of clay.

Previous to Bleininger's work a negative viscosity for clay slips had but rarely been observed, and, indeed, Dr. Max Simonis (51) had proposed this definition: "Clays are rocks which, pulverized and brought into suspension with equal or greater amounts of water, measurably 
increase the cohesion of the water. Nonplastics lack this property." As Simonis $(52,53)$ had previously noted that alkalies can cut down the viscosity of clay slips, it is evident that he overlooked the possibility of salts naturally occurring in clay having the same effect at sufficient dilution.

\section{PLASTICITY.}

Many plastic bodies consist of a more or less granular material, coated and held by a viscous substance. Instances are: Putty, which is a mixture of any white granular material (typically whiting) with linseed or a similar oil, the latter hardening on exposure to air; cake frosting, a mixture of granular sugar with the white of eggs, becoming hard on exposure to air; plaster of Paris, a mixture of gypsum crystals and an amorphous paste of uncrystallized plaster, hardening upon completion of the crystallization; wiping solder, a mixture of lead crystals in a fused eutectic mixture of lead and tin, hardening on cooling; mortars, mixtures of sand with lime or other cementing pastes, hardening on reaction with the air, or by internal reactions; waxes, mixtures of oils of high melting points with oils of lower melting points, hardening on cooling; and, finally, clays, mixtures of granular, nonplastic materials with moist organic and inorganic gels, hardening on evaporation of the water. The term "nonplastics" for granular materials requires qualification, since plastic bodies would lose plasticity if the granular constituent were removed and would become sticky. Plasticity depends on a proper ratio of granular material and viscous suspension medium.

P. Rohland (43) considers that the plasticity of clays depends on the amount of hydroxyl ions present in the water. When this is large, the negatively charged clay particles will go into colloidal suspension. When the hydroxyl concentration is depressed, as by additions of acid or depression of temperature, the clay will assume the gel condition and become plastic. For decreasing plasticity may be used all bases, organic and inorganic, all salts of strong bases with weak acids, which hydrolytically split off $\mathrm{OH}$ ions in large amounts. To this classification belong potash, soda, salts of phosphoric acid, salts of silicic acid. "Neutral salts with very few exceptions appear to behave indifferently." As indifferent salts he mentions sodium chloride, sodium sulphate, potassium nitrate, magnesium chloride, and others. "The causes of the abnormal behavior of several are not yet exactly known."

This conception is attractive by virtue of its simplicity and comprehensiveness. It seeks, however, to refer the plasticity of clays to their vehicle, a water solution of soluble salts, rather than to their own composition. It seems more logical, though perhaps more 
difficult in details, to refer plasticity to the gel structure of the clays themselves. It must be allowed that the condition of the water will have effects of the nature assigned by Rohland; but as clay is plastic when wetted with, for example, aniline (paint remover), linseed oil (kaolin putty), alcohol, glycerin (plastic medical dressing), etc., hydroxyl can by no means play the principal part. This is substantiated by the views of Coehn (25). (See p. 17.)

\section{ACTION OF ELECTROLY'TES.}

Plastic clays have very little, if any, of their colloid matter in the hydrosol condition. They hold in their natural deposits sufficient bases, especially lime, to keep them as coagulated gels. Anyone has but to look at the clear water coming from a pottery filter press to realize how completely absent is the sol form of the clay colloids. It is not until a sol has been coagulated and thus become a gel that it has any plasticity or marked adhesive and cohesive properties. Thus Hans Kuzel (45) has observed that the pure gels of colloid metals form exceptionally homogeneous plastic masses when the mechanically combined water is removed by appropriate expression. or other suitable means. (He adds nonplastics.) The sols of such metals are fluid, therefore wholly unplastic.

It is possible that much of the colloid matter in clays has never been in the sol form, but is a gelatinous residue left from rock decomposition, together with crystal rock fragments (46).

According to Hardy (10a), a sol is coagulated when its static charge. of electricity is neutralized. This is usually done by electrolytes. With a negative sol, such as a clay that has been brought into colloidal suspension, the positive ion of the electrolyte is of most influence in effecting precipitation, the acid ion taking little part. The power seems to vary but little in different positive ions of the same valence; but with certain sols divalent ions have about 60 times the precipitating effect of monovalent ions, and trivalent ions 600 times that of monovalent ions $(27,24,33)$. The effects are not so great on clays.

EXCHANGE OF BASES.

Eugene C. Sullivan (39) has carefully studied the interaction between minerals and water solutions. He concludes that "so far as the evidence goes, then, the action of silicates, clay, and other constituents of the earth's crust on solutions of such salts as do not dissolve in water with alkaline reaction, consists in an equivalent exchange of bases." He does not consider pure water, acids, or alkalies in this generalization.

If sodium carbonate be added to a clay which has just enough calcium (the most common "soluble salt" in clay is calcium sulphate) 
to keep the colloid matter in gel form, it will (the calcium being but loosely combined) react according to the following equation:

$$
\underset{\text { with gel }}{\mathrm{Ca}}+\underset{\text { the addition }}{\mathrm{Na}_{2} \mathrm{CO}_{3}} \rightarrow \underset{\text { insoluble }}{\mathrm{CaCO}_{3}}+\underset{\text { with the sol. }}{\mathrm{Na}_{2}}
$$

F. Förster (87) is to be credited with first perceiving the nature of this action of sodium carbonate on the clay gel. The calcium carbonate formed being insoluble no longer has influence on the colloid. The sodium, in amount equal to the calcium, has metal ions of lower valence than the calcium which originally stabilized the gel. As many times more sodium atoms than calcium atoms are required to precipitate the same amount of gel, it is evident that the clay gel will be broken up, or the clay will be deflocculated by the soda, and its plasticity will fall off in proportion to the completeness of the reaction. When, however, enough sodium ions have been adder, they may be expected to precipitate the gel anew.

Such is the case, as studied by Mellor, Green, and Baugh (47). These investigators took measurements of the time required for 200 cubic centimeters of an earthenware body slip to run from a modification of Mariotte's bottle. Reduced to a basis ${ }^{a}$ of time for water equals 10 seconds, their results were:

Addition of sodium carbo-

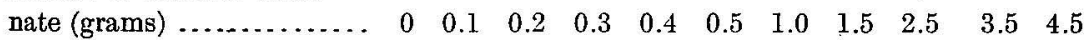

$\begin{array}{lllllllllllll}\text { Time required (seconds) } & \ldots & 10 & 8.7 & 7.4 & 6.5 & 6.1 & 6.1 & 6.1 & 6.1 & 7.8 & 13.9 & \text { (b) }\end{array}$

Similar results were obtained by them for potassium carbonate, sodium bicarbonate, sodium potassium carbonate, sodium sulphide, potassium hydroxide, gallic acid, ammonium gallate, and tannin. It can not be asserted that with each of these compounds the action is the same as with sodium carbonate, for the earthenware body is of too complex a nature, and the action must be studied on simpler substances for full conformation, but probably the explanation holds for most of these cases. The insolubility of the compound formed may not be so complete as that of calcium carbonate in every case; it is less so, for instance, with calcium hydroxide formed by action of potassium hydroxide. According to Simonis's results, sodium hydroxide and rubidium hydroxide behave similarly to potassium hydroxide.

When the added salt does not form an insoluble product with the salt in the clay, there is probably part replacement in accordance with the mass-action law. Thus on addition of sodium sulphate there was a falling off in viscosity, and sufficient sodium ion concentrations were not reached to reprecipitate the gel. Such was also the case with sodium sulphite and sodium chloride. It is therefore classified here with hydrochloric acid. Certain salts, however, were added

a Mellor, Green, and Baugh used water at various temperatures, which took in some cases 10 seconds and in others more, to flow from the viscosimeter. These results have been reduced to a common basis of 10 seconds.

$b$ Too stiff to flow through apparatus. 
in sufficient amounts to reprecipitate the gels, viz, potassium acid sulphate, potassium sulphate, potassium nitrate.

It is difficult to classify the action of hydrochloric acid and mereuric sulphate. The latter decomposes to insoluble sulphate and free acid.

Divalent ions in some cases reinforced the salt in the clay, in others the reverse, according to slight variations in precipitating power, such as have been shown by Schulze (33). Magnesium sulphate decreased viscosity. Substances increasing viscosity were calcium sulphate, copper sulphate, calcium chloride, and, according to Simonis, calcium hydroxide.

Trivalent ions reinforced the flocculation, even though associated with monovalent ions. The case studied was potassium aluminum sulphate $\left(\mathrm{K}_{2} \mathrm{SO}_{4} \cdot \mathrm{Al}_{2}\left(\mathrm{SO}_{4}\right)_{3} \cdot 24 \mathrm{H}_{2} \mathrm{O}\right)$.

\section{ORGANIC COLLOIDS.}

In some cases the action is probably not on the inorganic gel of the clay, but on the organic matter. Strong ammonia increased the viscosity in these experiments. Ammonia is known to be a solvent for humic acids. It is very likely that it acted on the somewhat insoluble or set humic acids and humates, forming ammonium humates, which, not having sufficient water for solution, assumed the gelatinous form and increased the viscosity. Similar action may be attributed to ammonium chloride, aniline, methylamine, and ethylamine. This possible explanation needs verification, and can not be considered as of weight until such studies have been made. All of the other basic ions studied were of simple nature. The effect of the complexity of the $\mathrm{NH}_{4}$ group may be of influence. Smaller additions than those tabulated may produce deflocculation.

Alcohol additions did not affect the viscosity. As water additions would have decreased the viscosity, so alcohol substitutions for water would have increased the viscosity. The action of alcohol is therefore similar to that of ammonia, a complex group, with solvent effect on organic matter.

Humic acid and grape sugar, being themselves colloids, increased the colloid content and the viscosity. Sodium biborate is possibly also to be classed as increasing viscosity, or on Binn's assumption of the basic nature of boron (48) might be considered as having a trivalent basic ion. ${ }^{a}$

MELLOR, GREEN, AND BAUGH'S EXPERIMENTS.

In the table of Mellor, Green, and Baugh's results below the times required for equal volumes of slips with various additions to flow through the same orifice are given (reduced to a common basis ${ }^{b}$ of time for water equals 10 seconds):

$a$ Work by the writer in 1909 shows that borax belongs in the first or second of the groups of the table. $b$ See footnote, p. 23. 
Effect of various additions on the viscosity of an earthenware body slip, measured by the time in seconds, consumed by a definite quantity in flowing from a Mariotte bottle viscosimeter.

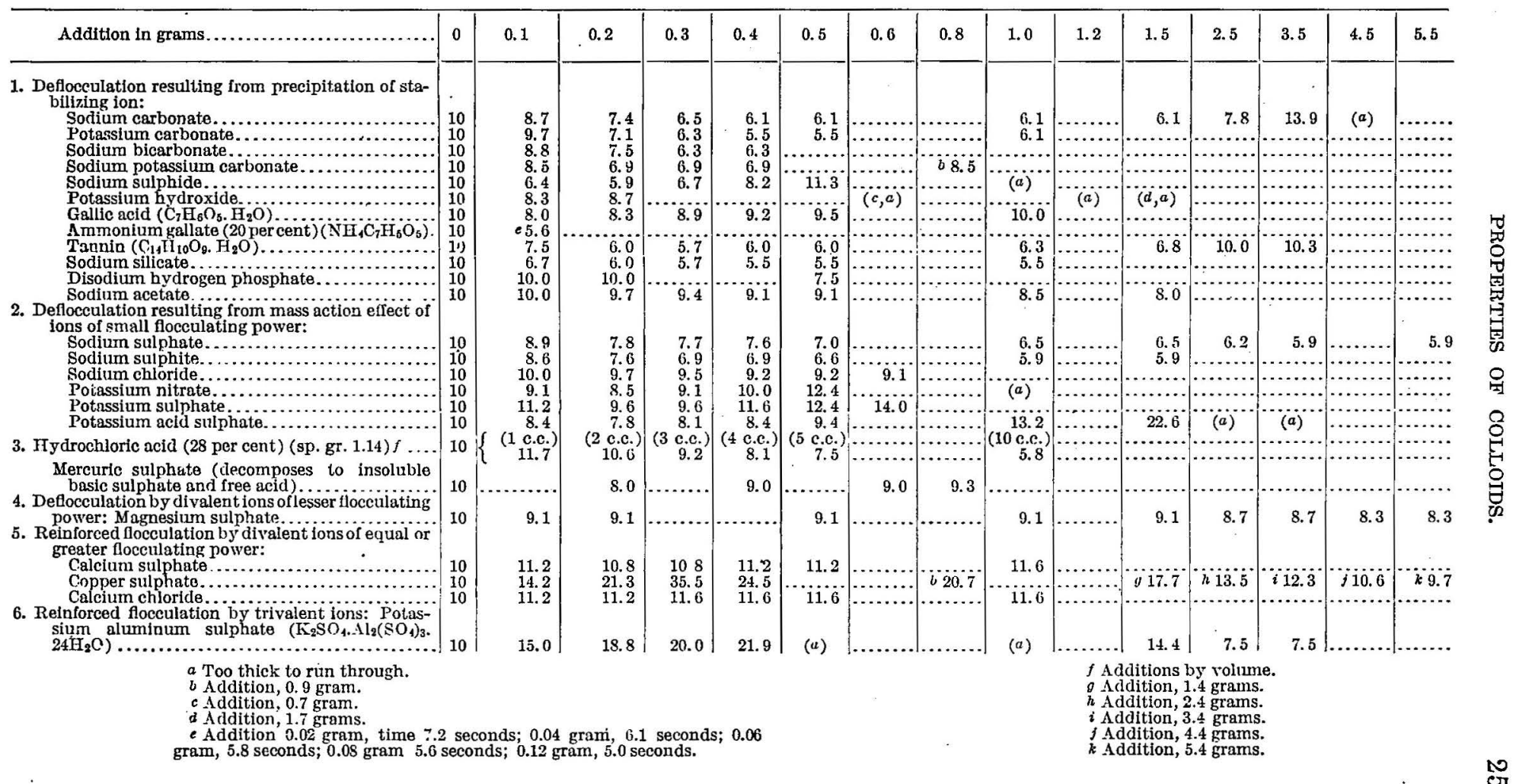



a Mariotte bottle viscosimeter-Continued.

\begin{tabular}{|c|c|c|c|c|c|c|c|c|c|c|c|c|c|c|c|}
\hline Addition in grams............... & 0 & 0.1 & 0.2 & 0.3 & 0.4 & 0.5 & 0.6 & 0.8 & 1.0 & 1.2 & 1.5 & 2.5 & 3.5 & 4.5 & 5.5 \\
\hline $\begin{array}{l}\text { 7. Reinforced flocculation by a complex group: } a \\
\text { Ammonium urate }\left(\mathrm{NH}_{4} \mathrm{C}_{5} \mathrm{H}_{3} \mathrm{~N}_{4} \mathrm{O}_{3}\right) \ldots \ldots \ldots \ldots\end{array}$ & 10 & 10.7 & (b) & & & & & & & & & & & & \\
\hline 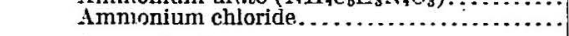 & 10 & 10.0 & 11.8 & 10.2 & 16.2 & (b) & & & & & & & & & \\
\hline Ammonia, 29 per cent solution $c_{\ldots} \ldots \ldots \ldots \ldots$. & 10 & $\left\{\begin{array}{l}\left(\begin{array}{l}1 \\
1 \\
13.0 .0\end{array}\right) \\
\text { c.c. })\end{array}\right.$ & $\left(\begin{array}{l}2 \underset{14.5}{c}) \\
14.5\end{array}\right)$ & $\left.\mid \begin{array}{ll}(3 & \text { c.c. }) \\
10.0\end{array}\right)$ & 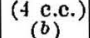 & & ......... & $\cdots \cdot$ & $\cdots$ & … & $\cdots$ & $\ldots \ldots$ & $\cdots \cdots$ & $\cdots$ & ........ \\
\hline Methylamine $\left(\mathrm{CH}_{3} \mathrm{NFF}_{2}\right) c \ldots$ & 10 & $\{(1$ c.c. $)\}$ & $\ldots \ldots$. & & & & & & & & & & & & -....... \\
\hline Ethrlamine $\left(\mathrm{C}_{\mathrm{O}} \mathrm{N}_{\mathrm{N}} \mathrm{N}\right) \mathrm{c}$ & & $\left(\begin{array}{l}(0) \\
\text { c.c. })\end{array}\right.$ & & ( 3 c.c. $)$ & & & & & & & & & & & \\
\hline Ethylamine $\left(\mathrm{C}_{2} \mathrm{H}_{5} \mathrm{NH}_{2}\right)^{c}$.. & 10 & 12.6 & 13.7 & (b) & $\cdots \cdots$ & $\cdots \cdots$ & $\cdots$ & $\cdots \cdot$ & $\cdots$ & $\cdots \cdots$ & $\mid \cdots \cdots$ & a....... & $\cdots \cdots$ & $\cdots \cdots$ & $\cdots \cdots \cdots$ \\
\hline Aniline $\left(\mathrm{C}_{6} \mathrm{H}_{5} \mathrm{NH}_{2}\right) c_{\ldots}$ & 10 & $\left\{\begin{array}{r}(0.1 \text { c.c. }) \\
11.6\end{array}\right\}$ & $\underset{(b)}{(0.2}$ c.c. $)$ & & & & & & & & & & & & - \\
\hline $\begin{array}{l}\text { 8. Reinforcer floceulation by colloids or by additions } \\
\text { of greater viscosity: } \\
\text { Jumic acid.... }\end{array}$ & 10 & {$\left[\begin{array}{ll}1 & 11.0\end{array}\right]$} & (W) & 12.3 & 12.6 & 13.4 & & & 16.0 & & & & & & \\
\hline $\begin{array}{l}\text { Grape sugar }\left(\mathrm{C}_{12} \mathrm{H}_{12} \mathrm{O}_{6}\right) \\
\text { Sodium biborate }\left(\mathrm{Na}_{2} \mathrm{~B}_{4} \mathrm{O}_{7}, 10 \mathrm{HI}_{2} \mathrm{O}\right) \ldots \ldots \ldots \ldots\end{array}$ & 10 & $\begin{array}{l}10.0 \\
10.3\end{array}$ & $\begin{array}{l}10.3 \\
10.7\end{array}$ & $\begin{array}{l}10.3 \\
10.7\end{array}$ & $\begin{array}{l}10.3 \\
10.7\end{array}$ & $\begin{array}{l}10.3 \\
11.0\end{array}$ & & & $\begin{array}{l}10.3 \\
12.0\end{array}$ & & 10.3 & ii.o & & ii. 0 & $\cdots$ \\
\hline A bsolute alcohol $\left(\mathrm{C}_{2} \mathrm{H}_{5} \mathrm{OH}\right) c_{\ldots} \ldots \ldots \ldots \ldots \ldots$ & 10 & $\left\{\begin{array}{r}\left(\begin{array}{rl}1 & \text { c.c. } \\
10.0\end{array}\right) \\
10.0\end{array}\right.$ & $(2$ c.c. $)$ & $\left(\begin{array}{c}\left(\begin{array}{c}3 \\
\text { ce.c. } \\
10.0\end{array}\right) \\
10.0\end{array}\right)$ & $\left(\begin{array}{lll}\left(\begin{array}{c}1 \\
\text { c c.c. }\end{array}\right) \\
10.0\end{array}\right)$ & $\begin{array}{c}(5 \text { c.c. }) \\
10.0\end{array}$ & …..... & ?....... & $\left(\begin{array}{c}10 \text { c.c. }) \\
10.0\end{array}\right.$ & $\cdots$ & (is c.c.) & $\left(\begin{array}{r}25 \text { c.c. }) \\
10.0\end{array}\right)$ & $\left|\begin{array}{r}35 \text { c.c. } \\
10.0\end{array}\right|$ & $\cdots \cdots$ & $\cdots \cdots$ \\
\hline
\end{tabular}




\section{LAWS OF COAGULATION.}

A promising theoretical treatment of coagulation is that of Hardy (10a), who says: "The concentration of acids necessary to coagulate electronegative colloid particles, and of alkalis necessary to coagulate electropositive particles, is determined by the laws which govern ordinary chemical equilibrium," that is, equicoagulate solutions of acids agree in their electric conductivity within the limits of experimental error.

Specific conductivity $=\mathrm{C}=\nu \alpha(u+v)$.

$a$ is the fraction of the total number of molecules, $\nu$, which are dissociated at any one moment, and $u+v$ is the sum of the velocity of the two ions.

In the case of the action of salts on these hydrosols, the relation is not so simple. $\mathrm{K}$ does not vary directly with $a(u+v)$, but contains a factor which is approximately squared or cubed by a change from a monovalent to a divalent or trivalent ion. The relation can therefore be best expressed as $\mathrm{K}=\nu a(u+v) \mathrm{A}^{x}$, where $x$ is positive and increases rapidly with an increase in the valency of the ion whose electric charge is of the opposite sign to that on the particles.

Action is on the liquid or on the particles or on both at various times.

Unfortunately little experimental work has been done along the line indicated by Hardy.

\section{ABSORPTION.}

\section{LACK OF DEFINITE RELATION OF ABSORPTION TO TEMPERATURE.}

It has been pointed out in the case of silica that a portion of the liquid medium is most tenaciously held by the gel. (See p. 16.) This is a universal and well-known property of colloids. 'In the case of hydrogels it may be said to correspond in a rough way to water of crystallization; but just as colloids have no definite form, neither do they retain a definite amount of water nor give it up at a definite temperature on heating. Cushman (38) has shown in the case of several hydrogels the proportion of water that they will absorb after being heated to increasingly high temperatures. Similar curves were obtained for silicic acid gel, ferric oxide gel, and two clays. The temperatures at which they lost the absorptive power completely are $840^{\circ}$ and $950^{\circ}$ for the two clays, $1,020^{\circ}$ for the ferric oxide gel, and $1,200^{\circ}$ for the silica gel. As the water regained was from over a sulphuric acid solution of 18 millimeters vapor pressure, it is, according to Cushman, not to be considered hygroscopic, but as due to absorption.

According to Van Bemmelen (54), hydrogels are not definite hydrates, as the vapor tension and hence the water content change continuously with temperature, while a true hydrate gives off a definite 
number of molecules of water at definite temperatures. The water of hydrogels may be replaced by other liquids, such as alcohol, glveerine, etc. The aqueous tension of colloids also undergoes irreversible changes on drying out, heating, etc.

\section{RELATION OF ABSORPTION TO PLASTIOITY.}

The amount of water required by clays to give them a plastic consistency (which may be considered as closely related to amount absorbed) is sometimes taken as a measure of plasticity, but Grimsley (9) notes that Ries in his work on the Michigan clays found examples where 19 per cent of water was required for a clay of low plasticity, and 17 or 18 per cent for another of high plasticity.

Grout (9) found that a shale which had increased largely in plasticity on weathering checked within 0.02 per cent of the combined water originally present. Therefore, plasticity can not be measured directly either by the combined or the absorbed water.

\section{DISTRIBUTION OF ABSORBED WATER AMONG CONSTITUENTS.}

The amount of water absorbed from the atmosphere by the various constituents of clay is remarkable.

For quartz, Patten and Gallagher (55) report at $25^{\circ} \mathrm{C}$.-

Absorption by quartz at $25^{\circ} \mathrm{C}$.

\begin{tabular}{|c|c|}
\hline Vapor pressure. & Moisture absorbed. \\
\hline Millimeters. & Per cent. \\
0.09 & 0.07 \\
8.00 & .10 \\
14.00 & .11 \\
18.30 & .12 \\
23.50 (water) & .61 \\
\hline
\end{tabular}

For feldspars, Day and Allen (56) find that the water of constitution (about 0.60 per cent) frequently reported for feldspars is in most cases really hygroscopic, and is the larger in amount the finer the samples are ground.

Von Dobeneck (57) reports the water absorbed by humus at $20^{\circ}$ C. as follows:

Absorption by humus at $20^{\circ} \mathrm{C}$.

\begin{tabular}{|c|c|}
\hline Humidity. & Moisture absorbed. \\
\hline Per cent. & Per cent. \\
30 & 4.05 \\
50 & 7.76 \\
70 & 10.58 \\
90 & 15.67 \\
100 & 18.02 \\
\hline
\end{tabular}


Briggs and McLane (58) subjected soils in a centrifugal machine to forces 3,000 times that of the earth's gravitation. The water retained varied from 3.6 per cent with coarse sandy soils to 46.5 per cent in the case of a heavy clay subsoil. Each per cent of clay or organic matter corresponded to 0.62 per cent of moisture; each per cent of silt to 0.13 per cent of moisture.

Referring to the work of Schloesing (see p. 8), it will be noted that he found the finest constituent of a very pure clay to have a gelatinous nature, with a decided reluctance to giving up water.

It will be seen from these figures that the large moisture content of air-dried clays is not to any noticeable degree due to the granular kaolin feldspar and quartz, but to the organic matter and to the mineral colloidal constituent of the clay.

\section{VOLUMES OF CLAY GEL IN VARIOUS SALT SOLUTIONS.}

Schloesing has noted the great bulk assumed by the clay gel in water. Patten and Gallagher (55) have studied the effect of various salt solutions on the bulk of 50 grams of Susquehanna clay shaken up with 150 cubic centimeters of solution and allowed to settle for 7 days, as given in the following table:

Effect of 150 cubic centimeters of various solutions on 50 grams of clay.

\begin{tabular}{|c|c|c|}
\hline \multirow{2}{*}{ Solute. } & \multicolumn{2}{|c|}{$\begin{array}{l}\text { Volume of solution in } \\
\text { soil. }\end{array}$} \\
\hline & $\frac{N}{2}$ solution. & ${ }_{10}^{\mathrm{N}}$ solution. \\
\hline Flocculation: & Cubiccenti- & Cubic centi- \\
\hline $\begin{array}{l}\text { Floceulation: } \\
\text { Calcium nitrate. }\end{array}$ & \begin{tabular}{r|} 
meters. \\
60.5
\end{tabular} & melers. 69.4 \\
\hline Ammonium nitratc.. & 73.0 & 89.4 \\
\hline Lime, unknown concentrations, 59.1 . & ....... & (.............. \\
\hline $\begin{array}{l}\text { Lime, unknown concentrations, } 72.0 \\
\text { Distilled water, } 75.4 \ldots \ldots \ldots \ldots \ldots \ldots \ldots\end{array}$ & $\cdots$ & (n.............. \\
\hline 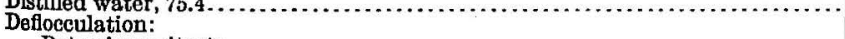 & & \\
\hline Potassium nitrate........ & 80.4 & a 70.1 \\
\hline Potassium carbonate..................... & 91.4 & 126.4 \\
\hline 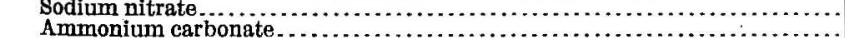 & $\begin{array}{r}97.7 \\
104.6\end{array}$ & $\begin{array}{r}a 69.8 \\
105.6\end{array}$ \\
\hline di-Potassium hydrogen phosphate. & 108.7 & 123.2 \\
\hline 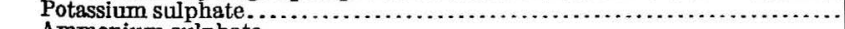 & 110.4 & 117.7 \\
\hline 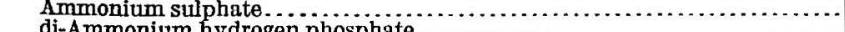 & 111. 3 & 117.6 \\
\hline 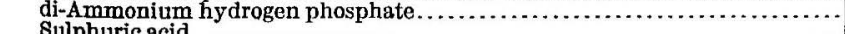 & 118.1 & 125.8 \\
\hline $\begin{array}{l}\text { Sulphuric acid }{ } \\
\text { Sodi }\end{array}$ & 126.1 & $\begin{array}{l}101.2 \\
113.8\end{array}$ \\
\hline ( & 126. 7 & 128. 7 \\
\hline Sodium carbonat & 128.1 & 131.9 \\
\hline
\end{tabular}

a Flocculation.

The deflocculation has not proceeded far enough to result in sol formation in most of these cases. It is probable that sol formation would not be reached at any concentration with potassium nitrate, sodium nitrate, potassium sulphate, ammonium sulphate, sulphuric acid, and sodium sulphate. 
The result is closely parallel to that of Mellor, Green, and Baugh on the viscosity of clay slips. Divalent lime, and complex ammonium ions caused a decrease in bulk and an increase of viscosity. Ammonium seems to present anomalies, for which it is possible, but not profitable, to frame explanations. F. Hofmeister (59) has shown that with the same positive ion, different negative ions give different amounts of swelling with plates of glue.

It has been pointed out by Weber (20) that the water associated with a gel is dissolved in the gel-a distinction from ordinary solutions with a considerable difference. Van Bemmelen (60) states that it is homogeneously distributed throughout the substance of the scel, not concentrated on the surfaces like hygroscopic water on glass.

\section{DISTRIBUTION OF SALTS IN GELS.}

The physical distribution of the salts associated with a gel is a subject of much interest. A small portion of one of the ions is intimately associated, probably by a sort of chemical combination, and is necessary for the stability of the gel state. This has already been discussed (p. 18). The amount required for this stability varies with different elements, and is greatest for the monovalent ions, least for those of highest valence.

A colloid of opposite sign may perform the same function as a salt ion of opposite sign in coagulating a sol or stabilizing a gel. According to Teague and Buxton $(36,62)$, whose work does not seem to be published in the language of their own country, some dyes are true crystalloids, soluble in water; others are true colloids, suspensions in water; and there are all intermediate gradations. In other words, there is no dividing line between crystalloids and colloids; but it is convenient to classify separately as colloids those substances whose ions are so large as to give preeminence to those phenomena that we call colloidal. But all dyes can be treated as in one group. Teagrue and Buxton (62), with especial reference to dyes, lay down this rule: "Slightly colloidal substances (sols of opposite sign) precipitate each other over a wide range of concentrations, but incompletely; highly colloidal substances, over a narrow range of concentrations, but completely." In their earlier article (36), they say that in the case of a highly colloidal color and one slightly colloidal-for example, congo red and methylene blue-the slightest excess of congo red dissolves the precipitate, but the weakly colloidal methylene blue dissolves nothing unless in considerable excess. In their later article (62), they say that highly colloidal substances can probably take the more colloidal member of a mutual colloid gel away from the weaker member. It thus appears that in the matter of replacements, colloid complexity has an effect similar to increase of valency with simple crystalloid ions. 
Des Bancels (64) states that (1) mixtures of two colloids of opposite signs cause a precipitation which is complete at a defifite proportion; but addition of an electrolyte capable of precipitating one of the two colloids prevents their mutual precipitation; (2) if to mixtures containing a constant quantity of negative colloid $\mathrm{A}$ and increasing proportions of an electrolyte which does not precipitate this colloid one adds a constant quantity of colloid $B$, it is noticed that for weak quantities of electrolyte the precipitate is a mixture of $\mathrm{A}$ and $\mathrm{B}$, for increasing amounts of electrolyte the precipitate consists of $\mathrm{B}$ alone, while for the strongest amounts of electrolyte the precipitate contains a mixture of $\mathrm{A}$ and $\mathrm{B}$; (3) the precipitate resulting from the mixture of two colloids of opposed signs can generally be dissociated by the addition of an electrolyte capable of precipitating one of the couple.

\section{ADSORPTION.}

\section{STATEMENT OF THEORY.}

After a sol has been coagulated by a certain amount of an opposite ion, the question is proper, What becomes of the excess of the coagulating ion or of other ions of the same sign that may subsequently be brought into the liquid? The replacements possible in the latter case have already been discussed (p. 22). As to the former case, there are two views: One, that the excess ions are collected on the surfaces of the gel, adsorbed, as is considered the case with gases held by charcoal; the other, that the excess ions are distributed between the outside liquid and the gel, as if the gel were the second of two immiscible liquids; that is, that the ions were held in solid solution in the gel.

Walker and Appleyard (61) have disproved the latter theory as applied to dyeing, and their proof is equally applicable in other cases. The adsorption theory not having been disproved, probably is correct.

The excess of the opposite ion that has not taken part in coagulating the gel and that is not adsorbed is probably in simple solution in the liquid medium, whether that medium be absorbed by the gel or free.

\section{CELlULAR STRUC'TURE OF GELS.}

For the adsorption theory it is necessary to consider that the gel has a surface proportional to its mass. On page 18 the circumstances that may lead to a cellular structure have been mentioned. W. B. Hardy (10) discusses such a state in the case of gelatine; Van Bemmelen (63) notes the similarity of such structures and emulsions; Lottermoser (65) describes a cell-like structure, which he calls an "emulsion colloid" but which Weber (20) has described as a gel 
swelled up to, near, or above the maximum solubility of water in the gel. Butschli and also Nagelli have described the microscopic appearance of the cellular structure of colloids.

The theory of a cellular structure having been accepted, its mathematical expression may. be considered. Bödeker (66) in 1859 considered adsorption as proportional to the square root of the initial concentration. Wolff (67) in the same year pointed out that the final, not the initial, concentration should be considered.

\section{PARTITION BETWEEN IMMISCIBLE LIQUWS.}

Nernst, in 1891, formulated a "partition law" for the distribution of a solute between two immiscible liquids. Distribution is contsidered dependent on the relative solution pressure in two solvents.

$$
\frac{\mathrm{C}_{a}}{\mathrm{C}_{b}}=\beta
$$

where $\mathrm{C}_{a}$ is the concentration in solvent $a, \mathrm{C}_{b}$ is the concentration in solvent $b$, and $\beta$ is a constant, amounting practically to the ratio of the solubilities in the two liquids.

If, however, the molecular weight in the solvent $b$ is $n$ times as great as in $a$, the equation takes the form

$$
\frac{\mathrm{C}_{a}}{\mathrm{C}_{b^{\frac{1}{n}}}^{\frac{1}{n}}}=\beta \text {, or } \mathrm{C}_{a}=\beta \mathrm{C}_{b^{\frac{1}{n}}}
$$

PARTITION BETWEEN A LIQUID AND A GEL.

In applying this to adsorption the most common form is

$$
\mathrm{C}_{a}=\frac{\mathrm{X}}{m}=\beta \mathrm{C}_{b^{\frac{1}{p}}}
$$

where $\mathrm{X}=$ the weight of the adsorbed substance, $m=$ the weight of the adsorbent, $\mathrm{C}_{b}=$ the concentration of the solution, and $\beta$ and $p$ are constants.

SILK AND PICRIC ACID.

For picric acid and silk, Walker and Appleyard (61) obtained

$$
\frac{s}{\sqrt[2.7]{w}}=35.5
$$

which is of the above form; $s=$ concentration of dye on silk, and $w=$ concentration of dye in water.

Taking logarithms-

Differentiating,

$$
\log s \doteq \log 35.5+\frac{1}{2.7} \log w .
$$

$$
\frac{d s}{s}=\frac{1-}{2.7} \frac{d w}{w}
$$


that is, if the concentration in water increases by 1 per cent of its value, the concentration in the silk will increase by $\frac{1}{2.7}$ per cent of its own value. It appears that the molecule is 2.7 times greater in water than in the fiber (if solid solution were to be assumed), which is most improbable, especially as picric acid $\left(\mathrm{C}_{6} \mathrm{H}_{2}\left(\mathrm{NO}_{2}\right)_{3} . \mathrm{OH}\right)$ has high electrolytic dissociation in water. Therefore, according to Walker and Appleyard, the phenomenon can not be explained by solid solution; although the mathematical expression has a similar form, which is to be ascribed to adsorption.

GELATINE AND TANNIN.

The colloid nature and homogeneity of silk being possibly somewhat questionable, the equation to represent the results of Wood (68) on the adsorption of tannin by gelatine has been worked out. The calculations are as follows:

Adsorption of tannin by 1 gram of air-dry gelatine ( $=0.74$ gram anhydrous).

\begin{tabular}{|c|c|c|c|c|c|c|c|}
\hline $\begin{array}{c}\text { Volume } \\
\text { of solu- } \\
\text { tion } \\
\text { (cubic } \\
\text { centi- } \\
\text { meters). }\end{array}$ & $\begin{array}{c}\text { Tannin } \\
\text { (grams). }\end{array}$ & $\begin{array}{c}\text { A. } \\
\text { Tannin } \\
\text { adsorbed } \\
\text { (grams). } \\
\text { adsornin } \\
\text { per gram } \\
\text { anhy- } \\
\text { drous } \\
\text { gelatine } \\
\text { grams). }\end{array}$ &. & Log A. & $\begin{array}{c}\text { Tannin } \\
\text { left in } \\
\text { solution }\end{array}$ & $\begin{array}{c}\text { B. } \\
\text { Tannin } \\
\text { per gram } \\
\text { water } \\
\text { (grams). }\end{array}$ & Log B. \\
\hline & & & & & & & \\
100 & 1 & 0.91 & 1.226 & 0.090 & 0.09 & 0.0009 & 4.955 \\
200 & 2 & 1.50 & 2.028 & .307 & .50 & .0025 & 3.398 \\
300 & 3 & 1.90 & 2.567 & .410 & 1.10 & .003667 & 3.565 \\
400 & 4 & 2.17 & 2.932 & .467 & 1.83 & .004575 & 3.661 \\
500 & 5 & 2.28 & 3.080 & .489 & 2.72 & .00544 & 3.736 \\
600 & 6 & 2.36 & 3.189 & .504 & 3.64 & .006067 & 3.783 \\
700 & 7 & 2.36 & 3.189 & .504 & 4.64 & .00663 & 3.822 \\
800 & 8 & 2.36 & 3.189 & .504 & 5.64 & .00705 & 3.849 \\
\hline
\end{tabular}

The foregoing calculations were made with a slide rule.

In figure $1, \operatorname{logs} A$ are plotted as ordinates and $\operatorname{logs} B$ as abscissas.

As the first five points lie closely on the same straight line, they represent data that may be expressed by an exponential equation.

Assume $\mathrm{A} \mathrm{B}^{n}=\mathrm{K}$. Taking $\operatorname{logarithms,~} \log \mathrm{A}+n \log \mathrm{B}=\log \mathrm{K}=\mathrm{K}^{\mathbf{1}}$. Selecting two convenient points on the straight line of figure 1 ,

or

$$
\begin{aligned}
& 0.5000+\overline{3} .749 n=\mathrm{K}^{1} \\
& 0.0611+\overline{4} .900 n=\mathrm{K}^{1}
\end{aligned}
$$

$$
\begin{aligned}
& 0.5000-2.251 n=\mathrm{K}^{1} \\
& 0.0611-3.100 n=\mathrm{K}^{1}
\end{aligned}
$$

These may be solved simultaneously for $n$ and $K^{1}$. From $K^{1}, K$ is obtained.

83865-Bull. 388-09-3 
Employing a slide rule, five-place logarithms. and seven-place logarithms, there are obtained, respectively:

$$
\frac{\mathrm{A}}{\mathrm{B}^{\cdot 5174}}=46.3, \frac{\mathrm{A}}{\mathrm{B}^{-51680}}=46.079 \text {, and } \frac{\mathrm{A}}{\mathrm{B}^{.5168023}}=46.09810 \text {. }
$$

The five-place logarithms secure the equation with sufficient accuracy only to three significant figures in the constant.

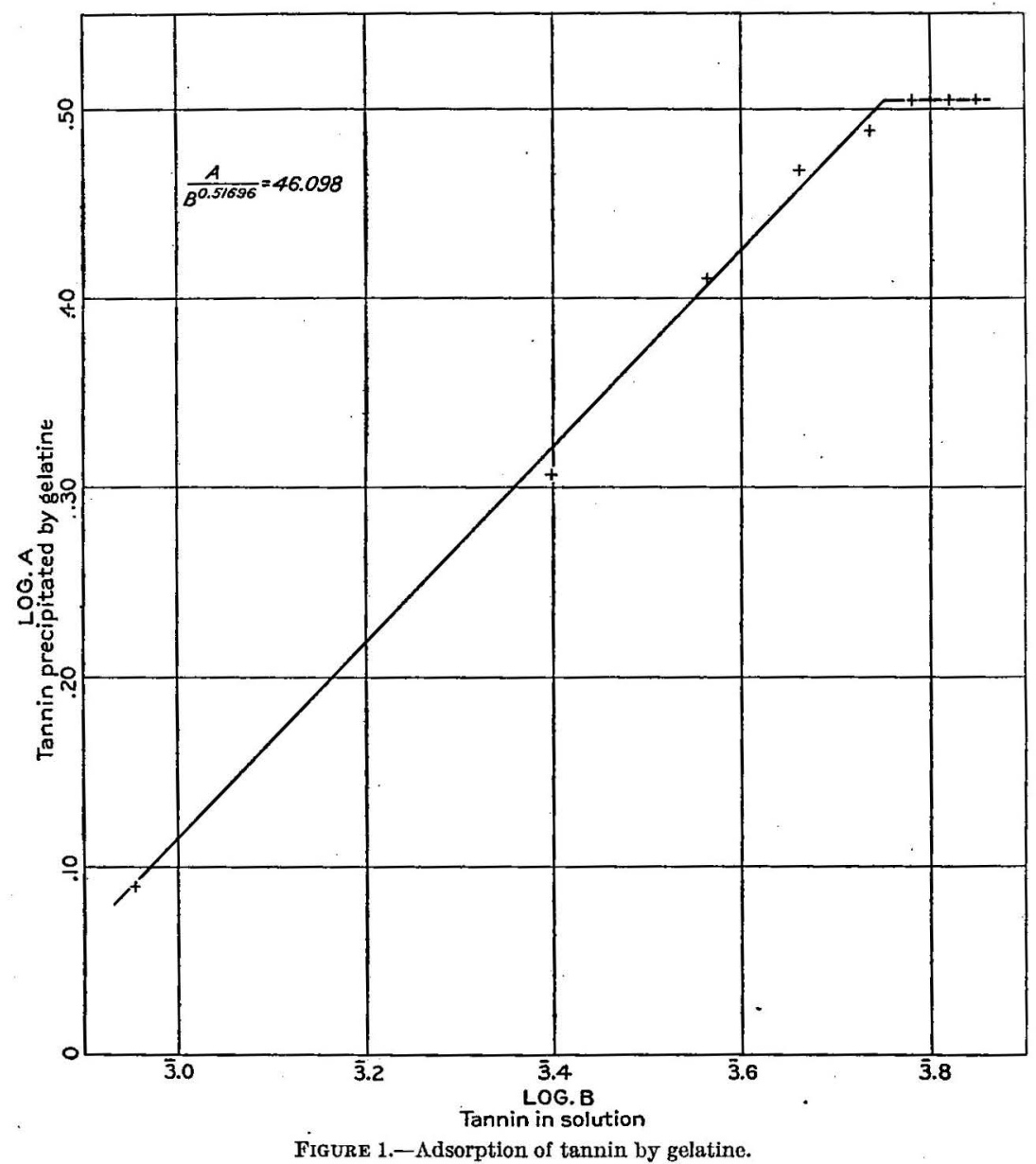

The same form of equation applies to tannin and gelatine as to picric acid and silk, but reaches a limit after which it fails to apply. That there is a superior limit to adsorption may have an important significance.

$$
\text { HAGERSTOWN LOAM AND GENTIAN VIOLET. }
$$

Cameren and Patten (69) have determined the adsorption of gentian violet $\left(\left(\mathrm{CH}_{3}\right)_{2} \mathrm{~N} \cdot \mathrm{C}_{6} \mathrm{H}_{3}: \mathrm{SClN}: \mathrm{C}_{6} \mathrm{H}_{3} \mathrm{NH}_{2}\right)$ by Hagerstown loam. The dye has a solubility of 6.8 per cent at $25^{\circ}$. 
Their results, as recalculated by the writer, are given in the following table:

Adsorption of gentian violet by Hagerstown loam.

\begin{tabular}{|c|c|c|c|c|}
\hline $\begin{array}{c}\text { Dye } \\
\text { added per } \\
\text { liter } \\
\text { (grams). }\end{array}$ & $\begin{array}{c}\text { A. } \\
\text { Dye adsorbed } \\
\text { per } \\
\text { gram of soil } \\
\text { (grams). }\end{array}$ & Log. A. & $\begin{array}{c}\text { B. } \\
\text { Dye remaining } \\
\text { in solution per } \\
\text { gram of water } \\
\text { (grams). }\end{array}$ & Log. B. \\
\hline 1.33 & 0.0019996 & 5.301 & 0.00000023 & 7.362 \\
2.66 & .0039998 & $\overline{3.602}$ & .00000140 & 6.146 \\
3.33 & .0049996 & 3.699 & .00000250 & 6.398 \\
6.67 & .0099825 & $\overline{3} .999$ & .0000120 & 5.080 \\
10.00 & .01495 & 2.175 & .0000325 & 5.512 \\
13.33 & .019817 & $\overline{2.297}$ &. .0001250 & 4.097 \\
20.00 & .02045 & 5.310 & .006525 & 3.815 \\
26.67 & .02025 & 2.306 & .013500 & $\overline{2} .130$ \\
\hline
\end{tabular}

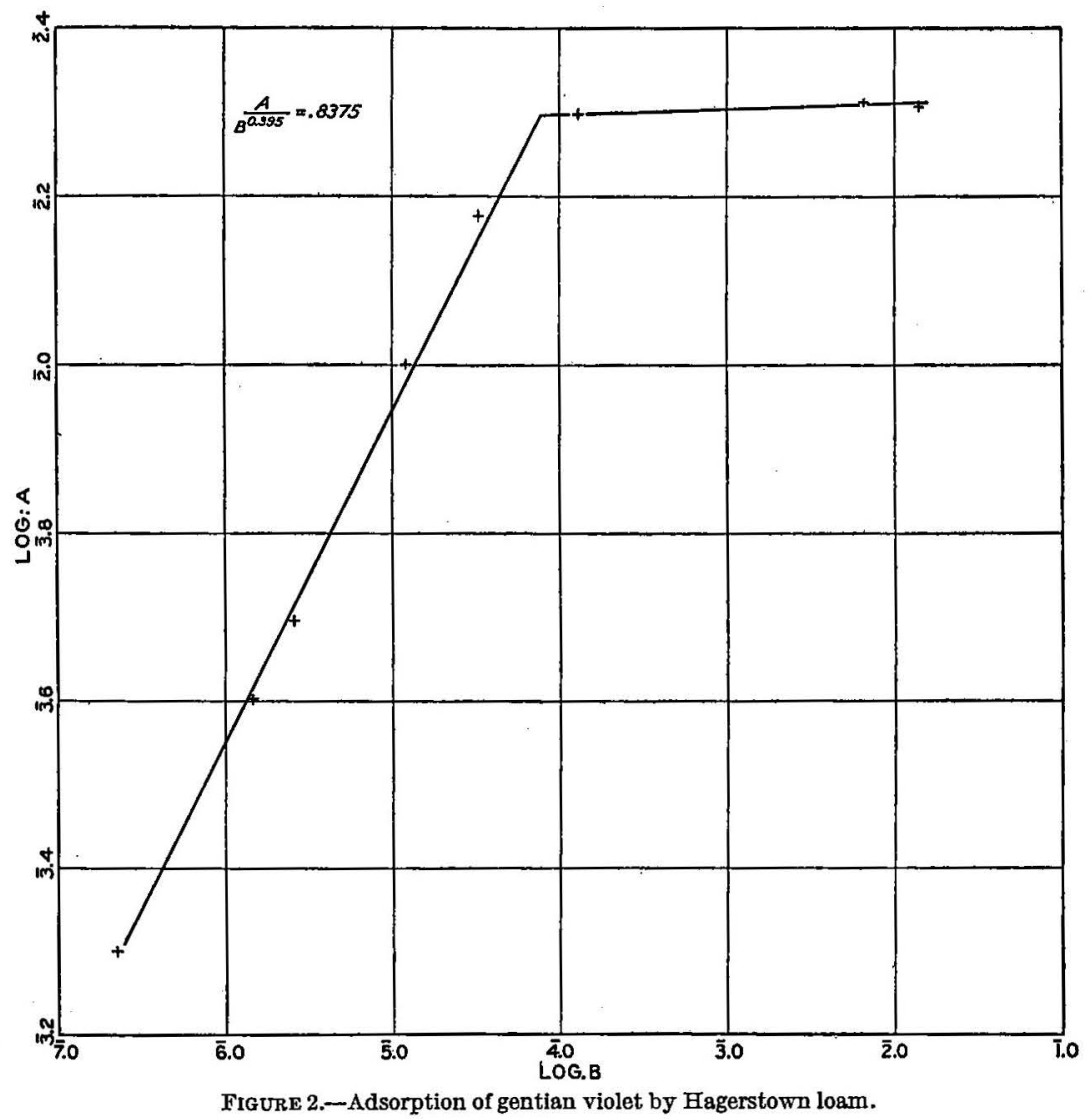

Studying these data in the manner just described (fig. 2), it is found that the first six of these points are accurately represented by the equation $\frac{\mathrm{A}}{\mathrm{B}^{0.30405}}=0.83723$ or $\frac{\mathrm{A}}{\mathrm{B}^{0.3040005}}=0.8375014$. 
Seven-place logarithms appear necessary to obtain a constant accurate in the fourth significant figure.

In similar manner to the preceding case, there is a superior limit to adsorption, beyond which the last two points lie.

\section{QUARTZ FLOUR AND GENTIAN VIOLET.}

Cameron and Patten have also studied adsorption of gentian violet by quartz flour. The writer has recast their results, as given in the following table:

Adsorption of gentian violet by quartz flour.

\begin{tabular}{|c|c|c|c|c|c|}
\hline Dye added per liter (grams). & $\begin{array}{c}\text { A. } \\
\text { Dyead- } \\
\text { sorbed per } \\
\text { gram of } \\
\text { quartz } \\
\text { (grams). }\end{array}$ & $\frac{\mathrm{A}^{\prime}}{\mathrm{A}}$ & Log. $A^{\prime}$ & $\begin{array}{c}\text { B. } \\
\text { Dye un- } \\
\text { adsorbed } \\
\text { per liter } \\
\text { of water } \\
\text { (grams). }\end{array}$ & Log. B. \\
\hline $0.04 \ldots$. & 0.00006 & 0.000061 & 5.786 & Trace. & \\
\hline Equation applies: & & & & & \\
\hline $.10 \ldots \ldots$ & .00014 & .0001457 & 4: 164 & 0.0001 & 4.000 \\
\hline 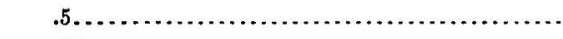 & .000743 & .000945 & 4.975 & .0040 & 3. 602 \\
\hline $.67 \ldots \ldots \ldots \ldots \ldots \ldots \ldots \ldots \ldots \ldots \ldots \ldots \ldots \ldots \ldots \ldots \ldots \ldots \ldots$ & .001984 & .0004572 & 3. 660 & .0108 & $a 2.034$ \\
\hline $1.33 \ldots$ & .001901 & .00416 & 3. 619 & .066 & 2. $8: 0$ \\
\hline $2.00 \ldots \ldots \ldots \ldots$ & .00266 & .01106 & 2.045 & .224 & $1.3 \div 0$ \\
\hline $2.06 \ldots \ldots \ldots \ldots \ldots \ldots \ldots \ldots \ldots \ldots \ldots \ldots \ldots \ldots \ldots \ldots \ldots \ldots$ & .00289 & .0166 & 2.220 & .740 & I. 869 \\
\hline $3.33 \ldots \ldots \ldots \ldots$ & .00295 & .01877 & 2.274 & 1.370 & 0.137 \\
\hline \multicolumn{6}{|l|}{ Equation fails: } \\
\hline $4.66 \ldots \ldots$. & .00297 & .01954 & 2. 291 & 2.668 & 0.427 \\
\hline 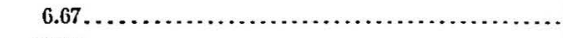 & .00293 & .01803 & 2. 256 & 4.710 & 0.673 \\
\hline 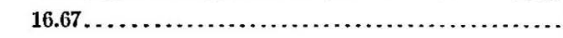 & .00290 & .01686 & 2.227 & 14.75 & $\overline{1} .169$ \\
\hline
\end{tabular}

$a$ Evidently erroneous.

The form of equation used in the three preceding cases failed to represent the data. In casting about for a more accurate numerical expression, the expedient was evolved of dividing A by $1-\frac{\mathrm{A}}{0.0035}$. It will be noted that 0.0035 is of the same order of magnitude as the maximum observed adsorption per gram, 0.00295. The latter figure, however, failed to work, and the value employed was the result of repeated trials to get a value that would give a straight line on the logarithmic diagram. Then if $\mathrm{A}^{\prime}=\frac{\mathrm{A}}{1-\frac{\mathrm{A}}{0.0035}}$, the equation $\frac{\mathrm{A}^{\prime}}{\mathrm{B}^{0.531404}}=0.01948113$ represents the data accurately from the most dilute solution up to practically the maximum of adsorption. 
In figure 3 the logarithmic curves for the equations are given for comparison. Thus $\mathrm{A} \mathrm{B}^{\mathrm{n}}=\mathrm{K}$ (the theoretical curve, which should be a straight line if the equation is correct); $\mathrm{A}^{\prime} \mathrm{B}^{\mathrm{n}}=\mathrm{K}$, where

$$
\mathrm{A}^{\prime}=\frac{\mathrm{A}}{1-\frac{\mathrm{A}}{0.00297}},
$$

0.00297 being the maximum observed adsorption; and $A^{\prime} B^{n}=K$, where $\mathrm{A}^{\prime}=\frac{\mathrm{A}}{1-\frac{\mathrm{A}}{0.0035}}, 0.0035$ being a value found by trial.

The superiority of the third curve is easily seen.

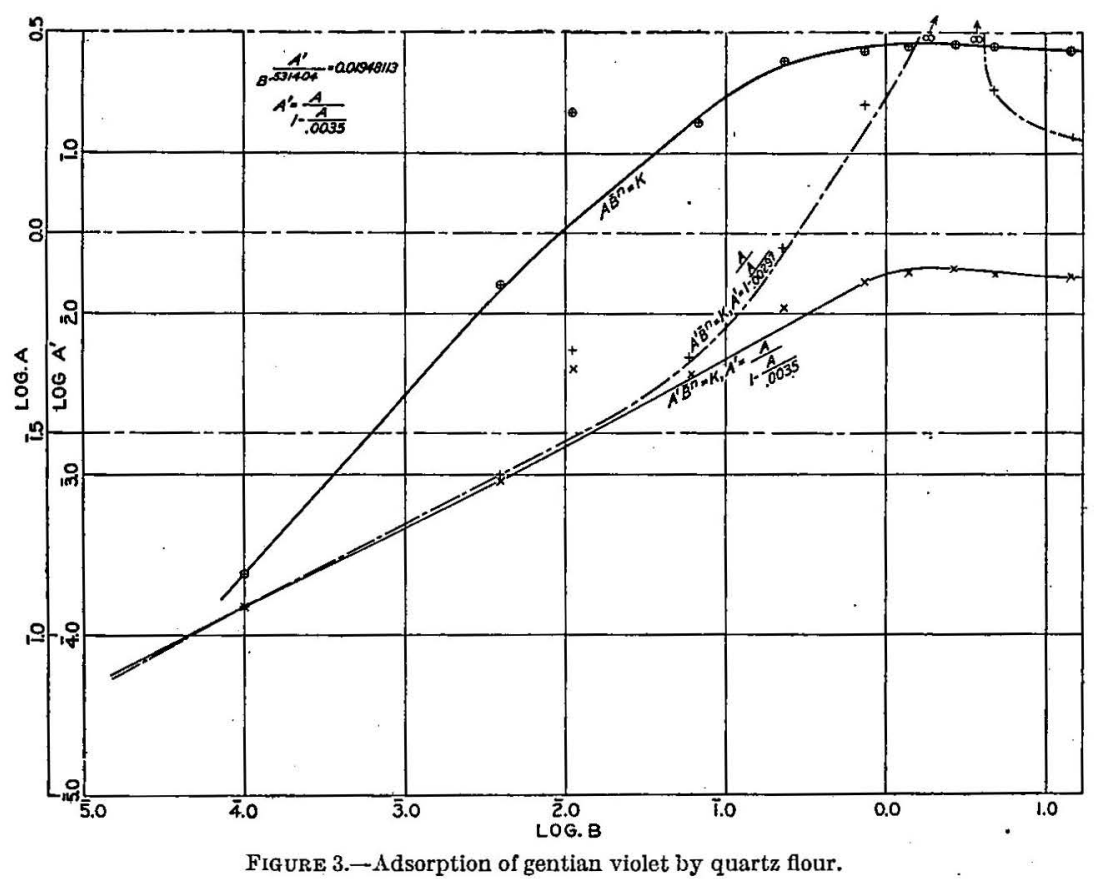

KLINGENBERG CLAX AND BARIUM CHLORIDE.

H. Hirsch has studied the adsorption of barium chloride by various clays. For Klingenberg clay his results, as recalculated, are given in the table following. 
Adsorption of barium chloride by 100 grams of Klingenberg clay in 1 liter water.

\begin{tabular}{|c|c|c|c|c|c|}
\hline $\begin{array}{l}\text { Barium } \\
\text { chloride } \\
\text { added } \\
\text { (grams). }\end{array}$ & $\begin{array}{c}\text { A. } \\
\text { Barium } \\
\text { chloride per } \\
\text { per gram of } \\
\text { clay } \\
\text { (grams). }\end{array}$ & $\begin{array}{c}\mathrm{A}^{\prime} . \\
\frac{\mathrm{A}}{1-\frac{\mathrm{A}}{0.0178}}\end{array}$ & $\log . \Lambda^{\prime}$ & $\begin{array}{l}\text { B. } \\
\text { Barium chlo- } \\
\text { ride remain- } \\
\text { ing in solu- } \\
\text { tion per gram } \\
\text { of water } \\
\text { (grams). }\end{array}$ & Log. B. \\
\hline 0.1 & 0.00096 & 0.001013 & 3.006 & 0.000004 & 6.602 \\
\hline .2 & .00192 & .00215 & 3. 333 & .000008 & 6.903 \\
\hline .3 & .00292 & .003492 & 3. 543 & .000008 & a. $\overline{6} 903$ \\
\hline .4 & .00352 & .00438 & 3.642 & .000048 & 5.681 \\
\hline .5 & .00424 & .005573 & 3. 746 & .000076 & 5.881 \\
\hline .6 & .00489 & .00675 & 3.829 & .000111 & 4.045 \\
\hline .7 & .00551 & .00798 & 3. 902 & .000149 & 4.173 \\
\hline .8 & .00603 & .00913 & 3.961 & .000197 & 4.295 \\
\hline .9 & .00654 & .01033 & 2.015 & .000246 & 4. 391 \\
\hline 1.0 & .00701 & .01155 & 2.063 & .000299 & 4.476 \\
\hline 1.5 & .00808 & .01484 & 2. 171 & .000692 & 4. 840 \\
\hline 2.0 & .00930 & .01948 & 2.290 & .001070 & 3.030 \\
\hline 2.5 & .01009 & .0233 & 2.368 & .001491 & 3.174 \\
\hline 3.0 & .01087 & .0280 & 2.447 & .001913 & 3. 282 \\
\hline 4. 0 & .01164 & .03377 & $\overline{2} .529$ & .002836 & 3.453 \\
\hline 5.0 & .01231 & .0400 & 2. 602 & .003769 & 3.577 \\
\hline 10.0 & .01412 & .0682 & 2. 833 & .008588 & 3.935 \\
\hline 15.0 & .01527 & .1074 & 1.031 & .013473 & 2.130 \\
\hline 20.0 & .01535 & .1115 & 1.048 & .018465 & 2.267 \\
\hline 25.0 & .01551 & .1211 & 1.084 & .023449 & 2.370 \\
\hline
\end{tabular}

$a$ Erroneous.

These are plotted in figure 4 . The equation representing the data is $\frac{\mathrm{A}^{\prime}}{\mathrm{B}^{0.517809}}=0.7646805$, where $\mathrm{A}^{\prime}=\frac{\mathrm{A}}{1-\frac{\mathrm{A}}{0.0178}}$.

SILVER IODIDE AND SILVER NITRATE.

A. Lottermoser and A. Rothe (71) have determined the adsorption of silver nitrate by fresh precipitated silver iodide. The concentrations. of the solutions employed were determined by means of electrical conductivities. The following is their table:

Adsorption of silver nitrate by silver iodide.

\begin{tabular}{|c|c|c|c|c|c|}
\hline $\begin{array}{c}\text { Coo } \\
\text { Silver } \\
\text { nitrate per } \\
\text { cubic centi- } \\
\text { meter of } \\
\text { original solu- } \\
\text { tion } \\
\text { (millimoles). }\end{array}$ & $\begin{array}{c}\text { B. } \\
\text { Silver } \\
\text { nitrate per } \\
\text { cubic centi- } \\
\text { meter of final } \\
\text { solution } \\
\text { (millimoles). }\end{array}$ & Log B. & $\begin{array}{c}\text { A. } \\
\text { Silver } \\
\text { nitrate ad- } \\
\text { sorbed per } \\
\text { gram of silver } \\
\text { fodide } \\
\text { (millimoles). }\end{array}$ & Log A. & $\begin{array}{c}\text { A as } \\
\text { com- } \\
\text { puted } \\
\text { from } \\
\text { the } \\
\text { equa- } \\
\text { tion. }\end{array}$ \\
\hline 0.00045 & 0.00019 & -3.7212 & 0.0023 & -2.6383 & 0.0024 \\
.00075 & .00045 & -3.3468 & .0026 & -2.5850 & .0028 \\
.00107 & .00073 & -3.1367 & .0029 & -2.5376 & .0031 \\
.00163 & .00123 & -2.9101 & .0034 & -2.4685 & .0035 \\
.00232 & .00188 & -2.7258 & .0038 & -2.4202 & .0038 \\
.00502 & .00450 & -2.3468 & .0045 & -2.3468 & .0046 \\
.01519 & .00928 & -2.0324 & .0051 & -2.2924 & .0051 \\
\hline .01456 & -1.8368 & .0054 & -2.2676 & .0057 \\
\hline
\end{tabular}


A millimole is one one-thousandth part of the molecular weight of a substance expressed in grams. In the case of silver nitrate a millimole is 0.170 gram.

The equation is $\frac{\mathrm{A}}{\mathrm{B}^{0.1998}}=0.0135$.

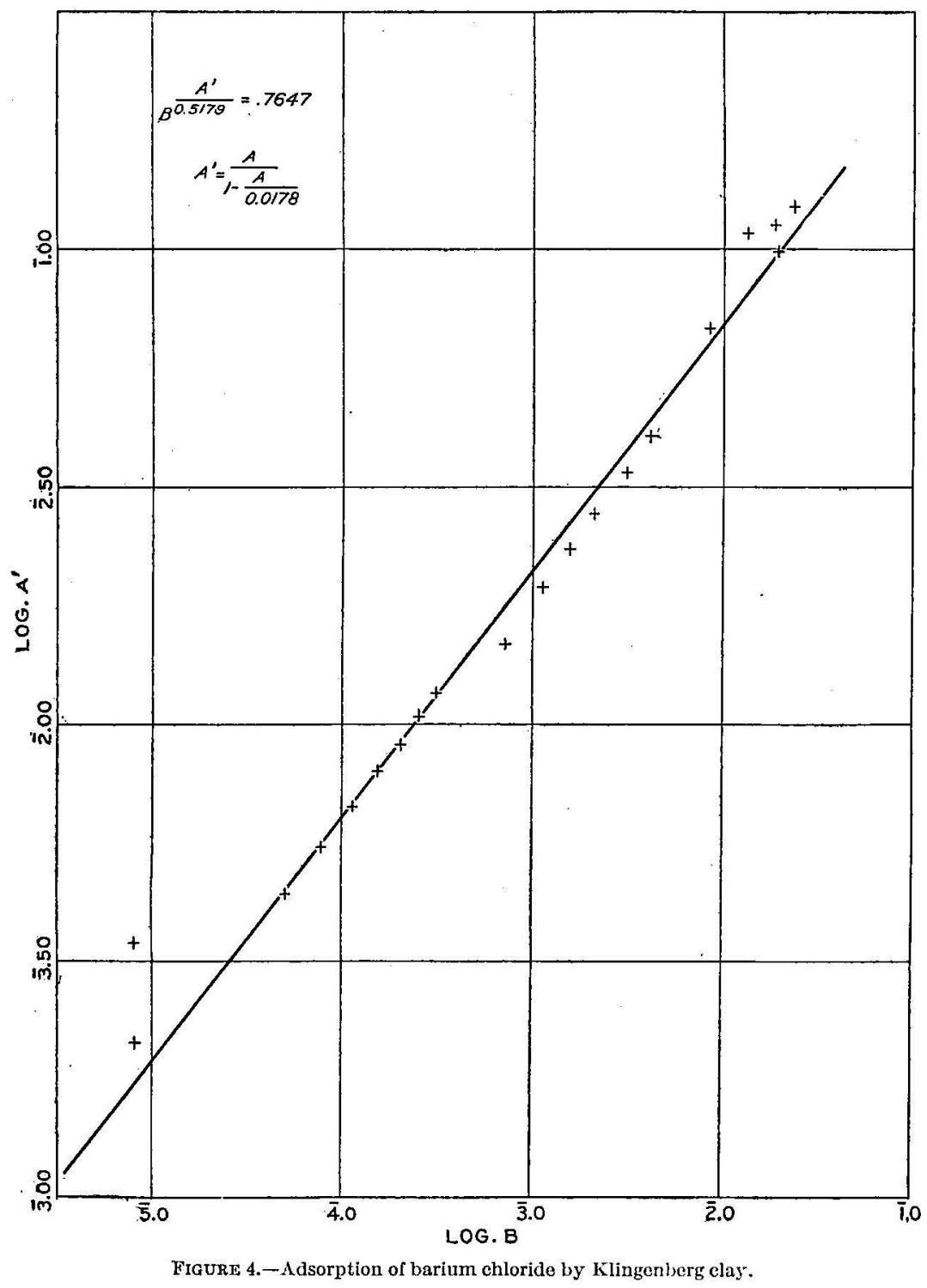

SILVER IODIDE AND POTASSIUM IODIDE.

Peptization.-These investigators further show that the freshly precipitated amorphous silver iodide may be peptized by treatment with the soluble iodides of either potassium, cadmium, or barium, as 
shown by the following table for potassium iodide, acting on 0.25 gram silver iodide in 25 cubic centimeters of water.

Effect of potassium iodide solution on silver iodide.

\begin{tabular}{|c|c|}
\hline $\begin{array}{l}\text { Concentration of } \\
\text { potassium iodide } \\
\text { in the solution } \\
\text { (normality). }\end{array}$ & Effect on silver fodide. \\
\hline $\begin{array}{l}0.0005 \\
.001 \\
.002 \\
.004 \\
.01 \\
.02 \\
.03 \\
.05 \\
.075 \\
.1 \\
.15 \\
.25\end{array}$ & $\begin{array}{l}\text { Very weak hydrosol formation. } \\
\text { Beginning of intense hydrosol formation. } \\
\text { Strong increase of the same. } \\
\text { Further increase. A visible alterntion of the sllver iodide structure. } \\
\text { Strong hydrosol formation. } \\
\text { Do. } \\
\text { Maximum hydrosol formation. } \\
\text { Decreased hydrosol formation. } \\
\text { Do. } \\
\text { Complete alteration of structure of silver iodide. } \\
\text { Almost no hydrosol formation. } \\
\text { No hydrosol formation. }\end{array}$ \\
\hline
\end{tabular}

The authors say that dried precipitates or dry preparations of silver iodide can not be peptized. That if the hydrosol is once completely precipitated it can not be peptized; that is, the hydrosol phase must never be completely eliminated, for then an "alteration of structure" will occur.

Adsorption.-As might be expected from this, on attempting to measure the adsorption of potassium iodide by silver iodide, they fail to obtain data that may be represented by the adsorption equations. The results follow:

$\kappa_{\mathrm{o}}=$ specific conductivity of the solution before adsorption.

$\kappa=$ specific conductivity of the solution at equilibrium.

Adsorption of potassium iodide by silver iodide.

\begin{tabular}{|r|r|r|r|r|r|r|}
\hline$\kappa_{0} .10^{6}$. & $\begin{array}{c}\text { Co } \\
\text { Potassium } \\
\text { 1odide at start } \\
\text { (moles per } \\
\text { 1iter). }\end{array}$ & $\kappa .10^{6}$. & $\begin{array}{c}\text { B. } \\
\text { Potassium } \\
\text { iodide at equi- } \\
\text { librium } \\
\text { (moles per } \\
\text { liter). }\end{array}$ & Log B. & $\begin{array}{c}\text { A. } \\
\text { Potassium } \\
\text { iodide adsorbed } \\
\text { per gram } \\
\text { silver iodide } \\
\text { (millimoles). }\end{array}$ & Log A. \\
\hline 45.1 & 0.000299 & 19.7 & 0.000130 & -3.886 & 0.0046 & -2.337 \\
72.2 & .000481 & 61.5 & .000410 & -3.387 & .0078 & -2.108 \\
176.0 & .001181 & 164.3 & .001102 & -2.959 & .0084 & -2.076 \\
280.8 & .001900 & 268.8 & .001819 & -2.740 & .0087 & -2.061 \\
448.2 & .003032 & 399.3 & .002701 & -2.569 & .0090 & -2.046 \\
694.8 & .004772 & 646.2 & .004438 & -2.353 & .0090 & -2.046 \\
873.2 & .005997 & 827.4 & .005683 & -2.246 & .0085 & -2.071 \\
$1,036.5$ & .007231 & 992.8 & .006926 & -2.160 & .0077 & -2.114 \\
$1,275.0$ & .008894 & $1,245.6$ & .008689 & -2.061 & .0055 & -2.260 \\
$1,381.4$ & .009637 & $1,359.4$ & .009483 & -2.023 & .0040 & -2.398 \\
\hline
\end{tabular}

In the logarithmic diagram (fig. 5) the second, third, fourth, and fifth points are exactly on a line, and, therefore, may be represented by an exponential equation, but the fifth point is at a maximum, higher initial concentrations resulting in decreased adsorption.

The authors suggest that this phenomenon may be due to structure alteration or to complex salt formation, but find no connection 
between it and hydrosol formation. The present writer has made calculations to ascertain if decreased dissociation due to increased concentration might account for the decreased adsorption. No such relationship was indicated.

TENNESSEE BALT, CLAY AND MALACHITE GREEN.

In investigation of the adsorption of malachite green by Tennessee ball clay No. 3, of the Tennessee Ball and Sagger Clay Company, Whitlock, Tenn., and the Potters' Supply Company, East Liverpool, Ohio, the logarithmic diagram (fig. 6) shows a similar maximum, but none of the points lie on the same straight line, even when a correc-

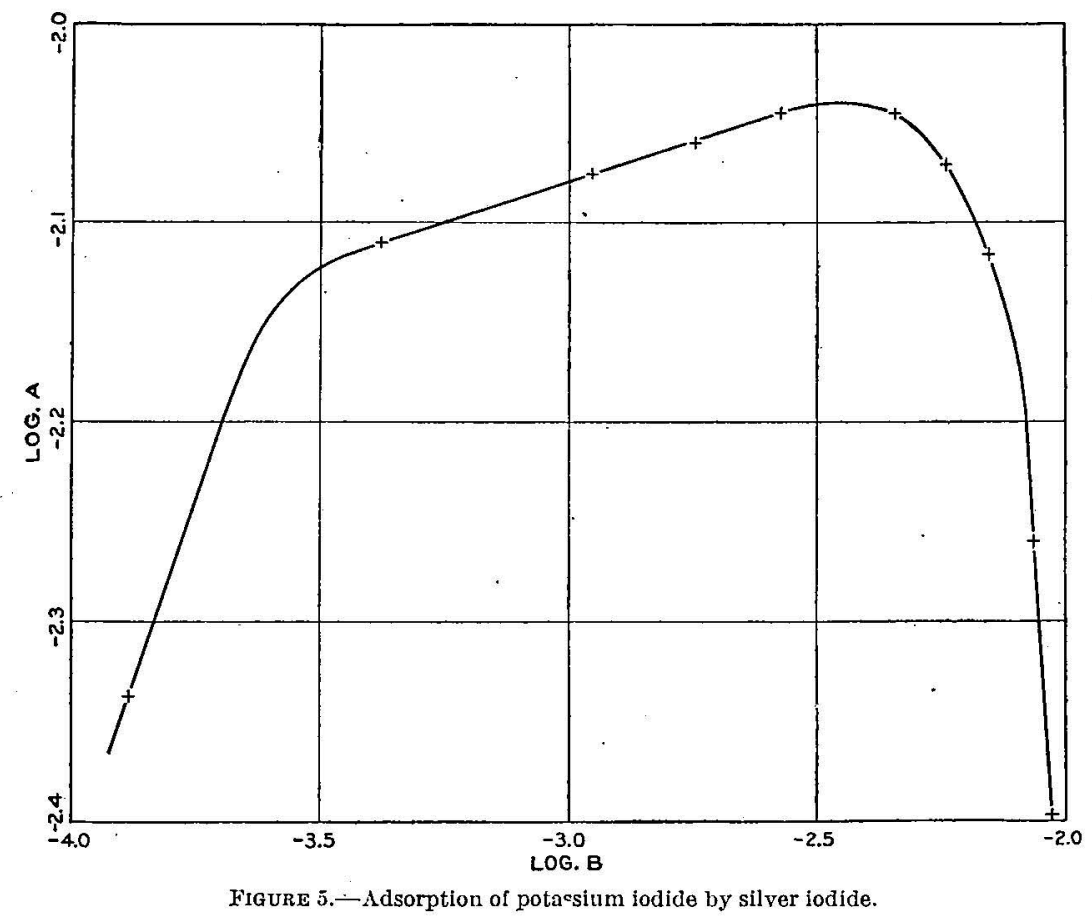

tion factor is introduced similar to that used in the discussion of Hirsch's results on the adsorption of barium chloride by Klingenberg clay.

SUMMARY.

In this discussion of equations are included only those cases which have been studied from very small concentrations up to the highest possible adsorption. We have then the exact equation $\mathrm{A} \mathrm{B}^{-n}=\mathrm{K}$, applying to-

Silk and picric acid,

Gelatine and tannin,

Hagerstown loam and gentian violet,

Silver iodide and silver nitrate; 
the corrected equation $\mathrm{A}^{\prime} \mathrm{B}^{-\mathrm{n}}=\mathrm{K}$, where $\mathrm{A}^{\prime}=\frac{\mathrm{A}}{1-\frac{\mathrm{A}}{\text { constant }}}$, applying to-

Quartz flour and gentian violet,

Klingenberg clay and barium chloride;

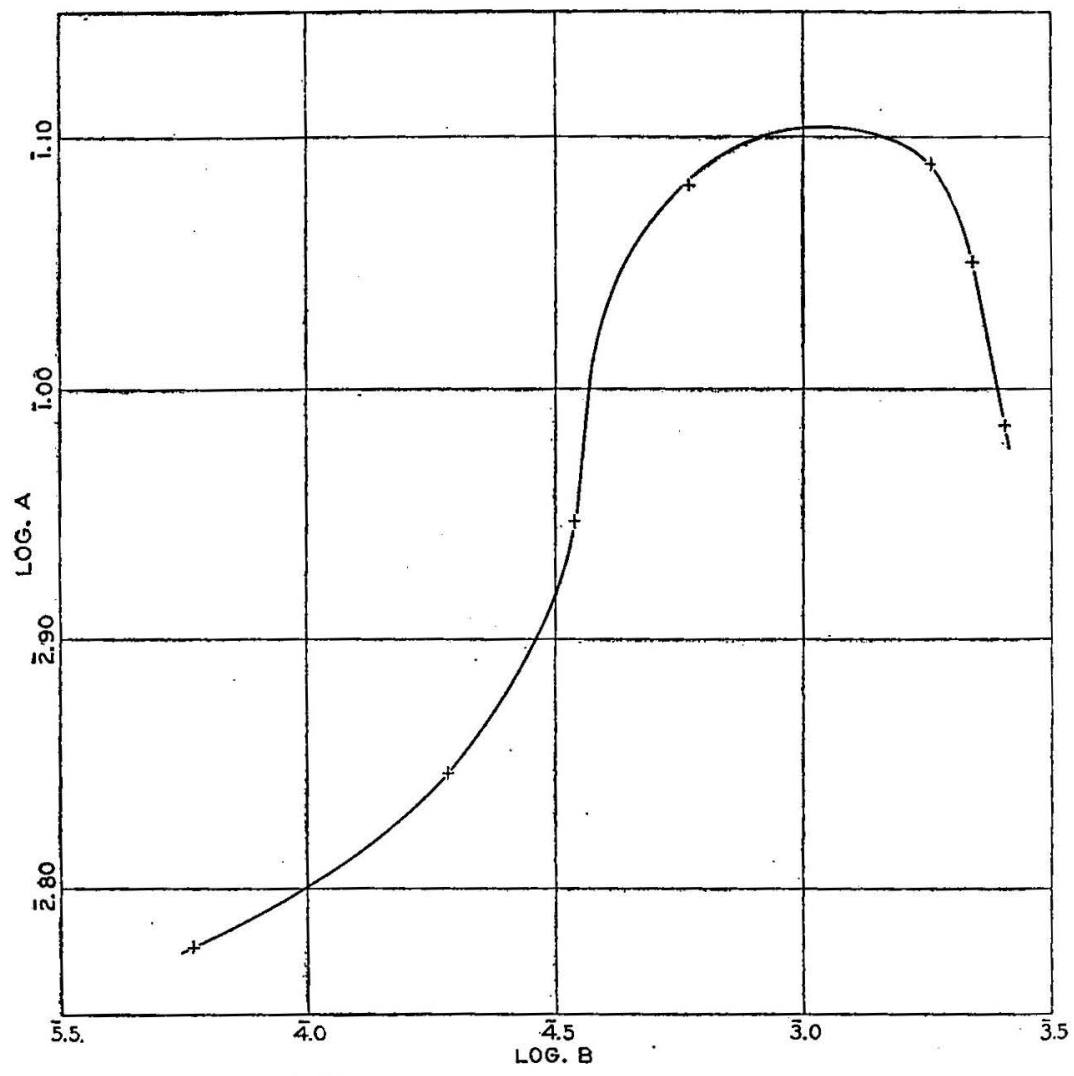

Figure 6.-Adsorption of malachite green by Tennessee Ball and Sagger Clay Company's Tennessee ball clay No. 3.

and the cases showing maxima and not permitting the use of such equations, as follows:

Silver iodide and potassium iodide,

Tennessee ball clay No. 3 and malachite green.

It does not yet seem possible to formulate an equation that shall apply to all cases of adsorption.

\section{DETERMINATION OF PLASTICTTY.}

DEPENDENCE ON COLLOIDS.

If the plasticity of clays is mainly due to a proper ratio of granular materials and active (that is, not "set") colloid gels, any means of establishing the relative or absolute amount of colloids in a clay should supply a measure of its plasticity. 
Of course, the shape and size of the granular materials (whether of crystal nature or "set" gels) will be of some effect, as will also the special nature of the active colloids present. Any methods applied to testing other colloids should be of value in testing clays. For instance, glues and clays are tested by the tensile-strength test for tensile strength or binding power. While this test is of value, it does not tell how workable a clay is. Sugars and oils are tested by measurements of viscosity. Simonis (51, 52, 53, 72, 73), Mellor (47), and Bleininger (49) have applied this test to clay slips. The two former have shown by this means how plasticity may be altered by additions to clay slips, especially in regard to their suitability for the casting process. Bleininger has shown in the case of three well-known clays that the more plastic has the greater viscosity.

\section{ADSORPTION TESTS OF CLAYS.}

Hirsch (70) in his paper on the behavior of clay in salt solutions saw the possibilities of adsorption. He said: "We hoped at first to be able to classify the clays according to their plasticities with the help of this process [adsorption of barium chloride]. The lean, very sandy brick clays fall completely out of the series, and partially show a greater adsorption than the fat, highly plastic clays." The present writer, having the information that colloids adsorb dyes, but without any details, also sought to apply this principle to the measurement of plasticity.

\section{ADSORPTION TESTS WITH BRILLIANT GREEN.}

On May 21, 1908, at a meeting of the Pittsburg section of the American Chemical Society, an informal discussion was held regarding the results then attained. The following table was shown. The comparisons were made colorimetrically with improvised apparatus of the crudest sort:

Dye remaining unadsorbed on treating various clays (50 grams each) with brilliant green (in 1,000 cubic centimeters water). $a$

\begin{tabular}{|c|c|c|c|c|c|c|c|c|}
\hline Dye used, grams .............. & 0.10 & 0.20 & 0.30 & 0.50 & $0.60^{\circ}$ & 1.00 & 2.00 & 3.00 \\
\hline 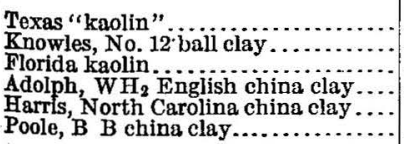 & $\begin{array}{l}0.002 \\
\cdots\end{array}$ & $\begin{array}{r}0.002 \\
.002 \\
.007\end{array}$ & $\begin{array}{c}0.004 \\
.031\end{array}$ & $\begin{array}{c}0.001 \\
.0073 \\
\cdots \cdots \cdots \\
\cdots \cdots \cdots\end{array}$ & $\begin{array}{r}0.061 \\
.021 \\
.111\end{array}$ & $\begin{array}{r}0.001 \\
.017 \\
.073 \\
.111 \\
.172 \\
.292\end{array}$ & \begin{tabular}{c}
0.0133 \\
.064 \\
.110 \\
$\cdots \cdots \cdots$ \\
\hdashline$\ldots \ldots \ldots$ \\
$\ldots . \cdots$
\end{tabular} & $\begin{array}{r}0.045 \\
\cdots \\
\cdots \cdots \\
\cdots\end{array}$ \\
\hline
\end{tabular}

a All experiments submitted herewith were made with tap water from Ohio River, filtered through gravel and led in by a long iron pipe.

In the column for 1.00 gram dye these clays fall approximately in the order of their plasticities. There are, however, various anoma- 
lies, the most striking of which is the apparent difference of $\mathrm{WH}_{2}$ and B B china clays, which are practically almost duplicates in plasticity.

In the discussion, Dr. Joseph H. James suggested that malachite green would be found a more stable dye, less likely to be affected by adventitious circumstances, and subsequently the use of that dye was adopted with decided advantage.

A further series of tests was, however, made with brilliant green. In each case the water, the crushed air-dry clay, and the dry dye were put in a small test blunger, blunged for 30 minutes, and then allowed to settle until apparently clear. The dye remaining in solution was determined colorimetrically.

Dye remaining unadsorbed on treating various clays (50 grams each, in 1,000 cubic centimeters water) with brilliant green dye.

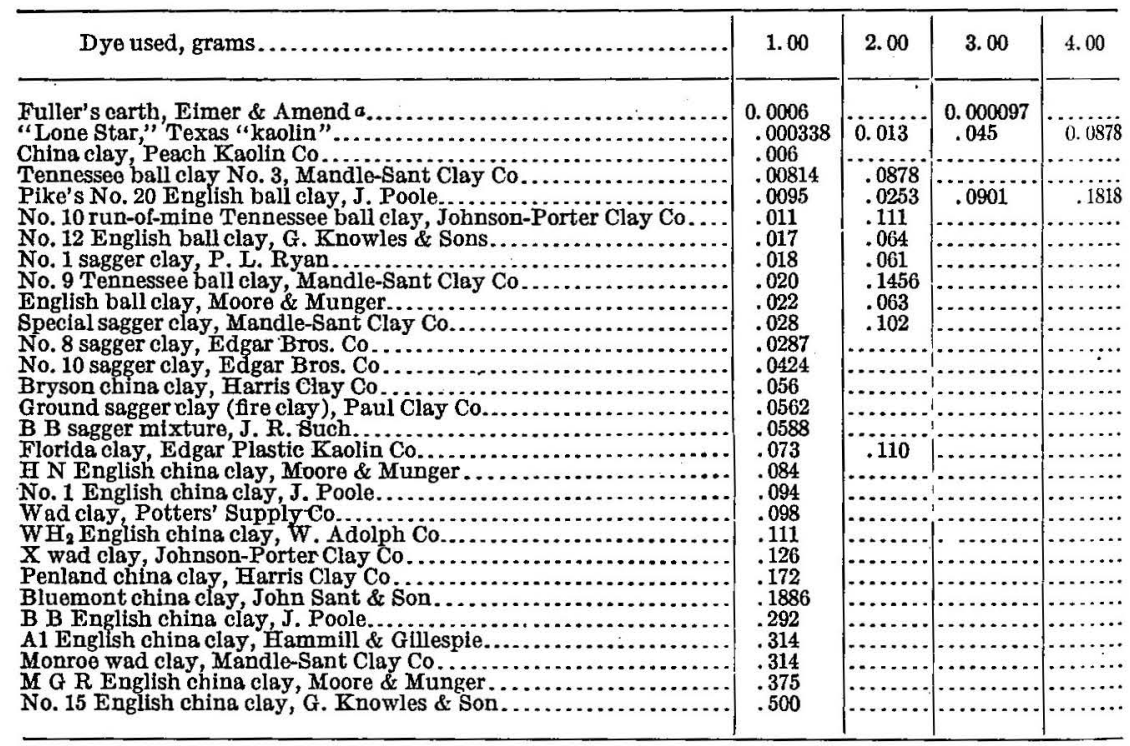

a With 7.00 grams, the result was 0.000827 ; with 10.00 grams, 0.00267 ; with 13.00 grams, 0.01054 ; with 18.00 grams, 0.1205 .

These clays fall neither in the order of plasticity nor of merit in the column with 1.00 gram dye; 2.00 grams dye give a somewhat better arrangement, Texas, Pike's No. 20, Ryan No. 1, M. \& M. ball, Knowles's, No. 12 ball, Tennessee No. 3 , special sagger, Florida, No. 10 run-of-mine, and Tennessee No. 9, falling in ascending sequence.

If, however, these clays are grouped so that only clays of a common origin are in the same column, the arrangement is more logical in each group. 
Dye unadsorbed (1 gram added), arrangea' by origin of clays treated.

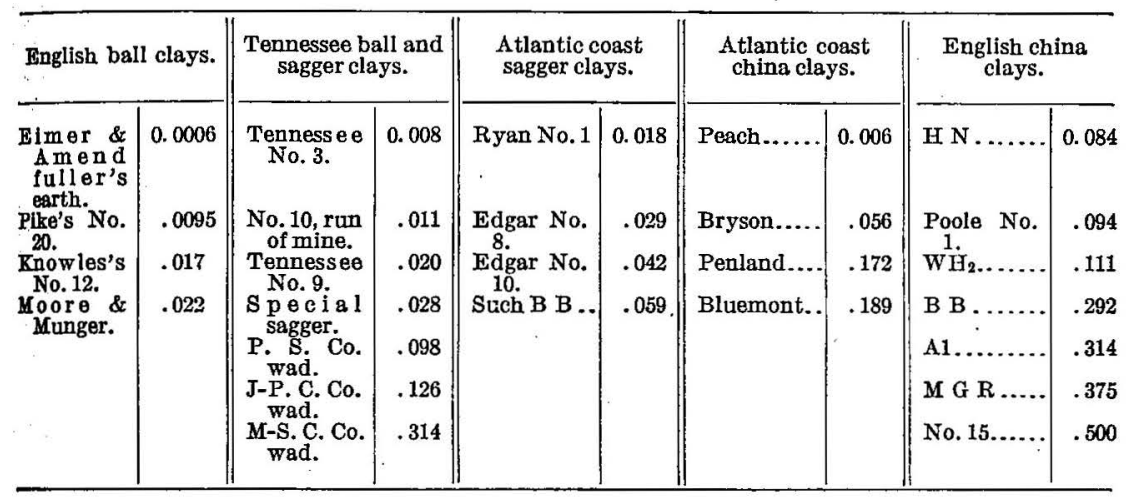

It would appear from this that the colloidal matter in any one of these groups, for example, Atlantic coast china clays, has an effect on brilliant green different from that of the colloidal matter in some of the other groups, for example, English china clays. Brilliant green may then be of use only to compare clays of a common origin, or to check the uniformity of a particular clay from time to time.

\section{COMPARISON OF BRILLIANTT GREeN WITH MALACHITE GREEN.}

Schultz and Julius (74) give the following formulæ:

Malachite green (oxalate), $\left(\mathrm{C}_{23} \mathrm{H}_{24} \mathrm{~N}_{2}\right)_{2}\left(\mathrm{C}_{2} \mathrm{H}_{2} \mathrm{O}_{4}\right)_{3}$, of which the molecular weight is 890.6 , or per one color base ion, 445.3.

Brilliant green crystals, $\mathrm{C}_{27} \mathrm{H}_{34} \mathrm{~N}_{2} \mathrm{O}_{4} \mathrm{~S}$; molecular weight, 482.4 .

The structural formulæ may be represented as shown in figure 7.

The brilliant green has the more complex color base, having four $\mathrm{C}_{2} \mathrm{H}_{5}$ groups against an equal number of $\mathrm{CH}_{3}$ groups in malachite green. According to Pelet-Jolivet and Wild (75), malachite green is wholly noncolloidal, while from the paper of Höber and Chassin (76), brilliant green seems also to be noncolloidal. The former authors find that dye solutions, under the influence of electrolytes, go over to the colloid condition, and think that contact with an adsorbent favors such a transformation.

\section{QUALITY OF WATER USED.}

The tap water used in this work contained considerable amounts of calcium sulphate and calcium carbonate, and lesser amounts of magnesium sulphate, magnesium carbonate, and sodium chloride. It would consequently have a considerable precipitating effect on the oxalic acid ions of the malachite green. This was found to be the case, but if the water were of constant composition, it should not affect the order of the clays in the classification, as equal volumes were 
used in all comparisons. However, it was found that acetic acid would prevent precipitation, and it was employed in a considerable number of tests with malachite green. It was then found, although a preliminary test had given the opposite result, that the weak concentration of acetic acid present acting on the iron stirrer of the blunger was effecting some decolorization of the dye. These results were accordingly discarded and the use of the blunger was abandoned entirely.

The results with acetic acid failed to give a more accurate classification than did the simple aqueous solution. Consequently the use of acetic acid was abandoned.
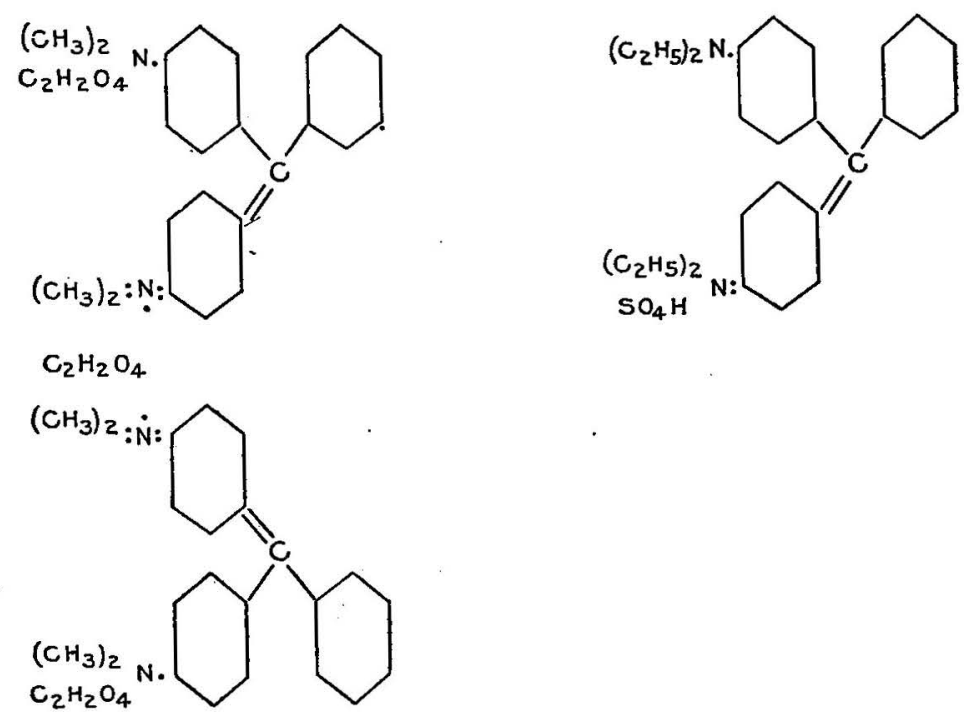

FIgURe 7.-Structural formulæ of malachite green and brilliant green.

MALACHITE-GREEN ADSORPTION AND PHYSICAL PROPERTIES OF CLAYS.

METHODS OF TESTING.

The following procedure was eventually adopted. Into a 500 cubic centimeter bottle with ground-glass stopper greased with vaseline, 20 grams clay and the dye were placed, then 400 culic centimeters water was added. The closed bottle was then fastened in the frame of a small ball mill (60 revolutions per minute) so that at every revolution it was upended. This gave a vigorous and complete agitation, which lasted for an hour. Although the clay appeared to settle clear in half an hour, the results were too large and erratic unless the settling continued over night. ${ }^{a}$ On the following

a Poole's No. 1 china clay (50 grams clay, 1,000 cubic centimeters water, 3 grams dye) gave:

July 30 , after standing some time Grams dye in excess.

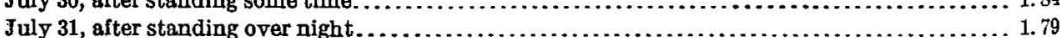

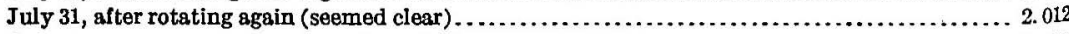

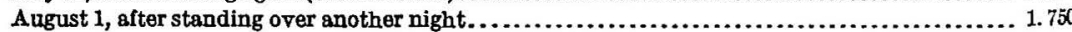




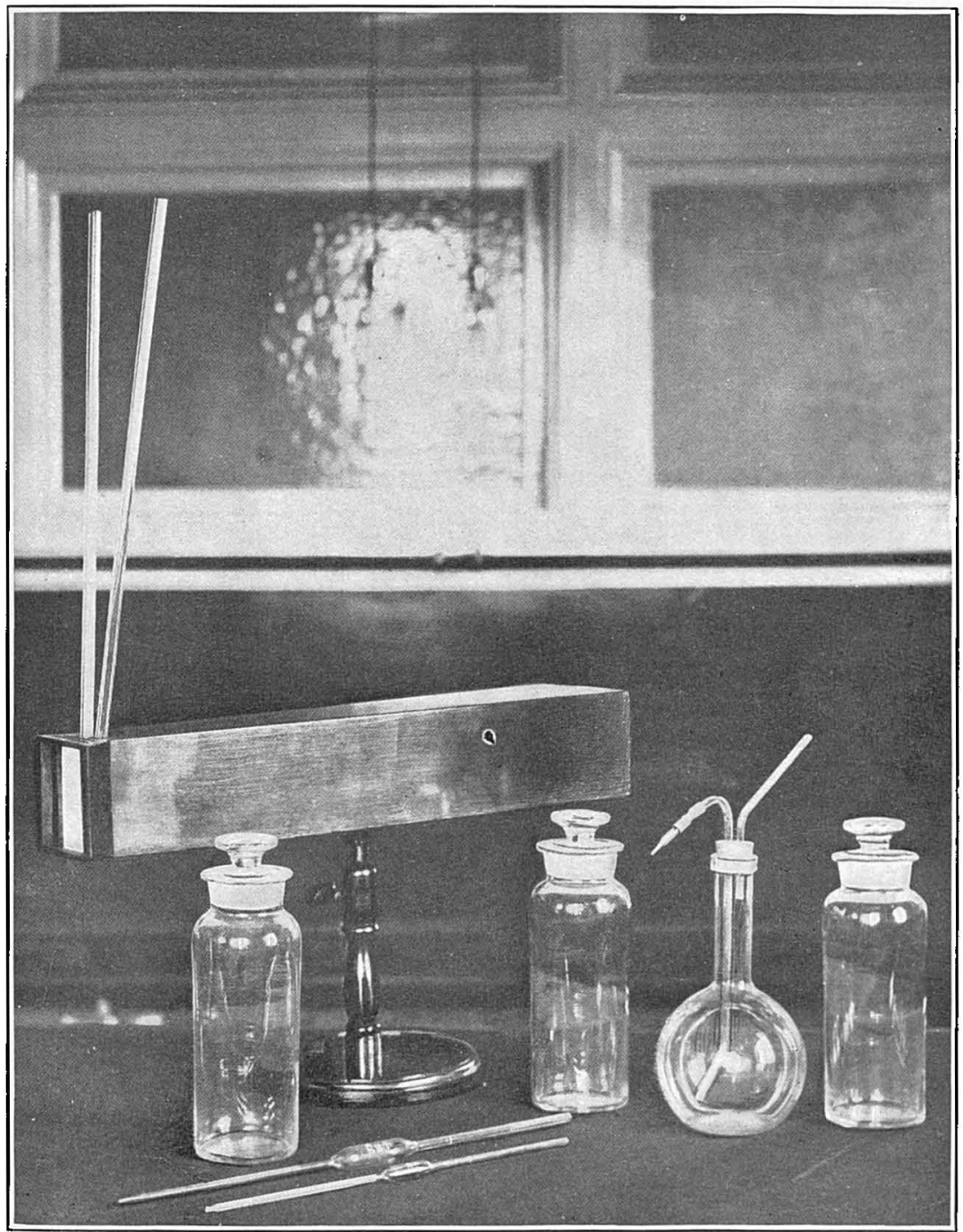

APPARATUS FOR MAKING COLOR COMPARISONS TO DETERMINE ADSORPTION DF DYESTUFF. 

day a convenient amount of the clear liquid was taken out by a pipette and put into one of a pair of "carbon" comparison tubes such as used in steel analysis, and compared by dilution with a standard solution of 3 grams per liter, using a camera while matching. (See Pl. I.)

RESULTS OF TESTS.

The powers of various clays to adsorb malachite green, together with other physical properties, are given in the following table, in which the clays, as elsewhere in this bulletin, are designated by their trade names: 


\begin{tabular}{|c|c|c|c|c|c|c|c|c|c|c|}
\hline \multirow[b]{2}{*}{ Designation of clay. } & \multicolumn{2}{|c|}{ Portion unabsorbed. } & \multirow{2}{*}{$\begin{array}{l}\text { A. } \\
\text { Jackson- } \\
\text { Purdy sur- } \\
\text { face factor. }\end{array}$} & \multirow{2}{*}{$\begin{array}{c}\text { B. } \\
\text { Cast air } \\
\text { shrinkage. }\end{array}$} & \multirow{2}{*}{$\begin{array}{l}\text { Fire shrink- } \\
\text { age } \\
\text { (cone 8). }\end{array}$} & \multirow{2}{*}{$\begin{array}{l}\text { C. } \\
\text { Relative } \\
\text { colloids. }\end{array}$} & \multirow{2}{*}{$\begin{array}{l}\text { D. } \\
\text { Surface con- } \\
\text { centration } \\
\text { of colloids } \\
\left(=\frac{\mathrm{C}}{\mathrm{A}}\right) .\end{array}$} & \multirow{2}{*}{$\begin{array}{c}\text { E. } \\
\text { specific air } \\
\text { shrinkage } \\
\text { of colloids } \\
\left(=\frac{\mathrm{B}}{\mathrm{C}}\right) .\end{array}$} & \multirow{2}{*}{ 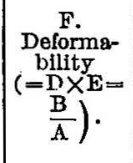 } & \multirow{2}{*}{$\begin{array}{l}\text { G. } \\
\text { Plasticlty } \\
(=\mathrm{C} \times \mathrm{F}= \\
\left.\frac{\mathrm{C} \times \mathrm{B}}{\mathrm{A}}\right) .\end{array}$} \\
\hline & $\begin{array}{l}1.00 \text { gram } \\
\text { dye used. }\end{array}$ & $\begin{array}{l}\text { 3.00 grams } \\
\text { dye used. }\end{array}$ & & & & & & & & \\
\hline Fuller's earth, Eimer \& Amend. & 0.00081 & 0.00351 & 121 & 25 & 23 & & & & 0.2066 & \\
\hline "Lone Star" Texas "kaolin" & $\left.\begin{array}{l}\text { Perfectly } \\
\text { clear? }\end{array}\right\}$ & .01075 & 123 & 12.0 & 12.8 & 154 & 1.25 & 0.0780 & 0977 & 10.34 \\
\hline A.H. Williams, Texas" kaolin" & & .01904 & & & $\begin{array}{l}13.2 \\
10.5\end{array}$ & $\begin{array}{l}139 \\
100\end{array}$ & & $\begin{array}{l}.1336 \\
.0850\end{array}$ & & \\
\hline $\begin{array}{l}\text { Jas. P. Prall, No. } 1 \text { ilght sage } \\
\text { J. Poole, Pike's No. } 20 \text { Engli }\end{array}$ & .00371 & $\begin{array}{l}.0470 \\
.0699\end{array}$ & $\begin{array}{l}168 \\
186 \\
185\end{array}$ & $\begin{array}{l}12.2 \\
11.9\end{array}$ & $\begin{array}{r}8.5 \\
11.6\end{array}$ & $\begin{array}{l}100 \\
97.5\end{array}$ & $\begin{array}{l}.544 \\
.597\end{array}$ & $\begin{array}{l}.0800 \\
.1220 \\
.1220\end{array}$ & $\begin{array}{l}.0462 \\
.0727 \\
.0643\end{array}$ & $\begin{array}{l}4.62 \\
7.27 \\
6.28\end{array}$ \\
\hline $\begin{array}{l}\text { Pfister \& Wüstl, Lischwit, Bohe } \\
\text { O. Knowles \& Sons. No. } 12 \text { Englis }\end{array}$ & & .0680 & & 8.5 & 10.8 & $\begin{array}{r}97.5 \\
96.5\end{array}$ & & .0872 & & \\
\hline $\begin{array}{l}\text { Mandle-sant Clay Co., Tenn } \\
\text { Hammill \& Gillespie, White }\end{array}$ & ( & $\begin{array}{l}.0848 \\
.089\end{array}$ & 184 & $\begin{aligned} 11.0 \\
9.8\end{aligned}$ & $\begin{array}{l}\text { 11. } \\
11.0\end{array}$ & $\begin{array}{l}95.2 \\
92.0\end{array}$ & .517 & $\begin{array}{r}.1191 \\
1207 \\
1064\end{array}$ & .0626 & $\begin{array}{l}\text { 5. } 96 \\
\text { 5. } 96\end{array}$ \\
\hline $\begin{array}{l}\text { Moore } \\
\text { Kentuc }\end{array}$ & .00258 & .1221 & 199 & 10.7 & 7.1 & 90.7 & .455 & .1181 & .0538 & 488 \\
\hline $\begin{array}{l}\text { Kentuc } \\
\text { sagge }\end{array}$ & & .186 & 173 & 11.3 & 8.6 & 87.0 & .502 & .130 & .0654 & 5.69 \\
\hline Mandle-Sant Clay Co., special sagger (Tenn.). & .00445 & 1591 & $\begin{array}{l}\text { yedì } \\
\text { 113? }\end{array}$ & 12.0 & 5.9 & 85.5 & $.757 ?$ & 1404 & $.1062 ?$ & $9.09 ?$ \\
\hline 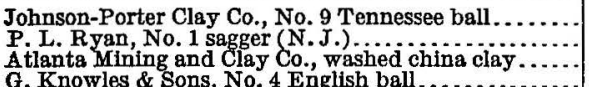 & .01635 & $\begin{array}{l}.1955 \\
.2083 \\
.219\end{array}$ & $\begin{array}{l}170 \\
150 \\
152\end{array}$ & $\begin{array}{r}12.3 \\
9.2 \\
9.4 \\
7.5\end{array}$ & $\begin{array}{r}10.2 \\
5.5 \\
7.6 \\
11.3\end{array}$ & $\begin{array}{l}79.7 \\
78.0 \\
76.7 \\
76.9\end{array}$ & $\begin{array}{l}.468 \\
.519 \\
.504\end{array}$ & $\begin{array}{l}.1544 \\
.1176 \\
.1224 \\
.1000\end{array}$ & $\begin{array}{l}.0724 \\
.0613 \\
.0618\end{array}$ & $\begin{array}{l}5.76 \\
4.79 \\
4.73\end{array}$ \\
\hline (n........... & .00731 & .2288 & 172 & 0.7 & 77.9 & $\begin{array}{ll}74.5 \\
77 .\end{array}$ & $\because 3$ & .1301 & 0.0560 & 420 \\
\hline 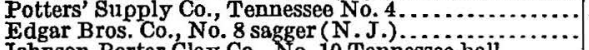 & 00268 & .263 & $178+$ & 9 & $\begin{array}{l}-1 \\
9\end{array}$ & 69.5 & $\begin{aligned} .399 \\
.390\end{aligned}$ & $\begin{array}{r}.1585 \\
.1293 \\
.1100\end{array}$ & .0638 & $\begin{array}{l}4.52 \\
3.51\end{array}$ \\
\hline $\begin{array}{l}\text { Johnson-Porter Clay Co, No. } 10 \text { Tennesse日 } \\
\text { Mandle-Sant Clay Co., Tennessee No. } 11 \text { bal }\end{array}$ & .020 & $\begin{array}{l}.2792 \\
.286\end{array}$ & & $\begin{array}{r}10.0 \\
9.4\end{array}$ & $\begin{array}{r}9.8 \\
10.5\end{array}$ & $\begin{array}{ll}67.5 \\
66.8\end{array}$ & .369 & $\begin{array}{r}.1482 \\
.1405\end{array}$ & .0512 & 3.45 \\
\hline $\begin{array}{l}\text { William H. Prall, N } \\
\text { Mandla-Ssnt Clay C }\end{array}$ & & .2828 & 117 & $\begin{array}{r}8.6 \\
12.0\end{array}$ & 6.9 & $\begin{array}{l}66.7 \\
66.0\end{array}$ & $.570^{\circ}$ & $\begin{array}{l}.1289 \\
.1818\end{array}$ & .0735 & 4.90 \\
\hline J. R. Such, B B mixture (sagger) (N. J & 02235 & .316 & 68 & 9.7 & 9.3 & 63.5 & .378 & .1527 & $\because 0577$ & $3.66^{-1}$ \\
\hline Wm. H. Cutter, sagger (N. J.) ..... & & .372 & & Tota & 1, 15.0. & 56.5 & $.437 ?$ & & 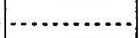 & \\
\hline $\begin{array}{l}\text { Edgar Bros. Co., No. } 10 \text { sagger ( } \\
\text { Paul Clay Co., ground sagger (fir } \\
\text { Mandle-Sant Clay Co., Georgia e }\end{array}$ & $\begin{array}{c}.00872 \\
.02325 \\
\cdots \ldots \ldots\end{array}$ & $\begin{array}{l}.494 \\
.578 \\
.683\end{array}$ & $\begin{array}{l}137^{\circ} \\
78\end{array}$ & $\begin{array}{l}8 \\
5.0 \\
\ldots \ldots\end{array}$ & $\begin{array}{l}5 \\
2.0\end{array}$ & $\begin{array}{l}45.0 \\
40.5 \\
37.4\end{array}$ & .328 & $\begin{array}{l}.1775 \\
.1234 \\
0.1\end{array}$ & $\begin{array}{l}.0583 \\
.0641 \\
\end{array}$ & $\begin{array}{l}2.63 \\
2.595 \\
\end{array}$ \\
\hline & & .775 & 187 & 9.6 & 8.8 & 35.5 & $.1898^{\circ}$ & .270 & .0513 & 1.824 \\
\hline Edgar Plastic Kaolin Co, Florida & .0343 & .925 & $\begin{array}{l}\text { yea. } \\
85\end{array}$ & 14.8 & 9.0 & 32.5 & $.382 ?$ & .455 & $.174 ?$ & 5.66? \\
\hline & :. & $\begin{array}{l}938 \\
.967\end{array}$ & 191 & $\begin{array}{c}7.9 \\
\ldots \ldots\end{array}$ & $\begin{array}{c}6.3 \\
\ldots . .\end{array}$ & $\begin{array}{l}32.3 \\
31.8\end{array}$ & .1692 & .244 & .0413 & 1. 335 \\
\hline 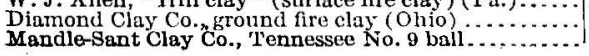 & . . .01895 & $\begin{array}{l}\text { 1. } 058 \\
1.137\end{array}$ & $\begin{array}{r}59 \\
192\end{array}$ & $\begin{array}{l}0.7 \\
9.7\end{array}$ & $\begin{array}{ll}2.0 \\
9.2\end{array}$ & $\begin{array}{l}30.4 \\
29.2\end{array}$ & $: .516$ & .332 & .0504 & 1. 473 \\
\hline
\end{tabular}




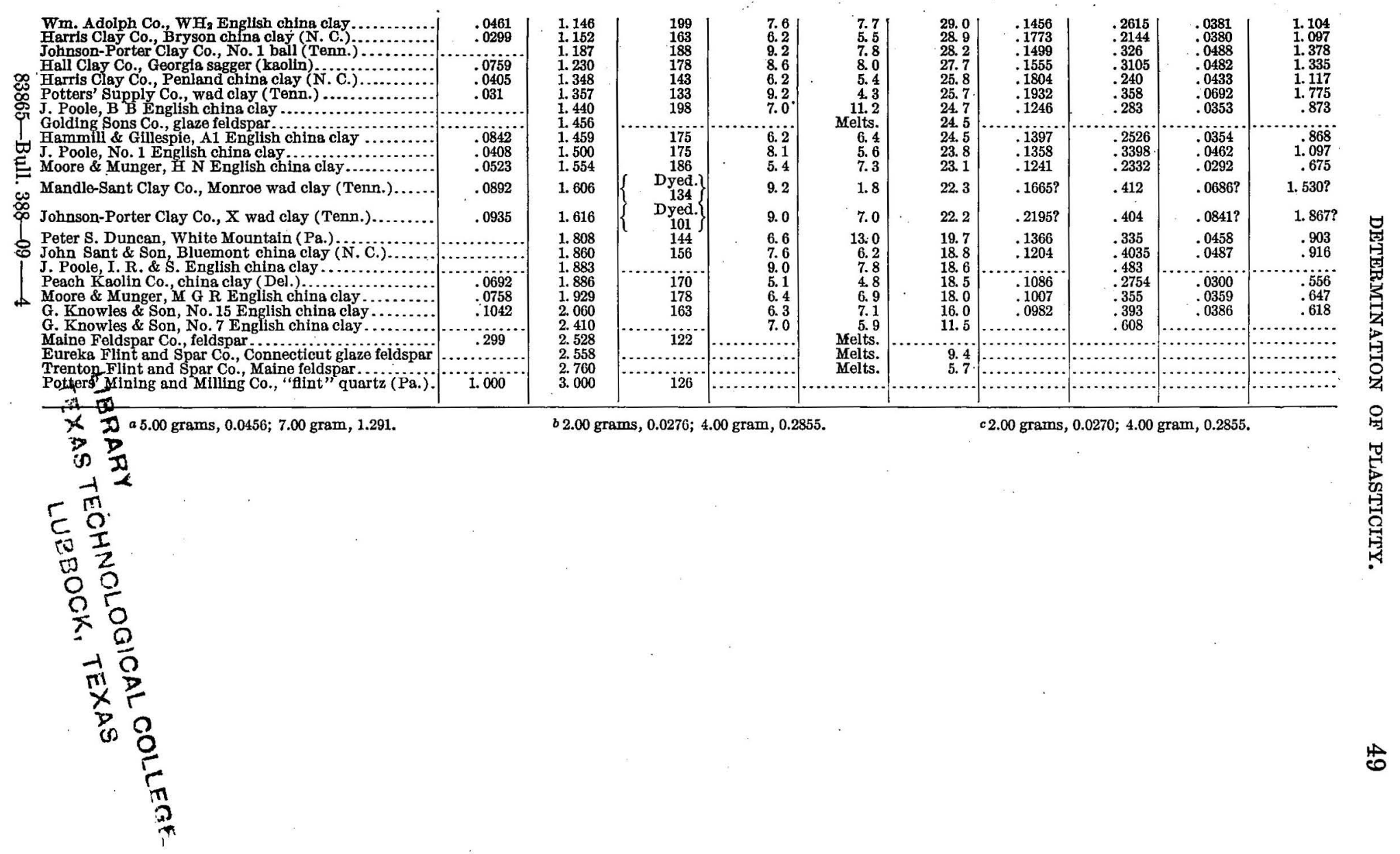


MALACHITE-GREEN ADSORPTION.

The results with 3.0-gram dye per 50.0 grams clay in 1,000 cubic centimeters water are used as a basis for comparison. From these, column $\mathrm{C}$ has been prepared by means of figure $8 .^{a}$ The principle is this: If there is a certain amount of colloids in, say, 10 grams of No. 3 ball clay, there is twice as much in 20 grams, three times as much in 30 grams, etc. Let us call the amount of colloids in 50 grams 100 , in 20 grams 40 , etc. Treating each of these amounts of No. 3 ball clay with 3 grams of malachite green, we obtain the curve shown in figure 8. Now suppose we take 50 grams of any other clay, say, Moore \& Munger's ball clay, and treat it with the same amount of

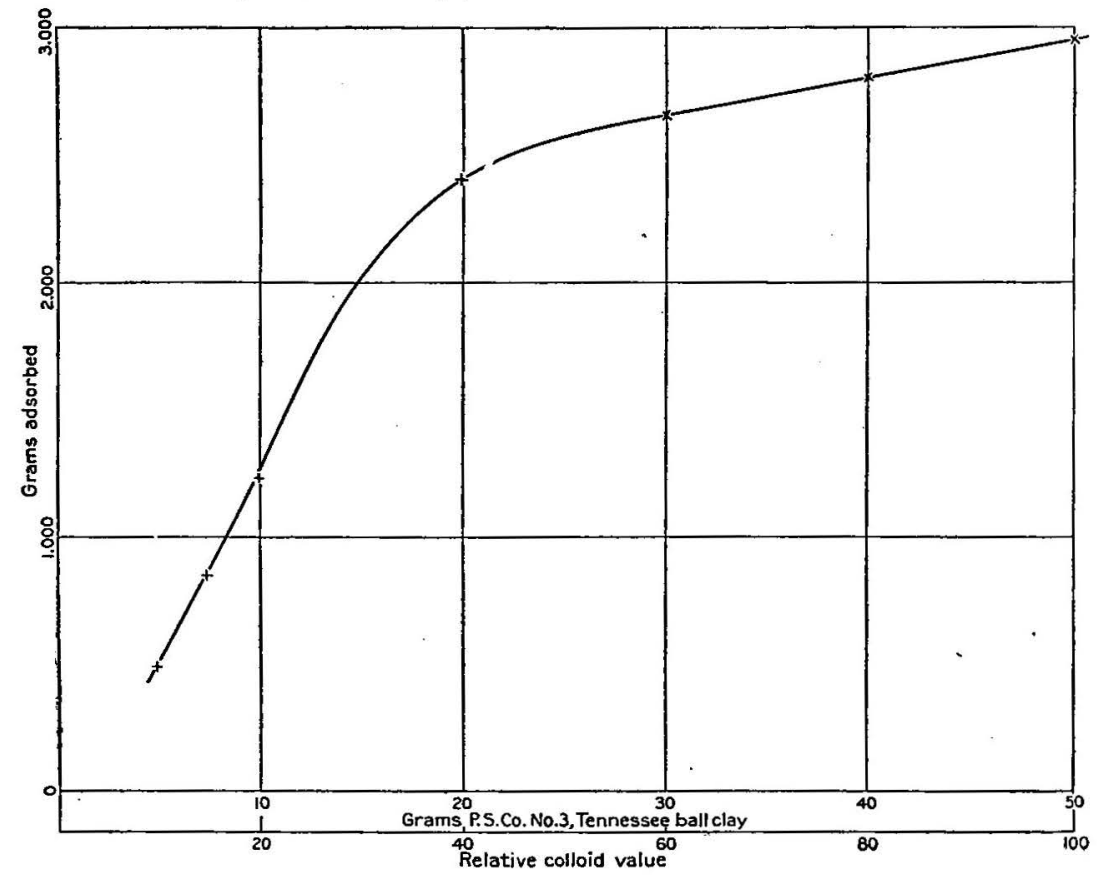

FIgURE 8.-Adsorption of malachite green by Potters' Supply Company's 'Tennessee ball clay No. 3.

dye, the amount of dye adsorbed proves to be 2.8779 grams; 2.8779 grams comes on the curve at 43.35 grams Tennessee ball No. 3 , or at 90.7 relative colloids; that is, it is assumed that clays adsorbing equal amounts of dye contain equal amounts of colloids, and these are expressed in terms of the amount present in Tennessee ball No. 3 .

PHysical PROPERTIES OF CLAYs.

Column A, Jackson-Purdy surface factor, contains numbers which it is convenient to assume are proportional to the total area of all the

a Work performed in 1909 with pure water and longer periods of shaking show that the two branches of the curve shown in figure 8 approximate straight lines, meeting at an angle. 
particles in a unit weight of clay, and are thus a measure of the fineness of the material. The method was originally proposed by W. Jackson (77) and made more general by Ross C. Purdy (78). The assumption is far from correct, as the colloids and soluble salts are not granular and the average size assumed for the smallest grains is incorrect, but it is a convenient approximation.

Column B, cast air shrinkage, contains values obtained by casting a clay slip into a plaster of Paris mold 10 centimeters in diameter, using approximately 50 grams of clay, and giving a test piece about 0.5 centimeter thick. A number of precautions are necessary for accurately comparable work, and it is regretted that some of these figures, three years old, do not have the precision of later work $(79,82)$.

The column of fire shrinkage at cone 8 is put in merely because of its general interest.

The surface factor, air shrinkage, and relative colloids were in some cases determined on one and the same sample; in others, on separate lots; and in still others they are averages of material examined over considerable periods. However, such error as is introduced in this manner is properly to be charged against the clay.

The maximum errors possible are probably 20 per cent in the case of the surface factor, 1 per cent for air shrinkage, and 5.0 per cent for relative colloids. The average errors, however, will not exceed 5 per cent for surface factor, 0.3 per cent for air shrinkage, and 2.5 per cent for relative colloids.

In column $\mathrm{D}$ has been put the surface concentration of colloids, obtained by dividing the relative colloids by the surface factor. It is an attempt to express numerically the density of the layer of colloid material that is considered as enveloping the granular material. Theoretically, not the surface factor but only that portion corresponding to the granular material should be used; but a method for obtaining this information has not yet been worked out. The values in this column should closely parallel the bonding power of these clays.

It is assumed that the various clay colloids will differ in their ability to absorb water, and, consequently, in their shrinkage. In column $\mathrm{E}$ it is attempted to measure this effect by calculating the specific air shrinkage, for which purpose the linear air shrinkage is divided by the relative colloids.

The lubricating layer, permitting motion to the granular particles, is made up of colloids holding water; and in column $\mathrm{F}$ this is estimated as deformability, directly proportional to the surface concentration of colloids and to their specific air shrinkage, hence to their product. 


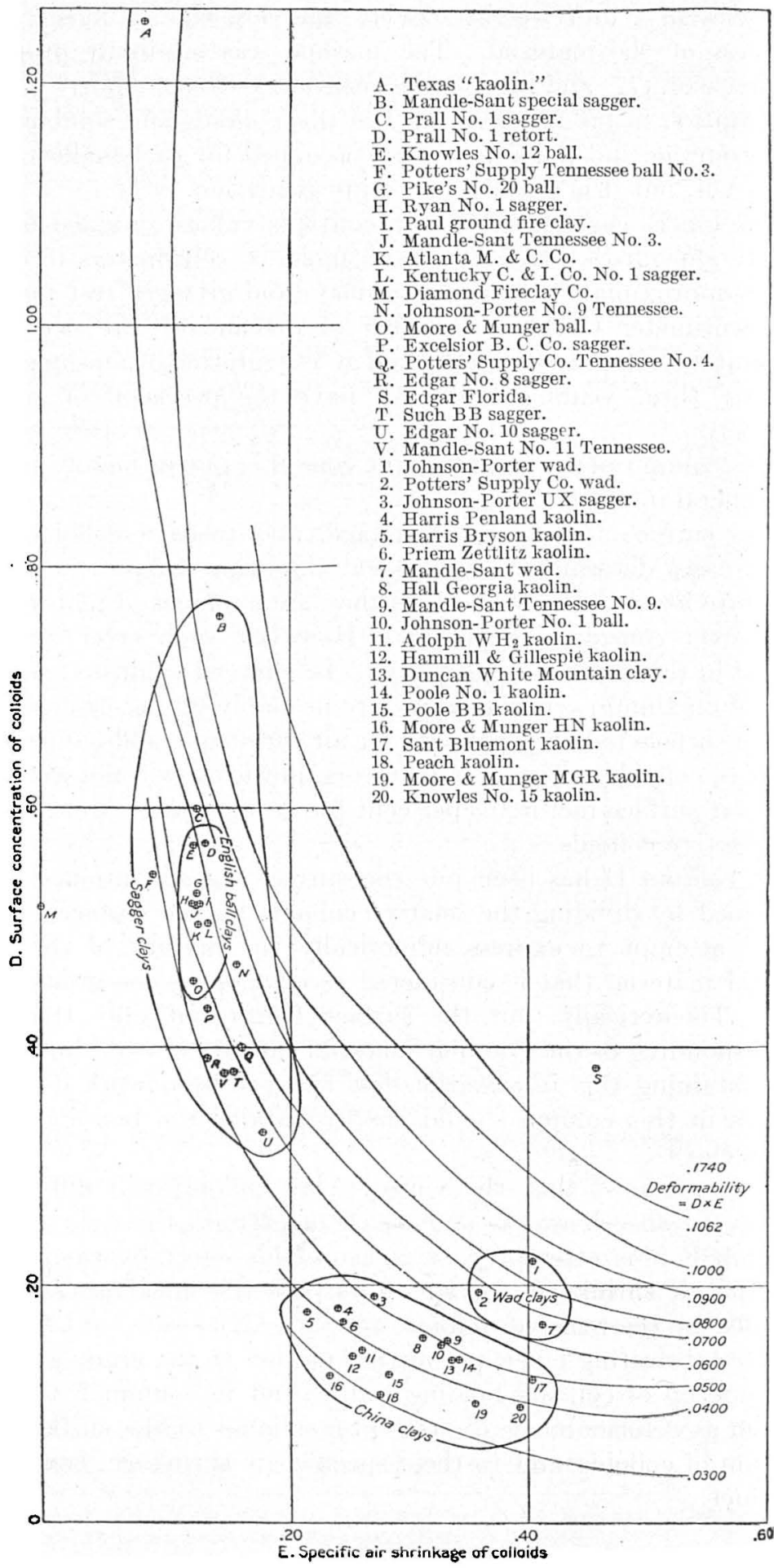

FIGURE 9. - Surface concentration and specific air shrinkage of clay colloids as related to deformability. 
The relations of columns D, E, and F are shown graphically in figure 9. It will be seen that ball and sagger clays fall in one group, having colloids of low specific air shrinkage. The china clays fall in another distinct group, having low surface concentration of colloids. The wad clays apparently form a distinct group with somewhat greater surface concentration of colloids than the china clays. The Texas and Florida "kaolins" a are distinct from all other clays and from each other. The two fire clays tested are closely associated with the ball and sagger clays. With finer grinding the resemblance would appear stronger.

Finally in column $G$ an expression is given for plasticity. Both Zschokke (80) and Grout (9) have experimentally determined plasticity as the product of a deformation by the force producing it. Similarly it is here taken as the product of the deformability by the force resisting deformation, assuming that this resistance is exerted by the colloids, which are the cementing materials supplying the cohesion of the clay. This is the product of columns $\mathrm{C}$ and $\mathrm{F}$, but $\mathrm{F}$ is the product of columns $\mathrm{D}$ and $\mathrm{E}$, and these represent $\frac{\mathrm{C}}{\mathrm{A}}$ and $\frac{\mathrm{B}}{\mathrm{C}}$ respectively; whence $\mathrm{G}=\frac{\mathrm{C} \times \mathrm{B}}{\mathrm{A}}$.

Since ordinarily the shrinkage (B) and the surface factor (A) are both highest with high colloidal matter (C), it is evident that $\frac{B}{A}$ will approximate a constant, and that plasticity is mainly due to the relative colloids $(\mathrm{C})$. The fraction $\frac{\mathrm{B}}{\mathrm{A}}$ seems to take care very satisfactorily of the variations in the nature of the colloid matter and of the size of grain.

It will be noted that increased fineness of grain is considered as cutting down the plasticity. It has been the writer's repeated observation that increased fineness of grain of the granular material in a clay or body is a source of weakness and trouble; that, having greater surface, more colloid matter is required to cement the fine granular matter together and so shrinkage and liability to crack are increased.

\footnotetext{
$a$ Work performed in 1909 shows that the surface factor of Florida clay is really 185, so that the data based on this determination are, in error, and the clay really falls nearer the other china clays on the deformability diagram.
} 


\section{PLASTICITY.}

\section{AS DETERMINED BY MALACHITE-GREEN ADSORPTION TESTS.}

In the following table the clays are arranged as classified by column G:

\section{Plasticity of various clays.}

Texas "kaolin" 10. 34

Ball and sagger clays:

Mandle-Sant special sagger................................. ? 9. 09

Prall No. 1 light sagger......................................

Ball clays-

Knowles No. 12 ball.................................. 6.53

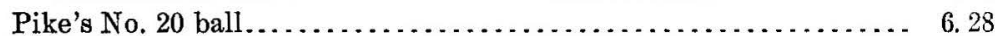

Mandle-Sant No. 3 Tennessee ................................ 5.96

Johnson-Porter No. 9 Tennessee ................................ . 5.76

Kentucky Construction and Improvement Co., No. 1 sagger....... 5. 69

Edgar Plastic Kaolin Co., Florida............................ ?5. 66

Prall, No. 1 retort..................................... 4. 90

Moore \& Munger, ball.................................. 4. 88

Ryan, No. 1 sagger...................................... 4.79

Atlanta Mining and Clay Co., Georgia........................ 4. 73

Potters' Supply Co., No. 3 Tennessee............................ 4. 62

Potters' Supply Co., No. 4 Tennessee........................... 4. 52

Excelsior Ball Clay Co., sagger............................. 4. 20

Such, B B mixture .................................. 3. 60

Edgar Bros. Co., No. 8 sagger............................. 3. 51

Johnson-Porter, No. 10 Tennessee.............................. 3. 45

Edgar Bros. Co., No. 10 sagger............................... 2.63

Paul Clay Co., ground fire clay............................... 2.595

Wad clays:

Johnson-Porter, $\mathrm{X}$ wad. .................................... ? I. 867

Johnson-Porter, UX sagger.................................... 1. 824

Potters' Supply Co., wad...................................... 1. 775

Mandle-Sant Clay Co., wad............................... ? 1.530

Mandle-Sant Clay Co., No. 9 Tennessee............................ 1.473

Johnson-Porter, No. 1 ball..................................... 1.378

China clays:

Hall Clay Co., Georgia sagger (kaolin) ....................... 1.335

Priem, Zettlitz, kaolin..................................... 1.335

Harris, Penland china clay ................................ 1.117

Adolph, $\mathrm{WH}_{2}$ china clay...................................... 104

Harris, Bryson china clay................................. 1. 0,17

Poole, No. 1 china clay ...................................... 1. $0 ! 7$

Sant, Bluemont china clay.................................. 916

Duncan, White Mountain clay.............................. .903

Poole, B B china clay ..................................... 873

Hammill \& Gillespie, Al china clay ........................... .86

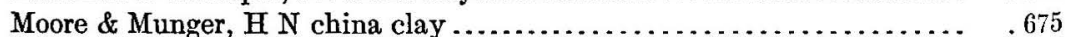

Moore \& Munger, M G $\mathbf{R}$ china clay ............................ .647

Knowles, No. 15 china clay.................................. . 618

Peach Kaolin Co., china clay.................................. . 556

Diamond Clay Co., ground fire clay.......................... . 000 
PLASTICITY AS FOUND IN PRACTICE.

Various anomalies have to be explained. Experimental errors in elutriation, due to incomplete deflocculation of the clays, have probably made too high the values marked with a ?. In these cases the dyed clay was elutriated. It was found out later that dyeing increases the size of the floccules and hence decreases the surface factor. The two No. 3 Tennessee ball clays occur on adjacent properties. It is believed that the shrinkage measurements or the surface factors of one or both are in error, the former having been made three years ago for one of the clays and the latter presenting difficulties in deflocculation. The Mandle-Sant No. 9 Tennessee ball is much more plastic than its position in the table indicates. Neither UX nor Johnson-Porter No. 1 ball is a strong clay, and they are correctly placed. Among the china clays there is the possibility of the addition of some whitening agent, or of wetting by salt water in transit across the ocean, that would interfere with the colloid test. The lowest English clay on the list, Knowles No. 15, has a very good reputation as a "safe" clay. The Diamond Clay Company's fire clay with finer grinding will have a measureable shrinkage, and is capable of being classed with the sagger clays if so ground. But as supplied, its shrinkage is less than the possible error of measurement, and it is correctly placed as to the plasticity in the coarse ground condition.

Very few people will agree exactly in their conception of plasticity. Each considers a body most plastic when it best suits his work. A jiggerman and a presser in the same clay shop will not agree as to the amount of moisture required in the body used. When a brickmaker calls a clay plastic he means that it will work well in his machine; but a potter means by the same phrase that it is fat enough to mix with considerable inactive material ("flint," spar, etc.) to make a workable body. An electric porcelain plant will have a tube, wet-press, or plastic body and a dry-press or insulator body. The writer hopes to show by later investigations that a certain "degree" or measure of plasticity is best suited to each class of manufacture.

The errors of measurement are in most cases small, and on the whole the table accurately represents those properties of clays that may be collectively described as plasticity.

In valuing clays, plasticity is but one of the factors to be considered; refractory properties, color, cleanness, etc., all go together in the selection of the clays to be used for the manufacture of wall and floor tiles, sanitary ware, terra cotta, pottery, etc. The measurement of the relative colloids, surface factor, and cast air shrinkage of various clays will give, however, an accurate and complete idea of their working properties or plasticity. 


\section{MISCELLANEOUS,APPYTCATIONS OF MALACHITE-GREEN TEST.}

\section{EFFICIENCY OF GRINDING.}

The Texas "kaolin" and the fire clays mentioned in the preceding pages were tested as supplied to the trade. They were also tested as to the effect of fine grinding.

Test of 50.0 grams Texas "kaolin," 5.00 grams malachite green, and 1,000 cubic centimeters of water.

Grams dye unadsorbed.

As supplied 0.0456

Ground 1 hour in ball mill with dye....................... .0314

Ground 2 hours in ball mill with dye.

.0315

Test of 50.0 grams Paul Clay Company's ground sagger (fire clay) with malachite green and 1,000 cubic centimeters of water.

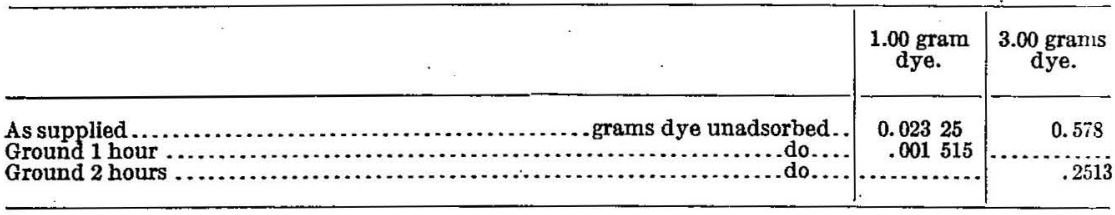

Test of 50.0 grams Diamond Clay Company's ground fire clay with malachite green and 1,000 cubic centimeters of water.

\begin{tabular}{|c|c|c|}
\hline . & $\begin{array}{c}1.00 \mathrm{gram} \\
\text { dye. }\end{array}$ & $\begin{array}{l}3.00 \text { granıs } \\
\text { dye. }\end{array}$ \\
\hline 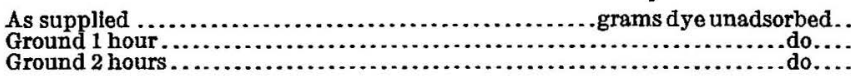 & $\begin{array}{c}0.01895 \\
.000309\end{array}$ & \\
\hline
\end{tabular}

In each of these cases finer grinding caused increased adsorption of dye, but the extent of the effect is markedly different in the three cases and seems to correspond to the development of the so-called "latent" plasticity of fire clay. This has already been ascribed (p. 13) to a reabsorption of water and a swelling to the original bulk of the clay, possessed ages ago before the clay had been subjected to pressure in its place of deposit.

The dye test then supplies a measure of the efficiency of grinding in increasing the plasticity of a fire clay.

It was noticed that brilliant green, instead of retaining its usual bluish-green tint, became a much purer green with Pike's No. 20 ball, Eimer \& Amend's fuller's earth, and Sant's Tennessee ball No. 3; no explanation is offered. Malachite green developed a purer blue with Eimer \& Amend's fuller's earth. 
FULLER'S EARTH.

Fuller's earth has been shown by W. L. Dubois (35) to be utterly unreliable as a means of estimating colorimetrically the amount of caramel in vinegar, when equal amounts of fuller's earth are used with equal amounts of vinegar. With pure vinegars any given lot of fuller's earth would have no effect on some vinegar, and would remove up to 60 or 70 per cent of the color from other vinegars. The results appeared extremely erratic. While this problem is separate from the present investigation, it is closely parallel; in both cases a colloidal earth is used to remove a coloring matter from solution. In the light of this experience it is thought that the following arrangements. would lead to comparable results: As, in this work, the addition of acetic acid increased the apparent intensity of the dye up to 33 per cent over that in aqueous solution, it would appear that vinegars should be brought to a uniform acidity before applying the fuller's-earth test; that is, either water or pure acetic acid should be added to bring the acetic acid to a standard concentration. Dubois used various fuller's earths of unknown colloidal strength to precipitate caramel of unknown strength. The proper procedure would seem to be to determine what proportion of a particular fuller's earth will remove caramel most completely from a particular vinegar when brought to the standard acetic-acid concentration. Then standardize this fuller's earth against a pure dye solution, such as the malachite green oxalate used in this work. In using other lots of fuller's earth such quantities should be taken as will have equal decolorizing action on the standard dye.

By this procedure the writer feels confident that the fuller's-earth test for caramel would be much improved.

\section{PARIS WHITES.}

The malachite green test has been applied to a number of "English cliffstone Paris whites" with the following results:

Test of English cliffstone Paris whites with 3 grams of malachite green dye.

\begin{tabular}{|r|r|r|l|}
\hline $\begin{array}{c}\text { Dye } \\
\text { unadsorbed. }\end{array}$ & $\begin{array}{c}\text { Relative } \\
\text { market } \\
\text { price. }\end{array}$ & $\begin{array}{c}\text { Surface } \\
\text { factor. }\end{array}$ & Remarks. \\
\hline 0.0218 & 150 & 182 & Claimed to be finest sold. \\
.0224 & 120 & 168 & \\
.0251 & 115 & 168 & \\
.0280 & 100 & 165 & \\
\hline
\end{tabular}

It appears that there is a close relationship between market price and fineness and dye precipitated. It is also to be remarked that carbonate of lime in this form removes the dye very completely from solution, and to a much greater extent than corresponds to the very slight plasticity it possesses. Way (15) observed the presence of 
gelatinous silica in the chalk formations; so that it will be necessary to find out whether pure calcium carbonate has the same action as this English cliffstone Paris white.

\section{FUTURE WORK.}

There is still considerable work to be done in connection with this test for colloids.

While malachite green seems excellent for the purpose, other dyes may be equal or better. Messrs. H. A. Metz \& Co. have kindly supplied a very comprehensive set of dyes for studying this point. The dye selected should be tested to see whether supplied in uniform quality from various sources.

The possible disturbing effect of various soluble salts and minerals should be determined.

The rate of deterioration of standard solutions should be studied.

These studies have been confined to high-grade clays, and a wider range of materials should be studied. Samples of the various bodies used in the ceramic industries have been collected, and it is intended to ascertain whether definite numerical limits can be given for the plasticity required by each.

It is also intended to study the process of aging clays, as this method will permit measurement of the progressive increases in plasticity.

It is intended to formulate a field test for plasticity that will determine whether the clay is worth more accurate investigation.

Seger (81) has noted in several places that there seems to be a close relationship between the amount of soluble salts in a clay and its plasticity. Purdy and Moore consider it "an exceedingly probable assumption that it is the influence of the adsorbed salts that gives to a clay its plasticity" (83). It is probable that in the malachite green test the color base is exchanged with the bases that stabilize the gel and with the bases of the soluble salts present, and that the oxalates of lime, etc., are precipitated. It is possible that a dye having its color base united with hydrochloric acid may supply an excellent means of studying the soluble salts in clay. Hirsch's work with aluminum chloride indicates the feasibility of such a procedure (70).

As an accurate surface factor is essential to a careful study of a clar, the best means of deflocculation of the clay particles before elutriation should be studied. It is not believed that ammonia, or long boiling, or violent shaking is the proper means; but that the formation of the clay hydrosol can be better effected by the addition of a more suitable chemical reagent or solvent. This is being studied. 


\section{SUMMARY.}

Clay is defined as a mixture of granular matter and a colloid gel. The sources of the colloid matter are organic, resembling peat, and inorganic, principally colloidal silicates and silica and less commonly alumina and ferric oxide.

Adsorption, the property colloids have of taking other substances out of solution or suspension, may in most cases be represented by exact equations.

The adsorption of a dye by clays supplies an approximate measure of plasticity.

The plasticity, taken as the product of the deformability by the force resisting deformation, reduces to the expression $\frac{\mathrm{C} \times \mathrm{B}}{\mathrm{A}}$, where $\mathrm{C}$ is the measure of colloids present, $\mathrm{B}$ is the cast air shrinkage, and $\mathrm{A}$ is the Jackson-Purdy surface factor.

The dye test supplies a measure of the efficiency of grinding in increasing the plasticity of a fire clay. Questions that call for further study are the possible finding of a better dye than malachite green, the disturbing influence of minerals and salts in clays, and the formulation of a field test for plasticity.

\section{REFERENCES.}

1. Schloesing, Th., The constitution of the clays: Compt. Rend., vol. 79, 1874, pp. 376-380, 473-477.

2. Van Bemmelen, J. M., Compounds of several solid dioxide hydrates with acids, salts, and alkalies: Jour. prakt. Chemie, 2d ser., vol. 23, 1881, pp. 324-349, 379-395.

3. Mayer, Adolph, Forschungen auf dem Gebiete der Agricultur Physik, vol. 3, pt. 2.

4. U. S. Dept. Agr., Bur. Soils, Bull. 24, 1904, p. 9.

5. Davis, Charles A., Peat: Eighth Ann. Rept. Geol. Survey Michigan, 1906, pp. 320,325 .

6. Schreiner and Reed, Certain organic constituents of soils in relation to soil fertility: U. S. Dept. Agr., Bur. Soils, Bull. 47, 1907, p. 10.

7. — Methods of analysis; humus in soil: U. S. Dept. Agr., Bur. Chem., Bull. 107, 1907, p. 19.

8. Acheson, E. G., Egyptianized clay: Trans. Am. Ceram. Soc., vol. 6, 1904, p. 31.

9. Grout, F. F., West Virginia Geol. Survey, vol. 3, 1906, p. 47.

10. Hardy, W. B., On the mechanism of gelation in reversible colloidal systems: Proc. Roy. Soc., vol. 66, 1899, pp. 95-109.

10a. Idem, p. 112.

11. Cushman, Allerton S., The colloid theory of plasticity: Trans. Am. Ceram. Soc., vol. $6, \mathrm{pp} .65-78$.

12. Wiley, Harvey W., Principles and practice of agricultural analysis, vol. 1, p. 120.

13. Eichorn, — Landw. Centralbl., vol. 11, p. 169.

14. Way, J. T., Jour. Royal Agr. Soc., vol. 11, 1850.

15. Way, J. T., On deposits of soluble or gelatinous silica in the lower beds of the chalk formation: Jour. Chem. Soc., vol. 6, 1854, pp. 102-106.

16. Van Bemmelen, J. M., The absorptive power of soils: Jahresber., 1888, pt. 2, p. 2737 . 
17. Warington, Robert, jr., On the part taken by oxide of iron and alumina in the absorptive action of soils: Jour. Chem. Soc., 2d ser., vol. 6, 1868, pp. 1-19.

18. Cameron, F. K., and Bell, James M., The mineral constituents of the soil solution: U. S. Dept. Agr., Bur. Soils, Bull. 30, 1905, p. 22.

19. Idem, p. 23.

20. Weber, Carl Otto, The chemistry of india rubber, London, Charles Griffin \& Co. (Limited), 1902, p. 79.

21. Van Bemmelen, J. M., The absorption of water in the colloids, especially in the gel of silicic acid: Zeitschr. anorg. Chemie, vol. 13, 1896, pp. 232-357.

22. — The Leuchter process of reducing or enlarging models: The Brass World, vol. 3,1907, p. 371.

23. Hillebrand, William Francis, Some principles and methods of rock analysis: Bull. U. S. Geol. Survey No. 176, 1900, pp. 52-53.

24. Whitney, W. R:, and Ober, J. E., The precipitation of colloids by electrolytes: Jour. Am. Chem. Soc., vol. 23, 1901, p. 844.

25. Coehn, - , [Electric charges]: Wied. Ann., vol. 64, 1898, p. 217.

26. Bredig, - , [Similarity of action of colloidal platinum and organic ferments]: Chem. Zeitung, vol. 24, 1900, p. 895. 233 .

27. Whitney, W. R., Colloids: Trans. Am. Electrochem. Soc., vol. 7, 1905, pp. 225-

28. Bredig, G., Zeitschr. angew. Chemie, 1898, p. 951.

29. Mayer, Schaeffer, and Terroine, Influence de la réaction du milieu sur la grandeur des granules colloidaux: Compt. Rend., vol. 145, 1907, pp. 918-920.

30. Spring, _- Recueil trav. chim. Pays-Bas, vol, 19, 1900, p. 204.

31. Lottermoser, $\Lambda$., The formation process of hydrosols and hydrogels: Zeitschr. phys. Chemie, vol. 60, 1907, p. 451.

32. Picton and Linder, Solution and pseudosolution: Jour. Chem. Soc., vol. 61, 1892, p. 171.

33. Schulze, — Jour. prakt. Chemie, vol. 25, 1882, pp. 431-452.

34. Proctor, H. R., Colloidal chemistry: Chem. News, vol. 98, 1908, pp. 152, 167, 175 .

35. Dubois, W. L., The fuller's earth test for caramel in vinegar: Jour. Am. Chem. Soc., vol. 29, 1907, p. 75. Also, U. S. Dept. Agr., Bur. Chem., Bull. 105, 1907, p. 23.

36. Teague, Oscar, and Buxton, B. H., The precipitation of aniline dyes: Zeitschr. phys. Chemie, yol. 60, 1907, p. 469.

37. Cushman, Allerton S., Rock decomposition and clay formation in the laboratory: Trans. Am. Ceram. Soc., vol. 8, 1906, p. 180.

38. Cushman, Allerton S., On the cause of the cementing value of rock powders and the plasticity of clays: Jour. Am. Chem. Soc., vol. 25, 1903, pp. 451-468.

39. Sullivan, Eugene C., The interaction between minerals and water solutions: Bull. U. S. Geol. Survey No. 312, 1907.

40. Rohland, Paul, The semipermeability of clays: Sprechsaal, vol. 39, 1906, p. 129.

41. Stover, Edward C., Bacteria in clay mixtures: Trans. Am. Ceram. Soc., vol. 5, 1903, pp. 358-361.

42. Picton and Linder, Solution and pseudosolution: Jour. Chem. Soc., vol. 71 , 1897, pp. 568-573.

43. Rohland, $P$., The means for altering the amount of plasticity of clays: Sprechsaal, vol. 39, 1906, pp. 1371-1372.

44. Clarke, F. W., Data of geochemistry: Bull. U. S. Geol. Survey No. 330, 1908.

45. Kuzel, Hans, Process of manufacturing incandescent metal filaments: German patent 194348, July 25, 1905.

46. Clarke, F. W., Data of geochemistry: Bull. U. S. Geol. Survey No. 330, 1908, p. 423. 
47. Mellor, J. W., Green, S. A., and Baugh, T., Studies on clay slip, I: Trans. English Ceram. Soc., vol. 6, pp. 161-170.

48. Binns, Charles F., The function of boron in the glaze formula: Trans. Am. Ceram. Soc., vol. 10, pp. 158-174.

49. Bleininger, A. V., The viscosicy of clay slips: Trans. Am. Ceram. Soc., vol. 10, pp. 389-395.

50. Henry, Charles, Spectophotométrie, viscosimétrie, et signes électriques des solutions: Compt. Rend., vol. 145, 1907, p. 1415.

51. Simonis, Max, Physical definition of clay and nonplastics: Sprechsaal, vol.38, 1905 , pp. $1625-1626$.

52. Simonis, Max, The tenacity of clay slips: Sprechsaal, vol. 38, 1905, p. 597.

53. Simonis, Max, Zettlitz clay and alkali: Sprechsaal, vol. 38, 1905, p. 881.

54. Van Bemmelen, J. M., The nature of colloids and their water content: Chem. Centralbl., 1888, p. 1255.

55. Patten and Gallagher, Absorption of vapors and gases by soils: U. S. Dept. Agr., Bur. Soils, Buill. 51, 1908.

56. Day and Allen, Isomorphism and thermal properties of the feldspars: Am. Jour. Sci., 4th ser., vol. 19, 1905, p. 127.

57. Von Dobeneck, —- Forsch. Geb. Agr.-Phys., vol. 15, 1892, p. 201.

58. Briggs and McLane, The moisture equivalent of soils: U. S. Dept. Agr., Bur. Soils, Bull. 45, 1907.

59. Hofmeister, F., The function of dissolved substances in processes of swelling: Zeitschr. phys. Chemie, vol. 7, 1891, p. 432. Arch. exp. Path. u. Pharm., vol. 28, 1891, pp. 210-238.

60. Van Bemmelen, J. M., Zeitschr. anorg. Chemie, vol. 23, 1900, pp. 321-372.

61. Walker, James, and Appleyard, James R., Absorption of dilute acids by silk: Jour. Chem. Soc., vol. 69, 1896, p. 1334.

62. Teague, Oscar, and Buxton, B. H., The Mutual coagulation of colloids: Zeitschr. phys. Chemie, vol. 62 , 1908, pp. 287-307.

63. Van Bemmelen, J. M., The formation of gels and their structure: Zeitschr. anorg. Chemie, vol. 18, 1898, pp. 14-36.

64. Des Bancels, J. Larguier, Colloid reactions and the mechanism of mordenting: Rev. gén. mat. color., vol. 12, pp. 193-201.

65. Lottermoser, A., The preparation of colloidal elements: Zeitschr. angew. Chemie, vol. 21,1908 , pp. 632-639.

66. Bödeker, —- Jour. Landwirtschaft, vol. 3, 1859, p. 48.

67. Wolff, - L Landw. Zeitung Nord und Mitteldeutschland, Nos. 32 and 33, 1859.

68. Wood, J. T., The compounds of gelatin and tannin: Jour. Soc. Chem. Ind., vol. 27, 1908, pp. 384-387.

69. Cameron, F. K., and Patten, H. E., The distribution of solute between water and soil.

70. Hirsch, H., Behavior of clay in salt solutions: Tonindustrie-Zeitung, vol. 28, 1904, p. 491.

71. Lottermoser, A., and Rothe, A., Adsorption of silver nitrate and potassium iodide by amorphous silver iodide: Zeitschr. phys. Chemie, vol. 62, 1908, pp. 359-383.

72. Simonis, Max, The settling of casting bodies and its prevention: Sprechsaal, vol. 39 , No. 5 , 1906 , p. 169.

73. Simonis, Max, Further contributions on the relations of clays and nonplastics toward electrolytes: Sprechsaal, vol. 39, 1906, pp. 1167, 1184.

74. Schultz and Julius: Organic colouring matters. 3d ed.

75. Pelet-Jolivet, L., and Wild, A., Dyestuffs in solution: Zeitschr. Chemie u. Ind. der Kolloide, vol. 3, 1908, pp. 174-177.

76. Höber, R., and Chassin, S., Dyes as colloids: Zeitschr. Chemie u. Ind, der Kolloide, vol. 3, 1908, pp. 76-80. 
77. Jackson, W., Trans. English Ceram. Soc., vol. 3, p. 16. Also Ceramic calculations.

78. Purdy, Ross C., The calculation of the comparative fineness of ground materials by means of a surface factor: Trans. Am. Ceram. Soc., vol. 7, 1905, p. 441.

79. Ashley, Harrison Everett, The testing of the raw materials of a whiteware pottery: Trans. Am. Ceram. Soc., vol. 9, 1907.

80. Zschokke, B., Investigations on the plasticity of clays: Bull. Soc. d'Encouragement, vol. 103, 1902, pp. 619-658. Baumaterialienkunde, 1902, Nos. 24, 25-26; 1903, Nos. 1-2, 3-4, 5-6. Tonindustrie-Zeitung, vol. 29, 1905, p. 1657.

81. Seger, Hermann August, Collected writings, translated by members of the American Ceramic Society, p. 357.

82. Ashley, Harrison Everett, Pottery plaster: Trans. Am. Ceram. Soc., vol. 10, 1908, pp. 76-90.

83. Purdy, Ross C., and Moore, J. K., Pyrophysical and chemical behavior of clay: Trans. Am. Ceram. Soc., vol. 9, 1907, p. 222.

84. Julien, A. A., On the geological action of the humus acids: Proc. Am. Assoc. Adv. Sci., 1879, pp. 311-410.

85. Borntrager, H., Zeitschr. anal. Chemie, vol. 39, 1900, p. 694, vol. 40, 1901, p. 639.

86. Graham, Thomas, Liquid diffusion applied to analysis: Philos. Trans. Royal Soc., 1861, pp. 183-224.

87. Förster, F., Die chemische Industrie, vol. 28 , No. 24. 


\section{INDEX.}

A. Page.

Absorption, discussion of .............. 27-31

relation of, to plasticity............... 28

to temperature . . . . . . . . . . . . . 27-28

Acheson, E. G., on added colloids.......... 12

Adsorption, destruction of, by heat........ 9

discussion of . ..................... 31-42

estimation of colloids by ............. 43-54

investigation of . ...................... 7

apparatus for, plate showing........ 46

theory of .......................... 31

Ageing, effect of ....................... 14

Alcohol, effect of, on clay .................. 24

Allen and Day, on absorption by feldspar... 28

Aluminum hydroxide, adsorption by ........ 10

Appleyard, J. K., and Walker, J., on adsorption.

on partition of solutes.

31

Ashley, H. E., work of . ................. 6

B.

Barium chloride, adsorption of, by Klingenberg clay .................... 37-38

chart showing..................... $\quad 39$

Baugh, T., Mellor, J. W., and Green, S. A., on clay slips................. 23-26

Bell, J. M., and Cameron, F. K., on sillica coatings................... 10

Bibliography .......................... 59-62

Binns, C. F., on action of boron........... 24

Bleininger, $\Lambda$. V., on viscosity of clays..... 20,43 preface by ....................... 5-6

Blunging, difficulties in............... 12-13

Bornträger, H., on peats : .............. 11

Bredig, G., on formation of soils.......... 17

Briggs and McLane, on absorption by soils.. . 29

Brilliant green, adsorption tests of......... 43-45 comparison of, with malachite green.... 45

Butschli, on structure of gels............. 32

Buxton, B. H., and Teague, O., on dyes.... 30

C.

Cameron, F. K., and Bell, J. M., on silica coatings.

Cameron, F. K., and Patten, H. F., on adsorption............................ 34-37

Charcoal, absorption and adsorption in..... 16 nature of

Chassin, S., and Hober, R., on brilliant green.

Clarke, F. W., on origin of silica gel.
Clays, absorption by. See Absorption. Page. adsorption tests of ................. 43-53 aging and drying of................. 12-14 constituents of, absorptive powers of . . . 28-29 definition of . . .................. $7-8,59$ effect of sodium carbonate on......... 22-23

further study of . . . . . . . . . . . . . . 58,59 plasticity of. Sce Plasticity.

properties of..................... 48-53

chart showing . ................. 52

viscosity of . .................... 20-21

Clay gels, stability of . . . . . . . . . . . . . . 19-20

volume of . . . . . . . . . . . . . . . . . . . . 29-30

Clay sols, stability of .................. 19-20

Coagulation, laws of $\ldots \ldots \ldots \ldots \ldots \ldots \ldots \ldots \ldots . \ldots \ldots$

nature of ........................ 15

Cochn, - on electrostatic charges..... 17-18

Colloids, addition of, to clay, effect of ....... 12

coating by...................... $7-8$

definition of . . . . . . . . . . . . . . . 7,12

forms of . . . . . . . . . . . . . . . . . . . . .

mixtures of $\ldots \ldots \ldots \ldots \ldots \ldots \ldots \ldots \ldots \ldots \ldots, \quad 31$

properties of..................... 20-42

sources of..................... 9-12, 59

Colloids, organic, nature of ............. 10-11

viscosity of ........................ 24

Color comparisons, apparatus for, plate showing..................... 46

Cushman, $\Lambda$. S., on plasticity........... 14

on temperature effects.............. 27

on water in clay . ................. 13

on Way's experiments................ 9

D.

Davis, C. A., on peats ................. 11

Day and Allen, on absorption by feldspar... 28

Definitions, statement of. .............. 7-8

Deflocculation, extent of, in salt solutions.... 29-30 nature of . . . . . . . . .

Des Bancels, J. L., on colloid mixtures..... 31

Drying, effects of. .................... 12-14

Dubois, W. L., on fuller's earth and vinegar. $\quad 57$

E.

Ebonite, nature of.................. 15

Eichhorn, — , on adsorption of zeolites... 9

Electrolytes, action of . ................ 22-27

F.

Feldspar, absorption powers of........... 28

aging of ......................... 14

Ferric hydroxide, adsorption by.......... 10 
Fire clays, grinding of, effect of............. 56 weathering of........................ 13

Förster, F., on nature of adsorption......... 23

Fuller's earth, effect of, on vinegar.......... $\quad 57$

\section{G.}

Gallagher, — $\longrightarrow$, and Patten, H. F., on absorption by quartz..............

Gates, W, D., on added colloids........... 12

Gelatine, adsorption of tannin by.......... 33-34 adsorption of tannin by, chart showing.. $\quad 34$

Gels, cellular structure of ................ 31-32

formation of ........................ 18-19

nature of........................... 14

partition of solute between liquids and. . 32-42 salts in, distribution of............... 30

solution of water by ................... 30

Gentian violet, adsorption of, by Hagerstown loam....................... 34-36

adsorption of, by Hagerstown.loam, chart showing ...................... 35

by quartz flour.................... $36-37$ chart showing................ 37

Geological Survey, investigations by........ 5-6

Graham, Thomas, nomenclature by........ 15

Green, S. A., Baugh, T., and Mellor, J. W., on clay slips................... 23-26

Green. Sec Malachite green; Brilliant green.

Grimsley, G. P., on absorption and plasticity............................

Grinding, effect of, on plasticity ........... 56,59

Grout, F. F., on drying clays.............. 12;28 on plasticity.

\section{H.}

Hagerstown loam, adsorption of gentian violet by .................... 34-36 adsorption of gentian violet by, chart showing.......................

Hardy, W. B., on action of electrolytes...... on coagulation.

on drying under pressure

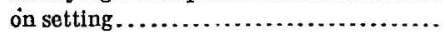
on structure of gelatine.

Henry, Charles, on viscosity................ Hillebrand, W. F., on dehydration of silica. Hirsch, H., on adsorption . ............ 37-38, Höber, R., and Chassin, S., on brilliant green. Hofmeister, F., on swelling of glue...........

Humic acid, nature of.

Humus, absorption by. adsorption by.

I.

India rubber, nature of

J.

Jackson, W., on clay particles.

James, J. II., on adsorption tests.

50-51

Julien, $A$. A., on humic acid.

Jullus and Schultz, on formulæ of greens.

K.

Kaolin, fractionation of nature of.
Klingenberg clay, adsorption of barium chloride by .................... $37-38$ adsorption of barium chloride by, chart showing..................... 39

Kuzel, Hans, on plasticity.................

L.

Linder and Picton, on ionic reactions........ 18 Liquids, partition of solute between gels and. 32-42 Liquids, immiscible, partition between...... 32

Lottermoser, $\Lambda$., on ionic reactions......... 18

on structure of gels..................

Lottermoser, A., and Rothe, A., on adsorption.......................... $3 s-41$

M.

McLane and Briggs, on absorption by soils. . Malachite green, adsorption of, by Tennessee ball clay.................. $41-42,50$ adsorption of, by Tennessee ball clay, charts showing................ 42,50

tests of. ........................ $46-50$ applications of............... 54, 50-58

Mayer, Adolph, on settling of clay.......... 19

Mayer, Schaeffer, and Terroine, on ionic reactions...................... 18

Mellor, J. W., Green, S. A., and Baugh, T., on clay slips................. 23-20

Moore, J. K., and Purdy, R. C., on plasticity. $\quad 58$

N.

Nagelli, —

Nernst, _ , on partition between immiscible liquids....................

o.

Ober, J. E., and Whitney, W. R., on electrostatic charges................ 17-18

on ionic reactions.

P.

- .

Paris whites, malachite green, tests of...... 57-58 Patten, H. E., and Cameron, F. K., on adsorption..................... 34-37

Patten, H. E., and Gallagher, _- on absorption by quartz.............. 28

Peats, adsorption by..................... 10-11 analyses of......................... 11 Pectinization, use of term.................. 15 Pectisation, use of term................... 15 Pectoid, use of term...................... 15 Pelet-Jolivet, L., and Wild, A., on malachite green......................... 45

Peptinization, use of term................ 15 Picric acid, partition of dye between silk and. 32-33 Picton and Linder, on ionic reactions........ 18 Plasticity, causes of..................... 21-22 determination of................... 42-55, 59 by malachite green................. 54 loss of, by drying.................... 12-14 nature of.......................... 8 relation of, to absorption................ 28 to colloids ........................ $42-43$ 
Potassium iodide, adsorption of, hy silver Puge. iodide....................... 39-41 adsorption of, by silver iodide, chart showing .................... 41

Pressure, drying under, effect of........... 13

Proctor, R. H., on inorganic sols........... $\quad 20$

Protection colloids, nature of.............. 20

Purdy, R. C., on clay particles............ 50-51

Purdy, R. C., and Moore, J. K., on plasticity. $\quad 58$

$$
\text { Q. }
$$

Quartz, absorption by

Quartz flour, adsorption of gentian violet by . . 36-37 adsorption of gentian violet by, chart showing.

R.

References, list of

Ries, $H$ on plasticity and absorption. ......

Rohland, Paul, on $\mathrm{OH}$ ions............... 14,21

on permeability of clays.............. 13

on plasticity of clays.................. 21-22

Rothe, $\Lambda$., and Lottermoser, $\mathbf{A}$., on adsorption....................... $38-41$

S.

Salt solutions, volume of clay gels in........ 29-30 Salts, distribution of, in gels............. 30-31 Schaffer, Mayer, and Terroine, on ionic reactions........................

Schloesing, Th., isolation of colloids by...... on absorption by clay...................

Schultz and Julius, on formulæ of greens.... .

Seger, H. A., on plasticity ..................

Set gels, examples of ................

Setting, nature of......................... 15

Silica, dehydration of .................. $\mathrm{J} 6 \mathrm{~b}-17$

Silica, gelatinous, adsorption by ........... 9-10

Silicates, hydrated, adsorption by.......... 9

Silk, partition of dye between picric acid and. 32-33

Silver iodide, adsorption of potassium iodide by.

adsorption of potassium iodide by, chart showing.

$39-41$

41

adsorption of silver nitrate by ......... 38-39

Simonis, Max, on viscosity of clays....... 20-21, 43

Sodium carbonate, action of, on clay ........ 22-24

Sols, formation of ...................... 17-18

nature of

Stover, E. C., on aging of clay............ 14

Structural materials, investigation of....... .
Sullivan, E. C., on interaction of minerals and solutions

Page.

T.

Tannin, adsorption of, by gelatine......... 33-34 adsorption of, by gelatine, chart showing. $\quad 34$

Teague, O., and Buxton, B. H., on dyes.... 30

Temperature, effect of, on absorption....... 27-28

Tennessee ball clay, adsorption of malachite green by .................. 41-42

adsorption of malachite green by, charts showing................... 42,50

Terroine, Mayer, and Schaffer, on ionic reactions..................... 18

$\mathrm{V}$.

Van Bemmelen, J. M., on settling of clay.... 19

on silica gel........................ 9-10

on solution in gels ..................... 30

on structure of gels................. 31

on temperature effects................. 27-28

Vinegar, effect of fuller's earth on......... 57

Viscosity, discussion of . ...............20-27

Von Dobeneck, - - , on absorption hy humus. $\quad 28$

W.

Walker, J., and Appleyard, J. R., on adsorption......................... 31

on partition of solutes............... 32-33

Warington, Robert, jr., on ferric and aluminum hydroxide.............. 10

Water, quality of, in tests . ........... $43,45-46$

Way, J. T., experiments of, on seat of adsorptive powers .................. 9

Weathering, effect of, on fire clays........ 13-14

Weber, C. O., on pectisation............... 15

on solution in gels .................... 30

on structure of gels................... 31-32

Weelans, Charles, on addition of colloids..... 12

Whitney, W. R., on formation of sols...... 17

Whitney, W. R., and Ober, J. E., on electrostatic charges .............. 17-18

on ionic reactions..................... 18

Wild, A., and Pelet-Jolivet, L., on malachite green....................... 45

Wiley, H. W., on Way's experiments...... 9

Wood, J. T., on adsorption of tannin........ 33

Z.

Zschokke, B., on plasticity. 






